\title{
DESENVOLVIMENTO DE UMA EQUAÇÃO PARA \\ ESTIMATIVA DO CUSTO ACUMULADO DE REPAROS E \\ MANUTENÇÕES PARA TRATORES AGRÍCOLAS DE PNEUS
}

\section{LUIZ FERNANDO GIOCONDO TEIXEIRA}

Engenheiro Agrônomo

Orientador: Prof. Dr. LUIZ ANTONIO BALASTREIRE

Dissertação apresentada à Escola Superior de Agricultura "Luiz de Queiroz", da Universidade de São Paulo, para obtenção do título de Mestre em Agronomia, Área de Concentração: Máquinas Agrícolas.

PIRACICABA

Estado de São Paulo - BRASIL

NOVEMBRO - 1995 
Para Ana Clara e Sílvia Marina. 


\section{AGRADECIMENTOS}

Meus sinceros agradecimentos ao Engenheiro Pedro Kassab, diretor da IPK Engenharia Ltda, pelo apoio dispendido, sem o qual a realização deste trabalho não teria sido possível.

Ao Engenheiro Wilson Pissolato, Gerente de Transportes da Usina Açucareira Estér S.A., pelo fornecimento dos dados para a realização deste trabalho.

Ao Prof. Dr. Rodolfo Hoffmann, pelas sugestões com relação à análise quantitativa dos dados.

Ao Prof. Dr. Luiz Antonio Balastreire, pela pronta e objetiva orientação durante a elaboração deste trabalho.

A todos aqueles que não foram citados nominalmente porém deram sua contribuição fica aqui registrada minha gratidão.

À minha esposa pelo apoio e compreensão recebidos durante a execução deste trabalho. 
"Blessed is the man whose machinery does not need repair". Comentário "pseudo-bíblico norte-americano. 


\section{SUMÁRIO}

Página

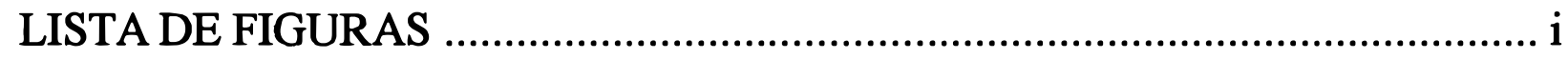

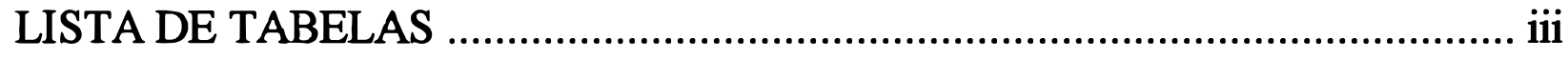

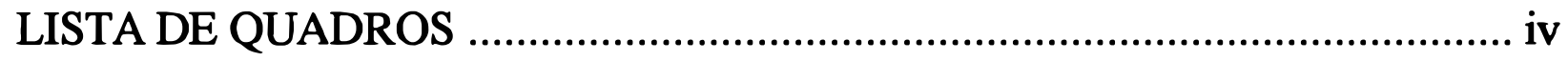

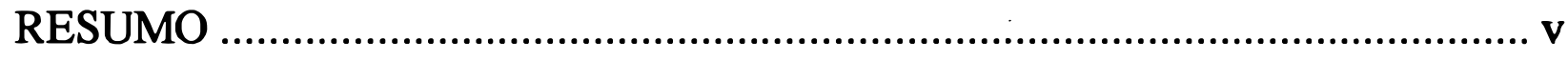

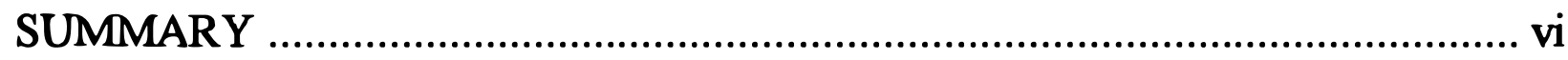

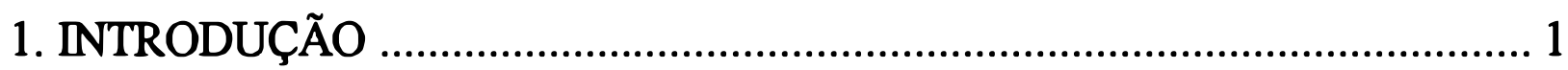

2. REVISÃO DE LITERATURA .......................................................... 3

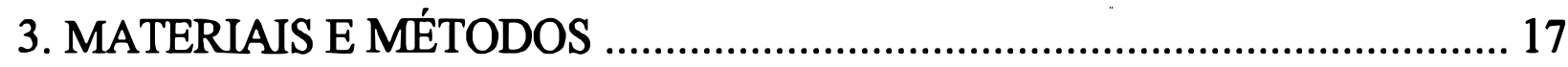

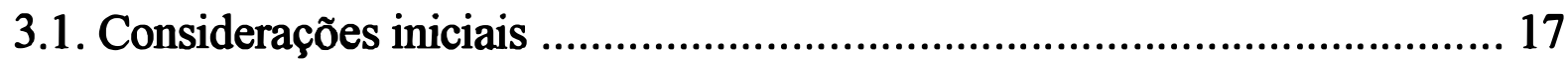

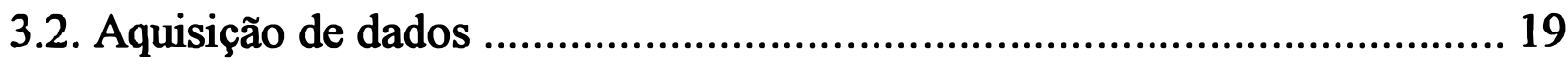

3.3. Teminologia utilizada ................................................................ 22

3.4. Metodologia de cálculo do custo total .............................................. 23

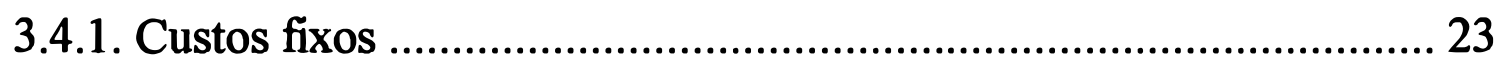

3.4.1.1. Depreciação ........................................................ 23

a. Método da Linha Reta .............................................. 24

b. Método dos Saldos Decrescentes ................................ 24

c. Método da Soma dos Dígitos dos Anos ......................... 24

d. Método do Fundo de Recuperação do Capital ............... 25

e. Método do Valor de Mercado ...................................... 25

3.4.1.2. Juros .......................................................................... 26

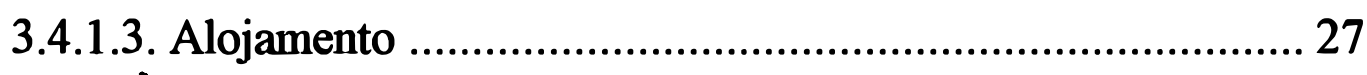

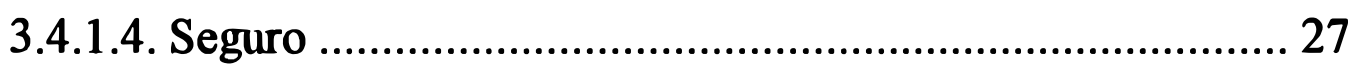


Página

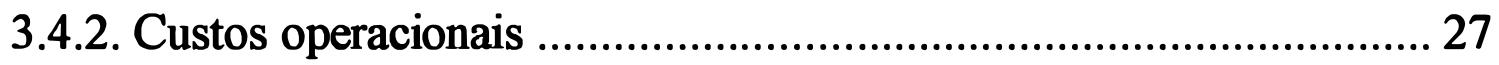

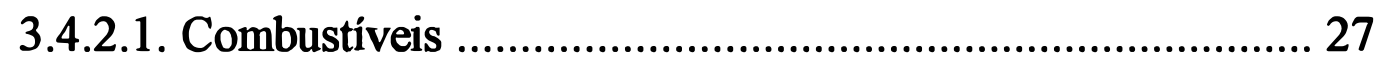

3.4.2.2. Lubrificantes ................................................................ 28

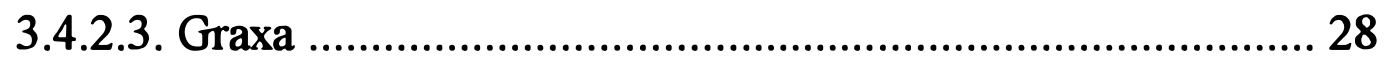

3.4.2.4. Manutenção ................................................................... 28

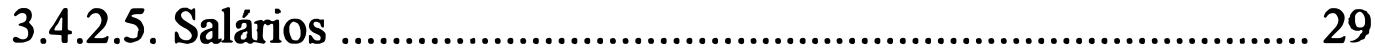

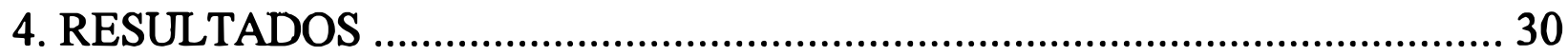

4.1. Análise preliminar dos dados obtidos ................................................ 30

4.2. Determinação da equação de custo acumulado de reparos e manutenções ............................................................................... 33

4.3. Determinação do custo total para um trator .......................................... 41

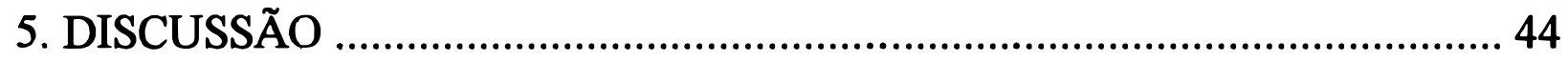

5.1. Comparação entre equações de estimativa de custo acumulado de reparos e manutenções .............................................................. 44

5.2. Comparação entre estimativas de participação percentual de custos de reparos e manutenções ................................................................... 51

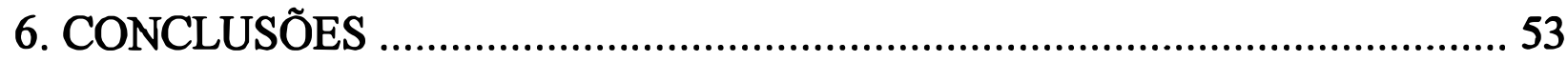

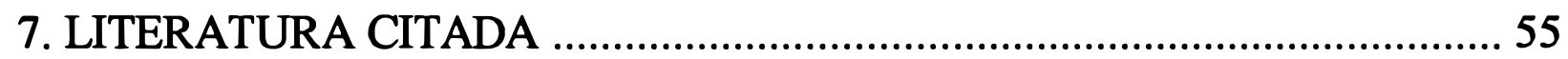

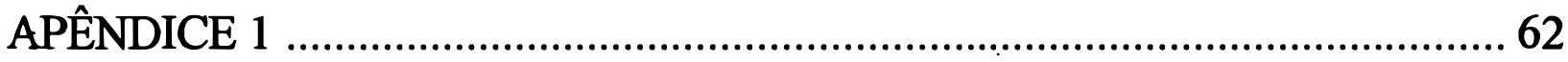

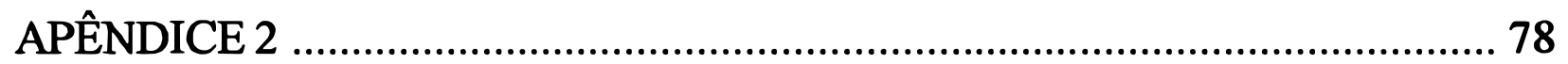

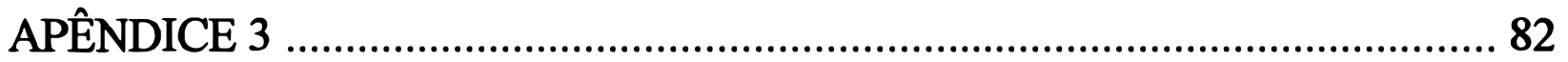

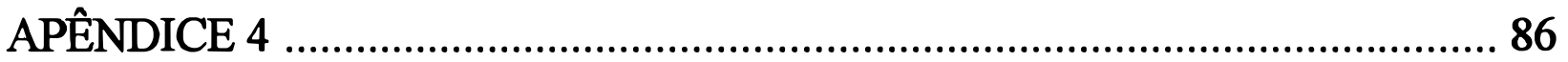




\section{LISTA DE FIGURAS}

Página

Figura 01: comparação dos diversos métodos de cálculo de depreciação, para um trator com custo de aquisição de US\$ 57,222.22, valor de revenda de $30 \%$ do custo de aquisição e a pesquisa de valor de mercado relatada por MOLINA (1994) 26

Figura 02: participação relativa dos diversos componentes do custo operacional, para os dados observados

Figura 03: participação relativa dos ítens componentes do custo de reparos e manutenções 33

Figura 04: comportamento observado dos dados de custos acumulados de reparos e manutenções durante o período estudado

Figura 05: forma das funções exponencial e logarítmica e seu ajuste relativo aos dados observados

Figura 06: funções linear e potencia e seu ajuste aos dados observados 
Página

Figura 07: ajuste das equações polinomiais de $2^{\circ}$ e $3^{\circ}$ graus aos dados observados 38

Figura 08: função escolhida para explicar os custos acumulados de reparos e manutenções, em função das horas acumuladas de operação

Figura 09: participação percentual dos itens componentes do custo total, conforme a simulação de fluxo de caixa proposta 43

Figura 10: equações de estimativa de custos acumulados de reparos e manutenções por Larsen\&Bowers (1965), Bowers\&Hunt (1970) e o presente estudo (1995) 45

Figura 11: comparação das equações de Hunt (1974), Farrow et alii (1980), Fairbanks et alii (1971) e este estudo (1995) 47

Figura 12: comparação do resultado pelas equações de Rotz (1985), Morris (1988), e este estudo (1995) 48

Figura 13: comparação entre as equações de Ward et alii (1985),

Zaidi et alii (1992) e o presente estudo (1995) 


\section{LISTA DE TABELAS}

Página

Tabela 01: uso anual e custo horário de reparos e manutenção 11

Tabela 02: participação percentual das diversas áreas na composição global de custos do setor sucro-alcooleiro 18

Tabela 03: média anual do emprego de tratores, em horas, nas diversas DIRAs, em comparação com o emprego na Usina da Barra S.A.

Tabela 04: composição dos itens do custo operacional para os três modelos de tratores, no decorrer do período estudado

Tabela 05: participação percentual do custo de reparos e manutenções no total do custo operacional durante

o período amostrado

Tabela 06: variação percentual dos componentes do custo de reparos e manutenções

Tabela 07: equações determinadas 35

Tabela 08: fluxo de caixa 
Página

Tabela 09: comparação entre as diversas equações de reparos

e manutenções

Tabela 10: índices recomendados para dispêndios com reparos

e manutenções

52

\section{LISTA DE QUADROS}

Quadro 01: composição da frota de tratores agrícolas da empresa 


\section{DESENVOLVIMENTO DE UMA EQUAÇÃO PARA \\ ESTIMATIVA DO CUSTO ACUMULADO DE REPAROS E \\ MANUTENÇÕES PARA TRATORES AGRÍCOLAS DE PNEUS}

Autor: LUIZ FERNANDO GIOCONDO TEIXEIRA

Orientador: Prof. Dr. LUIZ ANTONIO BALASTREIRE

\section{RESUMO}

Com o objetivo de se determinar uma equação para estimativa do comportamento dos custos de reparos e manutenções, para tratores agrícolas de pneus, foram analisados os relatórios de custos operacionais dos últimos oito anos em uma determinada empresa agrícola do estado de São Paulo.

Utilizando diversos métodos de análise quantitativa - regressões linear, exponencial, logarítmica, potência, polinomiais de segundo e terceiro graus e não-linear - procurou-se determinar a equação, se existente, que refletisse satisfatoriamente o comportamento observado na empresa, para os custos acumulados de reparos e manutenções. Tal procedimento foi equivalente ao adotado por outros autores consultados e que realizaram estudos semelhantes.

O comportamento dos custos é passível de ser explicado, com maior acurácia, pelo modelo da função potência, sendo que ajuste posterior por regressão não-linear, respeitando-se o modelo anterior, permitiu melhorar a precisão, sendo adotado como resposta final. 


\section{DEVELOPMENT OF A EQUATION TO ESTIMATE REPAIR AND MAINTENANCE ACUMULATED COSTS OF TIRE TRACTORS}

Author: LUIZ FERNANDO GIOCONDO TEIXEIRA

Adviser: Prof. Dr. LUIZ ANTONIO BALASTREIRE

\section{SUMMARY}

With the objective of determining an equation to estimate the behavior of repair and maintenance costs, for tyre tractors, eight years of operational cost reports of a São Paulo State agricultural company were analysed.

Utilizing various quantitative analysis methods - linear regression, exponential, logarithms, potential, polinomials of second and third degree and non-linears - a mathematical model which would satisfactorally reflect the behavior observed at the company, with relation to acumulated repair and maintenance costs was developed. The analysis procedure was equivalent to that adopted by others authors who performed similar studies.

The behavior of costs can be explained with greater accuracy, by means of the potential function model, which ajusted by non-linear regression, had it's accuracy improved, and was adopted as the final model. 


\section{INTRODUÇÃO}

A mecanização intensiva das atividades agrícolas, notadamente nos últimos trinta anos, possibilitou um grande aumento na produtividade da mão-de-obra, liberando contingentes de trabalhadores para outros setores da economia. Se por um lado a produtividade da mão-de-obra agrícola conheceu um grande incremento, por outro surgiu a preocupação de manter a integridade dos conjuntos mecanizados e, em consequência com o custo da manutenção dos mesmos em sua plena eficiência operacional. Tais custos vem sendo normalmente classificados como custos de reparos e manutenções.

Os dispêndios realizados com reparos e manutenções objetivam manter o conjunto mecanizado disponível durante o maior período e com a melhor condição operacional possíveis, não promovendo uma apreciação significativa no valor patrimonial ou de revenda do mesmo.

A participação dos custos operacionais da mecanização no custo total das atividades agrícolas varia em função das características de cada cultura em particular. Porém, independentemente da amplitude de sua participação, é um ítem de custo que representa um desembolso efetivo por parte da empresa, não representando um custo meramente contábil, como ocorre frequentemente com as despesas de depreciação e juros sobre o capital investido. Acrescente-se ainda o fato das necessidades de reparos nos conjuntos agrícolas ser um evento 
de caráter aleatório, portanto de dificil antecipação quanto ao momento de ocorrência.

O objetivo deste estudo é avaliar se o comportamento dos custos de reparos e manutenções, para tratores agrícolas de pneus, pode ser explicado por uma equação suficientemente confiável, para ser usada como parâmetro de estimativa dos mesmos, notadamente em função da intensidade de uso do trator, medida em termos de horas anuais de operação. 


\section{REVISÃO DE LITERATURA}

A literatura sobre custos de reparos e manutenções de máquinas agrícolas é um tanto restrita, notadamente em razão da dificuldade em se levantar históricos suficientemente detalhados à respeito. No entanto a preocupação com o comportamento desses custos remonta à década de 40 e os principais autores são comentados à seguir:

DAVIDSON (1948), recomendava a utilização de um índice de $2,0 \%$ do custo de aquisição do modelo equivalente novo como dispêndio anual com reparos de tratores agrícolas.

RICHEY et alii (1961), consideraram o custo de reparos como uma constante das horas de uso, baseado no custo total de reparos dividido pelas horas totais da vida útil do trator. Para um trator em operação de aração os autores consideraram um custo acumulado de reparos de $80 \%$ do preço de aquisição do modelo equivalente novo, para uma vida útil total de 15 anos.

JONES (1963), considerou os custos de reparos como um importante item de despesa, embora dependente do cuidado com a manutenção rotineira do trator. Relata que estudos efetuados em Kansas indicaram uma considerável variação nos mesmos, contudo o autor recomendou a adoção de um coeficiente de 3,5 \% do custo de aquisição do equivalente novo (ILP) como padrão para tratores com uso anual abaixo de 1.000 horas, para tratores com uso anual acima de 1.000 horas recomendou a utilização de 5,0 \% do ILP. 
LARSEN \& BOWERS (1965), utilizando-se de dados de composição de custos de máquinas agrícolas levantados nos Estados Unidos nos vinte anos anteriores determinaram uma equação para estimativa dos custos de reparos, para tratores agrícolas de rodas com utilização média de 600 horas/ano e uso acumulado de 6.000 horas. $O$ custo acumulado de reparos correspondeu à $40 \%$ do custo de aquisição do equivalente novo ao final do período observado. Os autores consideraram como vida útil total 12.000 horas, com custo acumulado de $120 \%$ do custo de aquisição do equivalente novo. $\mathrm{O}$ custo de reparos e manutenção correspondeu a um valor entre 15 à $20 \%$ do custo total ao final do período observado.

$$
\text { TAR = ILP . RC1 . RC2 . }(\text { L \% })^{\text {RC3 }} \text {, onde: }
$$

$\mathrm{TAR}=$ custo total acumulado de reparos até $\mathrm{L} \%$.

$\mathrm{L} \%=$ porcentagem da vida útil total no ponto em que se deseja determinar o custo acumulado de reparos.

$\mathrm{ILP}=$ preço de aquisição do modelo equivalente novo.

$\mathrm{RC1}=$ cte expressa pela razão de TAR por $I L P$, considerando-se $L=100$, sendo $\mathrm{RC} 1=1,2$.

$\mathrm{RC} 2=$ cte específica para cada equipamento, tratores de pneus, 0,000631 . $\mathrm{RC} 3$ = cte específica para cada equipamento, tratores de pneus, 1,6.

Para obter-se o custo acumulado de reparos para tratores de rodas diretamente em dólares emprega-se a fómula abaixo.

TAR (US\$) = ILP . 0,00076 . $(\text { HRS / } 120)^{1,6}$, onde: 
$\mathrm{TAR}=$ custo acumulado de reparos, em dólares.

ILP $=$ custo de aquisição do equivalente novo, em dólares.

HRS = horas totais acumuladas de operação.

BARGER et alii (1966), recomendaram a utilização de um índice em torno de 3,5\% do custo de aquisição do equivalente novo como estimativa do dispêndio anual com reparos de tratores agrícolas.

Importância relativa dos diversos ítens componentes do custo total de tratores agrícolas na operação de aração operando com aivecas de relhas de 16 polegadas:

$\begin{array}{lr}\text { Depreciação } & 24,0 \% \\ \text { Mão-de-obra } & 29,0 \% \\ \text { Diesel } & 16,7 \% \\ \text { Reparos e Manutenção } & 13,3 \% \\ \text { Juros sobre o capital } & 8,8 \% \\ \text { Taxas/Seguro } & 3,4 \% \\ \text { Abrigo } & 2,7 \% \\ \text { Lubrificantes } & 2,1 \%\end{array}$

BOWERS \& HUNT (1970), realizaram um levantamento de dados de vida útil estimada ( 20 anos ), horas de uso anual ( média de 493 horas/ano ), custo de aquisição e de manutenção para tratores agrícolas de rodas junto à cerca de 900 empresários agrícolas dos estados de Illinóis e Indiana durante o ano de 1966. O objetivo foi o de desenvolver fómmulas matemáticas para quantificar o custo de reparos para tratores agrícolas.

$$
\text { TAR }=0,156400 . X^{2}-0,000143 . X^{3} \text {, onde: }
$$

$\mathrm{TAR}=$ valor US $\$$ / 1,000.00 para se obter em \%.

$\mathrm{X}=$ horas acumuladas de uso dividido por 100 . 
O custo acumulado de reparos expresso diretamente em dólares é dado pela equação abaixo.

$$
\text { TAR }(\text { USS })=15,64 \text {. }(\text { HRS } / 120)^{2}-0,0143 \text {. }(\text { HRS / } 120)^{3} \text {, onde: }
$$

TAR = custo acumulado de reparos, em dólares. HRS = horas totais acumuladas de operação.

FAIRBANKS et alii (1971), pesquisando dados de custos de máquinas agrícolas durante o ano de 1968 junto à 114 empresários agrícolas do estado de Kansas obtiveram informações detalhadas sobre a composição dos custos totais. Com relação ao custo de manutenção, considerado difícil de ser estimado em função da extrema variabilidade nas condições e na forma de operação, o levantamento demonstrou que o mesmo pode ser expresso como uma função potência relacionada aos anos de uso.

Os resultados dos custos de manutenção relatados foram convertidos em custos acumulados como porcentagem do custo de aquisição das máquinas e as horas acumuladas de uso em porcentagem da vida útil estimada. Os resultados da pesquisa com uma amostra de 46 tratores equipados com motores de ciclo Diesel, com coeficiente de correlação de 0,77 , possibilitaram a determinação da seguinte equação.

$$
Y=0,0014 . X^{2,19} \text {, onde: }
$$

$\mathrm{Y}=$ custos acumulados de reparos, em porcentagem do preço do modelo equivalente novo.

$\mathrm{X}=$ horas totais acumuladas de operação, em porcentagem da vida útil total. 
A fórmula modificada para a obtenção do custo acumulado de reparos, diretamente em dólares, é a seguinte.

$$
\text { TAR }(\text { US\$) }=\text { ILP . 0,000014 . ( HRS / } 100)^{2,19} \text {, onde: }
$$

TAR = custo acumulado de reparos, em dólares.

HRS $=$ horas totais acumuladas de operação.

ILP = custo de aquisição do modelo equivalente novo.

Os autores relataram a importância relativa dos diversos componentes do custo total para tratores agrícolas de pneus:

$\begin{array}{lr}\text { Mão-de-obra } & 42,45 \% \\ \text { Depreciação } & 21,54 \% \\ \text { Diesel } & 12,57 \% \\ \text { Juros sobre o capital } & 9,03 \% \\ \text { Reparos } & \mathbf{8 , 0 4} \% \\ \text { Taxas diversas } & 2,39 \% \\ \text { Abrigo } & 1,21 \% \\ \text { Seguro } & 1,15 \% \\ \text { Lubrificantes } & 1,62 \%\end{array}$

HUNT (1973), divide os custos totais de máquinas agrícolas em fixos e variáveis. Custos fixos são aqueles efetuados independentemente da intensidade de uso do equipamento, tais como depreciação, remuneração do capital, seguro e alojamento. Custos variáveis são os dependentes do uso, como combustíveis, lubrificantes, reparos e manutenção e mão-de-obra de operação. Segundo o autor os custos de reparos e manutenção variam de acordo com a região, em função de diferenças de solos, culturas, condições climáticas e treinamento do operador. Em uma mesma propriedade os custos de reparos são extremamente variáveis. Parte da variação é devida à diferenças no uso do trator 
e parte causada na origem, quando da fabricação do mesmo. Grande parte da variação no custo de reparos pode ser atribuida ao caráter naturalmente aleatório das falhas mecânicas.

Importância relativa dos diversos componentes do custo total de tratores agrícolas segundo o autor:

$\begin{array}{lr}\text { Mão-de-obra de operação } & 42,35 \% \\ \text { Depreciação } & 21,54 \% \\ \text { Combustível } & 12,57 \% \\ \text { Juros sobre o capital } & 9,03 \% \\ \text { Reparos } & \mathbf{8 , 0 7} \% \\ \text { Taxas, Abrigo, Seguro } & 4,83 \% \\ \text { Lubrificantes } & 1,61 \%\end{array}$

HUNT (1974), acompanhando os custos de reparos e manutenção de 745 máquinas com motores do ciclo Diesel em 45 fazendas de milho em Illinóis, com utilização média de 424 horas/ano, abrangendo o período de 1958 à 1974, desenvolveu uma fórmula de previsão de custos de reparos em função do uso acumulado.

Os dados obtidos para tratores apresentaram um coeficiente de correlação de 0,996 .

$$
Y=0,012 . X^{2,033} \text {, onde: }
$$

$\mathrm{Y}=$ fator de custo em relação ao ILP.

$\mathrm{X}=$ uso acumulado, horas / 1.000 .

A fómmula para obtenção do custo acumulado de reparos, em dólares, diretamente em função das horas acumuladas de operação é a seguinte. 


$$
\text { TAR (US\$) = 0,012 . }(\text { HRS / } 1000)^{2,033} \text {. ILP , onde: }
$$

$\mathrm{TAR}=$ custo acumulado de reparos, em dólares.

HRS = horas acumuladas de operação.

ILP = custo de aquisição do modelo equivalente novo.

HUNT \& FUJII (1976), reexaminando os dados obtidos por Hunt (1974), determinaram a participação percentual de diversos ítens componentes do custo de reparos e manutenções. Os custos com mão-de-obra de manutenção corresponderam à $26,7 \%$ do custo total de reparos e manutenções, componentes substituídos à $69,8 \%$ dos quais $12,1 \%$ referiram-se à pneumáticos.

FARROW et alii (1980), analisaram os dados de custos totais de dez grandes empresas agrícolas do estado norte-americano de Washington, cujos tratores eram utilizados, em média, durante 673 horas/ano. Os dados referem-se ao período compreendido entre 1967 e 1978. Os autores determinaram a seguinte equação para estimativa dos custos de reparos e manutenções:

$$
\text { TAR = 0,09168. } X^{1,48560} \text {, onde: }
$$

TAR $=$ porcentagem do custo de aquisição do equivalente novo (\%IP). $\mathrm{X}=$ horas totais acumuladas de operação divididas por 100.

Para a obtenção do custo acumulado de reparos e manutenções diretamente em dólares, até o ponto desejado, a equação é:

$$
\text { TAR (US\$) = 0,0009168 . ILP . X }{ }^{1,48560} \text {, onde: }
$$


$\mathrm{TAR}=$ custo acumulado de reparos e manutenções, em dólares. $\mathrm{ILP}=$ custo de aquisição do modelo equivalente novo, em dólares. $\mathrm{X}=$ horas acumuladas de operação divididas por 100 .

MAYFIELD et alii (1981), realizaram um levantamento entre os anos de 1977 e 1980 para a determinação dos custos totais de tratores agrícolas. Para o cálculo da depreciação não foram empregados os métodos normalmente estabelecidos e sim uma pesquisa de mercado para a obtenção do valor de revenda dos tratores, sobre o qual foi considerada a taxa média de juros do respectivo período.

A composição do custo total, exceto mão-de-obra de operação, para um trator padrão de $120,8 \mathrm{kw}$ com emprego de 500h/ano durante 10 anos variou entre 1977 e 1980 de acordo com a descrição abaixo:

1977

Depreciação

Diesel e Lubrificantes .. $\quad 30,0 \%$

Juros

$18,0 \%$

Reparos.

$15,0 \%$

Taxas diversas

$7,0 \%$

1980

Depreciação

$22,0 \%$

Diesel e Lubrificantes .. $\quad 37,0 \%$

Juros

$25,0 \%$

Reparos.

$10,5 \%$

Taxas diversas

BUKHARI (1982), estudando uma amostra de 100 tratores, com motores de ciclo Diesel, na província de Tandojan (Paquistão), obteve dados que permitiram estabelecer a importância relativa dos custos de reparos e manutenção em relação aos custos totais e ao custo de aquisição do equivalente novo, conforme a tabela seguinte. 
Tabela 01: Uso anual e custo horário de reparos e manutenção.

\begin{tabular}{|c|c|c|c|c|}
\hline Uso anual (h) & $\mathrm{n}^{\circ}$ de tratores & $\begin{array}{l}\text { média de uso } \\
\text { anual (h) }\end{array}$ & $\begin{array}{c}\text { \% do } \\
\text { custo total }\end{array}$ & $\begin{array}{l}\text { \% do ILP * } \\
\text { (média/100h) }\end{array}$ \\
\hline << de 500 & 10 & 359 & 18.49 & 3.29 \\
\hline 501 a 1000 & 38 & 735 & 12.42 & 0.96 \\
\hline 1001 a 1200 & 11 & 1088 & 10.91 & 0.55 \\
\hline 1201 a 1400 & 8 & 1311 & 5.58 & 0.23 \\
\hline 1401 a 1600 & 8 & 1488 & 10.35 & 0.43 \\
\hline > de 1600 & 25 & 1972 & 6.88 & 0.26 \\
\hline
\end{tabular}

Fonte: Bukhan, 1982.

* ILP: custo de aquisição do modelo equivalente, novo.

WARD et alii (1985), analizaram 42 tratores de tração $4 \times 2$ e 21 tratores de tração $4 \times 4$ empregados em serviços gerais em florestas, tais como reboque de toras, carretas, limpeza de sub-bosques e outros, na Irlanda, no período compreendido entre 1972 e 1981 . Os tratores de tração 4x2 abrangiam a faixa de potência entre 35 à $50 \mathrm{kw}$ e os $4 \mathrm{x} 4$ de 36 à $90 \mathrm{kw}$. Os dados de custos de reparos e manutenção em função de horas acumuladas de operação mostraram um coeficiente de variação de 283,00 \% para os tratores de tração $4 \times 2$ e de $140,00 \%$ para os $4 \times 4$, em função do uso em diferentes locais e também devido ao fato de serem tratores de especificações variadas. Não foi possível obter-se precisão para uma situação específica para um dado modelo de trator.

Para tratores de tração $4 \times 4$ obteve-se a seguinte equação para estimativa de custos de reparos, com coeficiente de determinação de 0,98 :

$$
\text { TAR }=0,040555 \text {. }(\text { TAUh })^{1,923} \text {, onde: }
$$


TAR = custo acumulado de reparos como porcentagem do custo de aquisição do equivalente novo.

$\mathrm{TAUh}=$ horas totais de uso acumulado, como porcentagem de 12.000 horas, consideradas como vida útil total dos tratores.

A fórmula de WARD et alii alterada para a obtenção direta do custo de reparos e manutenção, em dólares, para tratores de tração $4 \times 4$ é a seguinte:

$$
\text { TAR }(\text { USS })=0,000406 \text {. }(\text { HRS / } 120)^{1,923} \text {. ILP , onde: }
$$

TAR = custo acumulado de reparos, em dólares.

HRS = horas totais acumuladas de operação.

$\mathrm{ILP}=$ preço de aquisição do modelo novo equivalente .

ROTZ (1985), propôs um novo modelo como padrão para determinação de custos de reparos e manutenção. $\mathrm{O}$ modelo prediz os custos como uma função potência, com a idade considerada como múltiplo de 1.000 horas de operação. Os parâmetros do modelo foram desenvolvidos para vários modelos de máquinas agrícolas. $\mathrm{O}$ autor levou em consideração a severidade de operação, para tanto estabeleceu a variável velocidade operacional de campo, $\mathrm{em} \mathrm{km} / \mathrm{h}$.

$$
\text { TAR = ILP . }\left(\text { RC1*}^{*}\right) \cdot(\text { USE . S })^{\text {RC2 }} \text {, onde: }
$$

TAR = custo acumulado de reparos e manutenção.

ILP $=$ preço de aquisição do modelo equivalente novo.

USE $=$ uso total acumulado, múltiplo de 1.000 horas.

$\mathrm{S}=$ velocidade de operação em campo, $\mathrm{km} / \mathrm{h}$.

$\mathrm{RC}^{*}=\mathrm{RC} 1 /(\mathrm{AS})^{\mathrm{RC2}}$. 
$\mathrm{AS}=$ velocidade padrão, $\mathrm{em} \mathrm{km} / \mathrm{h}$.

$\mathrm{RCl}=$ constante de custo padrão, 0,01 .

$\mathrm{RC} 2$ = constante de custo padrão , 2,00 .

A equação anterior é uma expansão da equação seguinte, para incluir a função velocidade de operação, pois a idade da máquina é definida pelo produto de horas de uso e velocidade de operação, fomecendo uma previsão mais acurada dos custo de reparos e manutenção. Quando a velocidade operacional for idêntica à velocidade padrão da operação usa-se a equação abaixo.

$$
\text { TAR }=\text { ILP } \cdot(\text { RC1 }) \cdot(\text { USE })^{\text {RC2 }}
$$

MORRIS (1988), pesquisando dados de reparos e manutenção dos últimos 30 anos da empresa Weasenham Farms Company, em Norfolk (UK), computou mensalmente os custos de manutenção, inclusive pneumáticos, verificou que estes representaram $28 \%$ dos custos de reparos executados na empresa. Para os reparos em oficinas especializadas as peças corresponderam, em média, à $45 \%$ do custo e mão-de-obra à $55 \%$. Cinquenta tratores com os registros completos entre os anos de 1972 e 1983, uso acumulado entre 2.500 e 7.000 horas e potência variando entre $40 \mathrm{kw}$ à $58 \mathrm{kw}$ foram selecionados para análise. Diferenças de calibração dos horímetros não foram consideradas significativas à ponto de alterar a análise.

Utilizando o método de regressão dos Mínimos Quadrados o autor determinou qual função - linear, polinomial, exponêncial ou potência - que ajustou-se melhor aos dados de custos de reparos e manutenção em função de horas de operação. A função potência foi a que melhor adaptou-se aos dados, 
representando uma base geral de estimativa de custos de reparos. Embora o conceito de horas de uso em si seja capaz de explicar somente $16 \%$ da variação observada nos custos de reparos. $O$ autor sugere que outros fatores não considerados, como o comportamento do operador, as condições de trabalho em campo, planos adequados de manutenção e procedimentos gerenciais, sejam importantes na determinação dos custos de reparos.

A função, determinada para tratores de tração $4 \times 2$ é:

$$
Y=\left(0,0996 \cdot X^{1,4775}\right) \cdot 10^{-3}, \text { onde: }
$$

$\mathrm{Y}=$ custo total de reparos, em \% do preço do equivalente novo.

$\mathrm{X}=$ horas totais acumuladas de uso.

A fórmula, modificada para a obtenção do custo de reparos e manutenção acumulado em dólares é:

$$
\text { TAR } \left.(\text { US\$ })=0,000996 \text {. ( HRS }{ }^{1,4775} \text {. 0,001 }\right) . \text { ILP, onde: }
$$

TAR (US\$) = custo acumulado de reparos e manutenção.

HRS = horas totais acumuladas de operação.

$\mathrm{ILP}=$ custo de aquisição do modelo equivalente novo.

ASAE (1989), relata a grande variabilidade dos custos de reparos de máquinas agrícolas. Índices de reparos e manutenção para as condições do Meio-oeste norte-americano são relatados no documento ASAE D230.4 para tratores de tração $4 \times 2$, como $120 \%$ do preço de aquisição do equivalente novo para uso acumulado de 10.000 horas, e para tratores de tração $4 \times 4$, como $100 \%$ do preço do equivalente novo para 10.000 horas. 
MIRANI et alii (1989), com base em dados obtidos entre os anos de 1975 e 1984 no Paquistão, determinaram a participação relativa dos diversos ítens componentes do custo total de algumas marcas/modelo de tratores agrícolas.

\begin{tabular}{lrr} 
& FORD-4600 & MF-265 \\
\cline { 2 - 3 } Depreciação & $13,16 \%$ & $12,42 \%$ \\
Juros & $8,12 \%$ & $7,58 \%$ \\
Abrigo & $2,54 \%$ & $2,38 \%$ \\
Seguro & $0,04 \%$ & $0,03 \%$ \\
Salário do operador & $13,56 \%$ & $12,68 \%$ \\
Combustível & $38,22 \%$ & $33,69 \%$ \\
Lubrificantes & $6,84 \%$ & $2,31 \%$ \\
Reparos e Manutenções & $17,51 \%$ & $28,90 \%$
\end{tabular}

NORONHA et alii (1991), em exemplo numérico para simulação de custo total de um sistema mecanizado, consideraram um trator com utilizaçào durante 987 horas/ano em atividades típicas do setor sucro-alcooleiro, tais como gradagem pesada (246,1 horas/ano), niveladora (188,3 horas/ano), aração (166,9horas/ano), subsolagem (125,2 horas/ano) e sulcação-adubação (26,2 horas/ano), durante dez anos acumulando um custo total de reparos e manutenções de US\$14,651.30, representando $9,74 \%$ do custo total ou 69,40 $\%$ do custo de aquisição do modelo novo.

ZAIDI et alii (1992), realizaram um levantamento de custos de manutenção para diversos tipos de equipamentos agrícolas, entre os quais tratores de pneus. O levantamento dos dados foi efetuado em 24 vilarejos do Paquistão. O objetivo foi o de verificar se equações de custos padrão determinadas para as condições dos EUA poderiam ser adotadas diretamente 
em outro país, deveriam ser adaptadas ou se o comportamento dos custos seria tão discrepante à ponto de não ser possível qualquer relação. Um total de 120 proprietários agrícolas foram pesquisados e obteve-se dados de 93 tratores, com os respectivos custos anuais de utilização. Cada máquina foi agrupada de acordo com a idade e a média anual de horas de uso, vida útil estimada em 12.000 horas, juntamente com o cálculo da média anual de custos de reparos. $\mathrm{O}$ custo anual foi expresso como porcentagem do custo de aquisição do modelo equivalente novo. Foi difícil propor um modelo preciso para reparos e manutenção devido ao comportamento aleatório dos mesmos, onde o desvio padrão geralmente excede aos valores médios anuais de custos.

$$
\mathbf{T A R}=\mathbf{A} \cdot(\mathbf{T A U h})^{\mathbf{B}} \text {, onde: }
$$

$\mathrm{TAR}=$ reparos totais acumulados, em \% do preço do equivalente novo.

TAUh $=$ horas totais acumuladas, em $\%$ da vida útil total. A e B = parâmetros do modelo.

O parâmetro B descreve a distribuição dos custos de reparos e manutenções durante a vida útil do trator e A descreve a magnitude dos custos. Para as condições da região pesquisada determinou-se o valor de 0,0669 para $\mathrm{A}$ e 1,5920 para B. A fómula modificada para a obtenção dos custos acumulados de reparos e manutenção em dólares apresenta-se abaixo.

$$
\text { TAR }\left(\text { US\$) }=0,000669 \text {. }(\text { HRS / } 120)^{1,592}\right. \text {.ILP, onde: }
$$

TAR ( US\$ ) = total acumulado de reparos e manutenção.

HRS $=$ horas totais acumuladas de operação.

ILP = preço de aquisição do equivalente novo. 


\section{MATERIAIS E MÉTODOS}

\subsection{Considerações iniciais}

A cultura da cana-de-açucar ( Saccharum $s p$ ), dadas as suas características de plantio e colheita permite um uso mais intensivo e homogêneo das máquinas durante $\mathrm{o}$ ano, comparativamente à outras culturas: o plantio ocorre de junho à março e a colheita de meados de abril à meados de dezembro. Além disso, como o replantio é feito a cada cinco ou mais anos a necessidade de máquinas para o preparo do solo é proporcionalmente menor que em outras culturas. Uma agro-industria sucro-alcooleira diferencia-se de qualquer outra empresa agrícola pelos seguintes fatôres:

- trabalha com grandes extensões de área,

- cultiva um só produto,

- possui máquinas específicas para as diversas operações.

O setor sucro-alcooleiro, em função de sua importância econômica para o estado de São Paulo, e de sua organização dotada de controles razoáveis com relação ao uso de máquinas agrícolas, foi o escolhido para 0 levantamento de dados para este trabalho. Além disso, embora várias operações não sejam mecanizadas, é um setor com emprego intensivo de mecanização, como demonstra a tabela à seguir. 
Tabela 02: Participação percentual das diversas áreas na composição global de custos do setor sucro-alcooleiro.

\begin{tabular}{|l|l|}
\hline Setor de Lavoura & $42 \%$ \\
\hline Setor Industrial & $34 \%$ \\
\hline Setor de Mecanização & $20 \%$ \\
\hline Setor Administrativo & $4 \%$ \\
\hline
\end{tabular}

Fonte: Banchi ( 1988).

Os tratores de pneus possuem funções específicas, dentre as diversas atividades de mecanização, tais como: preparo periódico do solo, cultivo e adubação de soqueira, aplicação de defensivos, reboque de "julietas", etc. Estas divisões são possíveis porque as operações estendem-se durante vários meses do ano. Uma "Usina" não reflete a realidade agrícola da cultura da cana-de-açucar, que é formada também por pequenos, médios e grandes produtores, que fornecem a matéria-prima às "Usinas". Contudo, como elas respondem por grande parte da matéria-prima ela pode fornecer informações importantes sobre o emprego de tratores. 
Tabela 03: Média anual do emprego de tratores, em horas, nas diversas DIRAs, em comparação com o emprego na Usina da Barra S.A .

\begin{tabular}{|l|c|}
\hline Local & Horas/ano \\
\hline Usina da Barra & 1.357 \\
\hline DIRA de Bauru & 1.296 \\
\hline DIRA de S. J. R. Preto & 1.268 \\
\hline DIRA de Ribeirão Preto & 1.198 \\
\hline DIRA de P. Prudente & 1.094 \\
\hline DIRA de Marília & 1.026 \\
\hline DIRA de Sorocaba & 882 \\
\hline DIRA de São Paulo & 826 \\
\hline
\end{tabular}

Fonte: Nojimoto ( 1987 ).

\subsection{Aquisição de dados}

Para a obtenção dos dados para o presente trabalho utilizou-se os relatórios mensais de custos operacionais da frota de máquinas agrícolas de uma agro-industria sucro-alcooleira situada na DIRA de São Paulo, estado de São Paulo.

Os relatórios de custos operacionais ( apêndice 1 ) apresentam os dados agregados mensalmente por centro de custo individual (trator), dividido nos seguintes ítens: salário do operador, encargos sociais do operador, diesel, lubrificantes, pneus, serviços de terceiros, peças consumidas do almoxarifado, mão-de-obra da oficina própria e despesas de materiais e serviços para grandes reformas . 
Foram empregados os dados referentes aos tratores marca VALMET, modelos $118 \times 4$ ( 7 tratores), $128 \times 4$ ( 9 tratores ) e $148 \times 4$ ( 3 tratores ) - apêndice 4 - no período compreendido entre janeiro de 1987 e dezembro de 1994.

Somente os tratores VALMET foram considerados por ser a única marca da frota da empresa, com razoável número de tratores, que ainda se encontra em produção, embora com modelos atualizados, outras marcas/modelos não apresentaram um número razoável de unidades para a amostra ou deixaram de operar no país com linhas de tratores agrícolas.

Quadro 1. : Composição da frota de tratores agrícolas da empresa.

\begin{tabular}{|c|c|c|c|c|}
\hline MARCA E MODELO & $\begin{array}{l}\text { NÚMERO DE } \\
\text { TRATORES }\end{array}$ & $\begin{array}{l}\text { POT NO } \\
\text { VOLANTE (kw) }\end{array}$ & $\begin{array}{l}\text { MÉDIA ANUAL } \\
\text { DE USO (hrs) }\end{array}$ & $\begin{array}{l}\text { OPERAÇŐES } \\
\text { USUAIS }^{2}\end{array}$ \\
\hline VALMET 118X4 & 07 & 86,00 & 1.750 & GR/RE/AR/AS \\
\hline VALMET 128x4 & 09 & 89,70 & 1.492 & GR/RE/AR/AS \\
\hline VALMET 148x4 & 03 & 106,60 & 1.424 & GR/RE/AR/AS \\
\hline FORD 6600 & 09 & 63,30 & 1.261 & PV/CR/GR/RC \\
\hline FORD 4810 & 04 & 48,40 & 1.864 & PV \\
\hline FORD 4600-10 & 18 & 46,40 & 233 & CR/PV/CT/EN \\
\hline CBT 8240 & 04 & 61,00 & 769 & EN/AR/GR \\
\hline MF 290x4 & 03 & 62,50 & 845 & SC/RL \\
\hline MF 265 & 06 & 47,80 & 1.179 & CR/CT \\
\hline CASE 2470/4490 & 09 & & 2.423 & SB/GR \\
\hline CAT D6D/E & 08 & 104,00 & 1.341 & LM/GD/SL \\
\hline FROTA TOTAL & 80 & - & 1.227 & 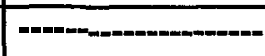 \\
\hline
\end{tabular}

1: média durante 0 ano de 1991.

2: $\mathrm{GR}=$ gradagem, $\mathrm{RE}=$ reboque de julietas, $\mathrm{AR}=$ aração, $\mathrm{AS}=$ adubação de soqueira, $\mathrm{CR}=$ carreta, $\mathrm{CT}=$ cultivador, $\mathrm{EN}=$ enleirador, $\mathrm{LM}=$ lâmina, $\mathrm{PV}=$ pulverizador, $\mathrm{RC}=$ roçadora, $\mathrm{RL}=$ rolo compactador, $\mathrm{SB}=$ subsolador, $\mathrm{SL}=$ sulcador, $\mathrm{SC}=$ esparramadora de calcáreo. 
Como custos de reparos e manutenções foram considerados os dados referentes à pneumáticos, serviços de terceiros tais como retíficas de motores e bombas injetoras, consumo de peças do almoxarifado próprio, mãode-obra da oficina própria e despesas com grandes reformas, geralmente de entre-safra.

Nos relatórios os valores do período compreendido entre janeiro de 1987 e fevereiro de 1991 encontravam-se em OTN/BTN médio mensal, foram convertidos para dólar médio mensal pelo câmbio oficial de venda do período correspondente. Os dados posteriores já eram apresentados em dólar médio mensal.

A opção por utilizar a cotação do dólar e não a indexação dos custos acumulados de reparos e manutenções ao custo de aquisição do modelo novo equivalente, durante o período observado deveu-se à dificuldade em avaliar o valor de mercado efetivamente praticado pelos representantes do fabricante, não adotando simplesmente o valor de tabela, em decorrência das bruscas oscilações provocadas pelos diversos planos econômicos lançados pelo governo.

Com os dados de custos acumulados de reparos e manutenções e horas acumuladas de operação foi feita uma análise quantitativa, pelo Método dos Mínimos Quadrados, através de regressões - linear, logarítmica, exponencial e potência - e também polinomiais de segundo e terceiro graus, para determinar qual função ajustava-se melhor aos dados obtidos. Utilizou-se para tanto o programa STATPACK da Northwest Analytical com ajuste posterior por regressão não-linear através do módulo NLIN do programa STATISTICAL ANALISYS SYSTEMS (S.A.S.). 


\subsection{Terminologia utilizada}

Neste trabalho foi considerada a terminologia proposta pela American Society of Agricultural Engineers (ASAE), através do padrão S495, para os termos empregados em custos de conjuntos mecanizados agrícolas, que propõe as seguintes definições:

- Custo médio acumulado, custo total durante um determinado período dividido pelo número de unidades de tempo, usualmente considera-se a unidade de tempo como sendo o ano calendário.

- Custos operacionais, custos que dependem diretamente da intensidade de uso do conjunto mecanizado, tais como combustível, lubrificantes, mão-de-obra de operação e reparos e manutenções.

- Custos fixos, aqueles que não dependem diretamente da intensidade de uso, como depreciação e remuneração do capital, taxas diversas, seguro e alojamento. $\mathrm{O}$ custos fixos oneram o custo total do conjunto independente de sua produtividade.

- Custos totais, são a soma dos custos operacionais e fixos.

- Manutenção, limpeza, troca de lubrificantes e componentes de substituição periódica e ajustes rotineiros. Engloba as atividades necessárias para manter 0 conjunto mecanizado em condições de plena eficiência operacional.

- Reparo, restauração do conjunto mecanizado, ou seus sub-conjuntos, à sua plena condição operacional após quebra, desgaste natural ou excessivo, acidente, etc.. Reparos não adicionam valor ou prolongam a vida do conjunto mecanizado. 
- Grandes revisões, reforma extensiva visando recuperar a eficiência do conjunto mecanizado e manter sua utilidade, neste ítem são incluídas as reformas de entre-safra, correntes na atividade sucro-alcooleira.

- Obsolescência, considera-se como obsoleta a máquina cujo modelo foi substituído pelo fabricante, sofrendo inovações tecnológicas, ou aquele cujas partes sobressalentes não estão mais disponíveis no mercado de reposição.

\subsection{Metodologia de cálculo do custo total}

Para a definição da forma de cálculo do custo total de conjuntos mecanizados agrícolas considerou-se o padrão ASAE EP496 detalhado à seguir;

3.4.1. Custos fixos: são aqueles debitados independentemente da utilização ou não do conjunto mecanizado, são também denominados custos de propriedade.

3.4.1.1. Depreciação: é definida como a perda de valor que um conjunto sofre no mercado devido ao aparecimento de modelos mais modernos, ao desgaste provocado pelo uso, à mudança na forma de utilização ou por quebras e acidentes.

Segundo NORONHA (1981) depreciação é uma reserva contábil destinada à prover fundos necessários para a substituição do capital investido em bens produtivos de longa duração, em função de desgaste e/ou obsolescência. É uma forma que a empresa possui para recuperar o bem de capital, repondo-o quando tornar-se economicamente inútil.

Os métodos usualmente empregados para o cálculo da depreciação são: 
a. Método da Linha Reta, onde o valor da máquina é depreciado de um valor constante dado pela expressão,

$$
\mathbf{D}=\frac{(\mathbf{P}-\mathbf{S})}{\mathbf{V}}, \text { onde: }
$$

$\mathrm{D}=$ depreciação.

$\mathrm{P}=$ preço de aquisição do equipamento.

$\mathrm{S}=$ valor de sucata ou revenda.

$\mathrm{V}=$ vida econômica, em períodos de tempo, geralmente anos.

b. Método dos Saldos Decrescentes, usa uma taxa constante de depreciação aplicada sobre o valor residual do ano anterior.

$$
\begin{aligned}
& \text { Dt }=\text { B. }(1-d)^{t-1} \cdot d \\
& \text { VRt }=\text { B. }(1-d)^{t} \\
& d=1-(\operatorname{VR~} n / B)^{1 / n}, \text { onde: }
\end{aligned}
$$

$\mathrm{Dt}=$ depreciação no período $\mathrm{t}$.

$\mathrm{B}=$ preço de aquisição ou base depreciável.

d = taxa de depreciação

$\mathrm{VR}=$ valor residual.

c. Método da Soma dos Dígitos dos Anos, ao contrário dos dois métodos anteriores, a taxa de depreciação é decrescente neste caso. Mas esta taxa se aplica sempre ao mesmo valor ( B - S ) como no método linear. Desta forma, a taxa de depreciação e o valor residual decrescem à medida que o bem vai se depreciando. 


$$
\mathbf{D n}=\left(\frac{\mathbf{N}}{\mathbf{F}}\right) \mathbf{Y}(\mathbf{B}-\mathbf{S}), \text { onde: }
$$

$\mathrm{Dn}=$ taxa de depreciação no período $\mathbf{n}$.

$\mathrm{N}=$ período ou ano corrente para o cálculo.

$\mathrm{F}=$ soma dos dígitos naturais dos $\mathrm{n}$ períodos de vida útil.

$\mathrm{B}=$ preço de aquisição

$\mathrm{S}=$ valor de revenda ou sucata.

d. Método do Fundo de Recuperação do Capital, neste método o cálculo da depreciação é feito de forma a constituir uma reserva, sobre a qual incidem juros, de forma à reunir capital suficiente para a reposição do bem no final da vida útil do equipamento.

$$
\mathbf{V n}=(\mathbf{P}-\mathbf{S})_{\mathbf{X}}\left[\frac{(1+\mathbf{i})^{\mathbf{L}}-(1+\mathbf{i})^{\mathrm{n}}}{(1+\mathbf{i})^{\mathbf{L}}-1}\right]+\mathbf{S}, \text { sendo: }
$$

$\mathrm{Vn}=$ valor da reserva no ano $\mathbf{n}$.

$\mathrm{P}=$ custo de aquisição do equipamento.

$\mathrm{S}=$ valor de revenda ou sucata.

$\mathrm{i}=$ taxa de juros do período, normalmente anual.

$\mathrm{L}=$ ano corrente para o cálculo, ano $\mathrm{n}$.

e. Valor de Mercado, outro método, o mais preciso, para calcular a depreciação se utiliza de uma pesquisa de mercado para estabelecer o real valor do conjunto usado. MOLINA (1994), realizou um levantamento no suplemento Agrofolha do jornal Folha de São Paulo, no período compreendido entre 21 de novembro de 1989 e 17 de setembro de 1991 e observou que o trator sofre uma depreciação em torno de $30 \%$ do custo de aquisição no primeiro ano e praticamente tende a ser linear à partir do segundo, com uma taxa aproximada de $10 \%$ ao ano e valor de revenda em torno de $30 \%$ do custo de aquisição. $\mathrm{Na}$ média desse levantamento a vida útil situou-se em torno de 15 anos. 


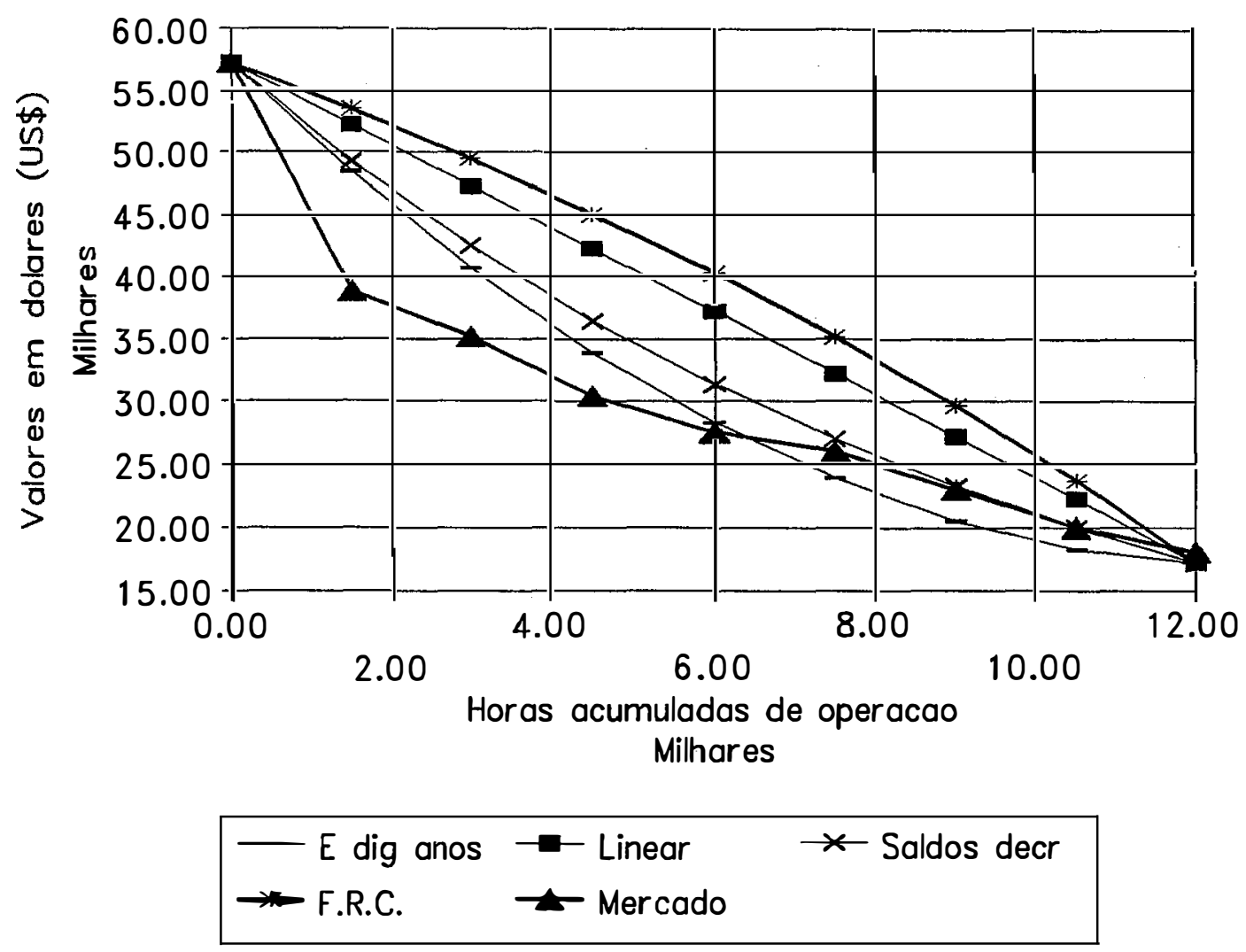

Fig. 01: comparação dos diversos métodos de cálculo de depreciação para um trator com custo de aquisição de US\$ 57,222.22, valor de revenda de $30 \%$ do custo de aquisição e a pesquisa de valor de mercado relatada por MOLINA (1994).

3.4.1.2. Juros, são calculados sobre o capital médio investido na aquisição das máquinas e se constituem em um custo de propriedade. $\mathrm{O}$ método recomendado é o Fator de Recuperação do Capital (CRF), que multiplica o saldo do investimento no bem de produção, dado pela fómmula abaixo.

$$
\mathbf{C R F}=\frac{\mathbf{i}(1+\mathbf{i})^{\mathbf{L}}}{(1+\mathbf{i})^{\mathbf{L}}-1}, \quad \text { onde: }
$$

$\mathrm{i}=$ taxa de juros no período, normalmente anual.

$\mathrm{L}=$ ano corrente ou número de períodos anuais. 
3.4.1.3. Alojamento, como raramente se constrói especificamente um abrigo para as máquinas, utilizando-se galpões já existentes, costuma-se adotar para 0 cálculo do alojamento uma porcentagem do custo inicial da máquina, normalmente de $0,75 \%$ ao ano.

3.4.1.4. Seguro, seguros feitos junto às seguradoras tem prêmios variando entre $2,5 \%$ à $10,0 \%$ ao ano sobre o custo de aquisição. Como ainda não é uma prática usual a contratação de seguros o mesmo deve ser bancado pelo empresário, nestes casos admite-se um fundo de segurança de $0,75 \%$ ao ano sobre $o$ custo de aquisição do bem, índice idêntico à financiamentos governamentais.

3.4.2. Custos operacionais: são aqueles de dependem diretamente da intensidade de uso que se faz do equipamento.

3.4.2.1. Combustíveis, a quantidade de combustíveis gastos em determinada operação depende do tipo de combustível que se utiliza e da carga exercida sobre o motor. Como nos ensaios dos tratores são levantadas curvas de potência para a t-d-p e barra de tração, o consumo pode ser estimado à partir dos resultados obtidos nos mesmos.

Segundo o documento ASAE D497 a potência fornecida à barra de tração pode ser convertida em potência equivalente na t-d-p para uma dada operação. Com esta potência equivalente pode-se calcular a razão entre a mesma e a potência máxima na tomada-de-potência, fornecida pelo ensaio do trator. Esta relação é designada por X e representada por: 


$$
\mathbf{X}=\frac{\text { potencia.equivalente..t }-\mathbf{d}-\mathbf{p}(\mathbf{k w})}{\text { potencia.maxima..t }-\mathbf{d}-\mathbf{p}(\mathbf{k w})}
$$

Uma vez obtido o valor de $X$, o consumo de combustível ( $1 / k w h$ ) pode ser estimado por:

$$
\operatorname{Diesel}(\mathrm{I} / \mathrm{kwh})=2,64 . \mathrm{X}+3,91-0,20 \cdot \sqrt{738,00 . X+173,00}
$$

A média genérica de consumo de combustível (Diesel) pode ser calculada pela fórmula seguinte, quando não for possível determinar a potencia equivalente.

$$
\mathbf{Q}_{\mathrm{avg}}=0,200385 . \mathrm{P} \text {, sendo que: }
$$

$\mathrm{Q}_{\text {avg }}=$ média de comsumo de Diesel, em $\mathrm{l} / \mathrm{h}$. $\mathbf{P}=$ potencia nominal do motor, em $\mathrm{kw}$.

3.4.2.2. Lubrificantes, o consumo de lubrificantes líquidos pelo motor, em litros por hora, pode ser calculado à partir da equação abaixo, para motores de ciclo diesel, ou se considera um consumo entre 0,0378 e 0,0947 1/h.

$$
\text { Consumo }=0,00059 . P+0,02169 \text {, onde: }
$$

$\mathrm{P}=$ potência nominal do motor, em $\mathrm{kw}$.

3.4.2.3. Graxa, o consumo pode ser considerado como $0,5 \mathrm{~kg}$ a cada dez horas de operação, em condições normais de utilização.

3.4.2.4. Manutenção, dentre as despesas de manutenção devem ser computadas as realizadas para manutenção, reparos e grandes revisões. 
3.4.2.5. Salários, os salários diretos, beneficios e encargos sociais referentes à mão-de-obra devem ser computados no cálculo do custo operacional. Esses salários devem ser incluídos mesmo que as máquinas sejam operadas pelos proprietários e devem ser no mínimo iguais à média prevalescente na região. 


\section{RESULTADOS}

\subsection{Análise preliminar dos dados obtidos}

Analisando-se os dados dos relatórios de custos operacionais observou-se a seguinte participação relativa dos ítens componentes durante o período estudado.

Tabela 04: Composição dos ítens do custo operacional (US\$/hora) para os tres modelos de tratores no decorrer do período observado, em porcentagem para mão-de-obra de operação (\%MDO), Diesel (\%DIESEL), lubrificantes (\%LUBR) e reparos e manutenções (\%R\&M).

\begin{tabular}{|c|c|c|c|c|c|c|c|}
\hline ANO & MODELO & Horas Oper. & $\% \mathrm{MDO}$ & \%DIESEL & \% LUBR & \% R\&M & US\$/hora \\
\hline \multirow[t]{2}{*}{1987} & $118 \times 4$ & 1.301 & 48,65 & 19,29 & 2,21 & 29,85 & 11,99 \\
\hline & $128 \times 4$ & 1.275 & 68,49 & 23,02 & 3,01 & 5,49 & 7,69 \\
\hline \multirow[t]{2}{*}{1988} & $118 \times 4$ & 1.546 & 51,97 & 14,53 & 3,48 & 31,72 & 13,42 \\
\hline & $128 \times 4$ & 1.436 & 64,81 & 20,97 & 4,57 & 12,35 & 11,16 \\
\hline \multirow[t]{3}{*}{1989} & $118 \times 4$ & 1.572 & 65,64 & 5,32 & 3,17 & 25,88 & 12,66 \\
\hline & $128 \times 4$ & 1.174 & 72,99 & 7,98 & 4,11 & 14,91 & 10,63 \\
\hline & $148 \times 4$ & 530 & 72,73 & 13,87 & 6,36 & 7,04 & 8,13 \\
\hline \multirow[t]{3}{*}{1990} & $118 \times 4$ & 1.732 & 65,75 & 14,27 & 2,83 & 17,14 & 11,29 \\
\hline & $128 \times 4$ & 1.681 & 63,01 & 16,26 & 2,22 & 18,51 & 12,69 \\
\hline & $148 \times 4$ & 2.016 & 66,79 & 22,89 & 2,58 & 7,74 & 11,15 \\
\hline \multirow[t]{3}{*}{1991} & $118 \times 4$ & 1.749 & 64,43 & 12,03 & 2,93 & 20,61 & 11,87 \\
\hline & $128 \times 4$ & 1.492 & 66,10 & 14,28 & 3,11 & 16,51 & 11,63 \\
\hline & $148 \times 4$ & 1.424 & 70,17 & 16,89 & 2,77 & 10,16 & 10,80 \\
\hline \multirow[t]{3}{*}{1992} & $118 \times 4$ & 1.703 & 53,58 & 10,84 & 2,75 & 32,83 & 15,66 \\
\hline & $128 \times 4$ & 1.279 & 57,85 & 15,52 & 3,33 & 23,30 & 14,26 \\
\hline & $148 \times 4$ & 1.336 & 59,84 & 18,40 & 3,17 & 18,59 & 13,66 \\
\hline \multirow[t]{3}{*}{1993} & $118 \times 4$ & 1.928 & 52,32 & 10,53 & 1,65 & 35,51 & 17,91 \\
\hline & $128 \times 4$ & 1.662 & 48,95 & 13,20 & 1,75 & 36,10 & 19,29 \\
\hline & $148 \times 4$ & 1.188 & 52,94 & 16,16 & 1,36 & 29,54 & 18,36 \\
\hline \multirow[t]{3}{*}{1994} & $118 \times 4$ & 1.942 & 56,94 & 9,96 & 1,68 & 31,41 & 21,85 \\
\hline & $128 \times 4$ & 1.651 & 54,58 & 13,81 & 2,13 & 29,48 & 22,63 \\
\hline & $148 \times 4$ & 1.386 & 48,75 & 14,91 & 1,84 & 34,50 & 25,41 \\
\hline MEDIA & $=$ & 1.505 & 60,13 & 14,57 & 2,77 & 22,53 & 14,28 \\
\hline
\end{tabular}


Durante o período observado - janeiro de 1987 à dezembro de 1994 - os ítens componentes do custo operacional, mão-de-obra de operação (inclusive encargos sociais), combustível ( Diesel ), lubrificantes e graxas (incluindo óleos para motor, transmissão e sistema hidráulico), reparos e manutenções ( considerando reformas de entre-safra ), apresentaram a participação média mostrada na figura abaixo, Fig. (02).

M-D-O OPER (60.13\%)

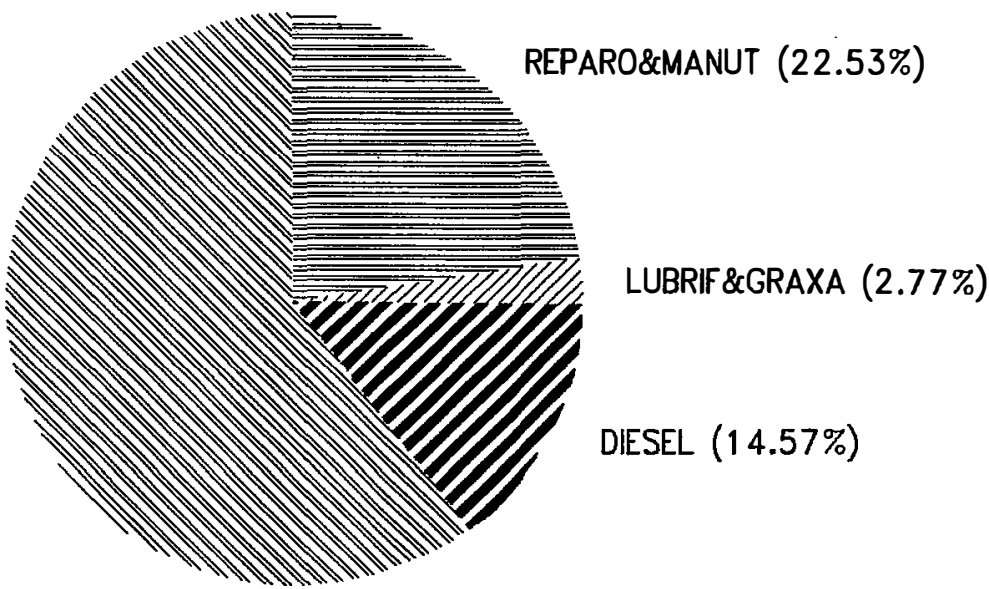

Fig. 02: participação relativa dos diversos componentes do custo operacional, para os dados observados.

Os custos de reparos e manutenções apresentaram a participação média de $22,53 \%$ do custo operacional, entretanto ocorreram flutuações expressivas na participação dos mesmos, em decorrência das oscilações econômicas, provocadas pelos diversos planos de estabilização lançados pelos governos no período, Cruzado II em 1987 à Collor II em 1991. 
Tabela 05: participação percentual do custo de reparos e manutenções no total do custo operacional (Custo Op.) durante o período amostrado.

\begin{tabular}{|r|l|l|l|l|l|l|l|l|}
\hline ANOS & 1987 & 1988 & 1989 & 1990 & 1991 & 1992 & 1993 & 1994 \\
\hline \% do Custo Op. & 18,61 & 22,78 & 17,86 & 16,30 & 17,02 & 26,07 & 34,85 & 30,98 \\
\hline
\end{tabular}

Os ítens componentes do custo de reparos e manutenções apresentaram a composição percentual mostrada abaixo, extremamente variável, durante o período observado.

Tabela 06: variação percentual dos componentes do custo de reparos e manutenções.

\begin{tabular}{|l|c|c|c|c|c|c|c|c|}
\hline ITENS ANOS & 1987 & 1988 & 1989 & 1990 & 1991 & 1992 & 1993 & 1994 \\
\hline PNEUS \% & 1.82 & 6.25 & 0.95 & 1.76 & 3.45 & 2.85 & 6.11 & 7.23 \\
\hline PEÇAS \% & 37.19 & 38.75 & 61.91 & 61.23 & 50.55 & 26.32 & 22.01 & 32.61 \\
\hline TERC \% & 42.83 & 23.28 & 30.74 & 29.44 & 0.93 & 2.84 & 2.77 & 3.74 \\
\hline M-D-O \% & 13.79 & 20.06 & 1.11 & 1.37 & 40.60 & 25.01 & 24.78 & 31.47 \\
\hline REFOR \% & 4.38 & 11.67 & 5.28 & 6.20 & 4.46 & 42.98 & 44.33 & 24.95 \\
\hline
\end{tabular}

Desdobrando o custo de reparos e manutenções ( $22,53 \%$ do custo operacional ) em seus diversos componentes temos a seguinte participação percentual, média dos oito anos: dispêndio com pneumáticos de $3,80 \%$, peças do almoxarifado da empresa 41,32 \%, serviços externos de terceiros $17,07 \%$, mão-de-obra da equipe da oficina própria da empresa 19,77 \% gastos com grandes revisões, ou reformas de entre-safra $18,03 \%$. 


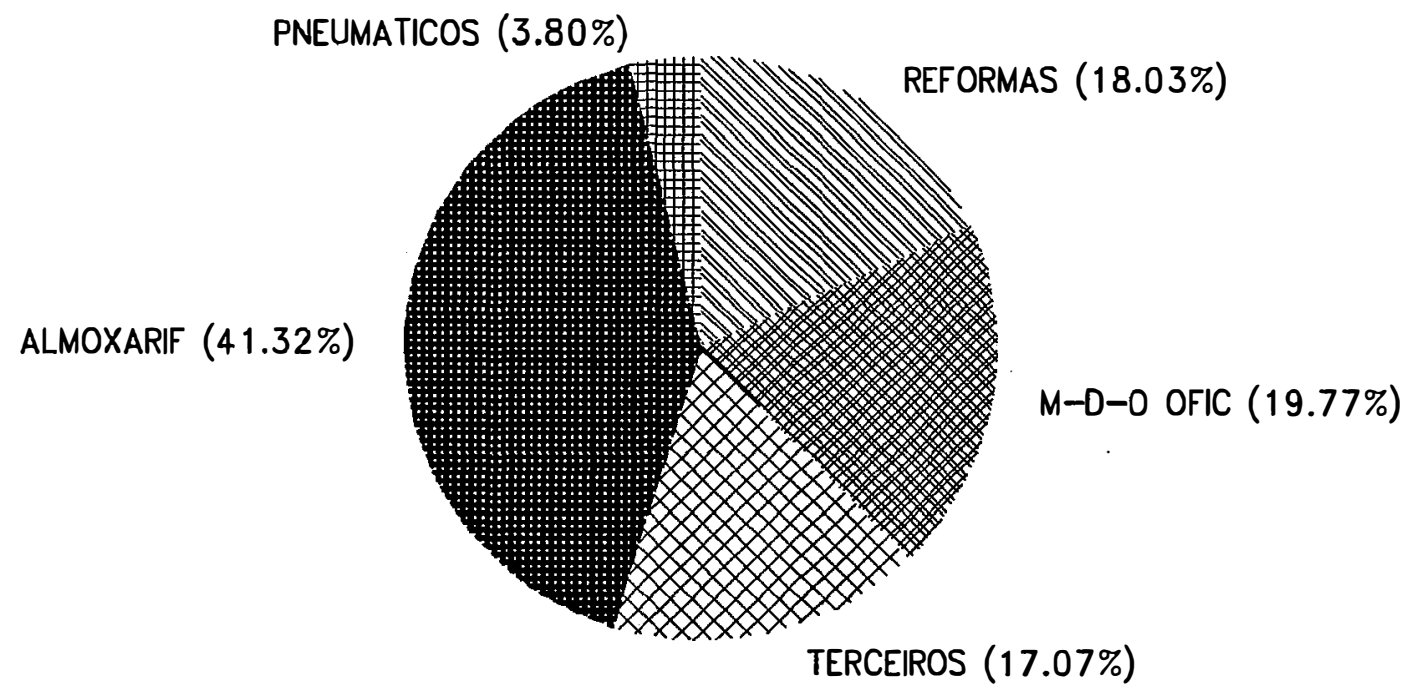

Fig. 03: participação relativa dos ítens componentes do custo de reparos e manutenções.

4.2. Determinação da equação de custo acumulado de reparos e manutenções (R\&M)

Os dados de custos anuais acumulados de reparos e manutenções (US\$) em função das horas acumuladas de operação, para os tratores da amostra, 139 observações no intervalo de 227 à 15.535 horas acumuladas de operação, apresentaram um coeficiente de variação de $171,18 \%$ e correlação linear de $89,58 \%$. Os valores observados, independentemente da máquina ao qual se referiam, foram agrupados em um único conjunto de dados para fins da análise quantitativa. 


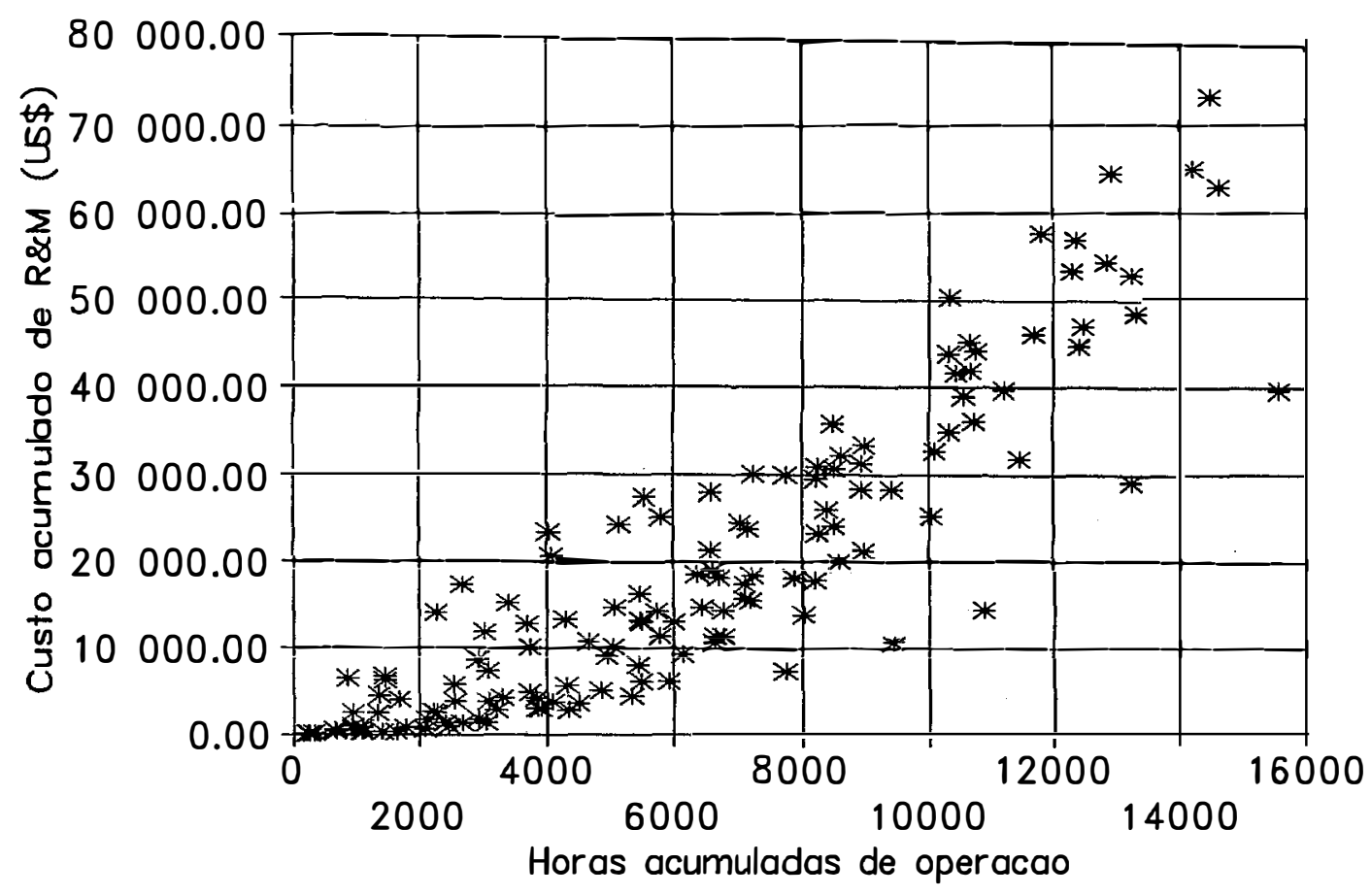

* valores observados

Fig. 04: comportamento observado dos dados de custos acumulados de reparos e manutenções durante o período estudado.

Com os dados acima calculou-se regressões linear, exponencial, logarítmica e potencia, pelo método dos mínimos quadrados, bem como polinomiais de segundo e terceiro graus para determinar qual função ajustaria-se mais adequadamente aos dados levantados ( apêndice 2 ). Os resultados são apresentados na tabela seguinte. 
Tabela 07: equações determinadas.

\begin{tabular}{|l|l|l|l|l|}
\hline Modelo & Equação & C. Deter. & C. Corr. $^{2}$ & D\&W $^{3}$ \\
\hline Exponencial & $\mathrm{Y}=1.250,9280 . \exp ^{(0,0003 . \mathrm{X})}$ & 0,6864 & 0,8285 & 0,3253 \\
\hline Logaritmica & $\mathrm{Y}=-108.242,00+15.009,05 \cdot \log (\mathrm{X})$ & 0,5587 & 0,7474 & 0,7476 \\
\hline Linear & $\mathrm{Y}=-6.434,858+(4,055 \cdot \mathrm{X})$ & 0,8025 & 0,8958 & 1,6649 \\
\hline Potencia & $\mathrm{Y}=0,0166 \cdot \mathrm{X}^{1,5653}$ & 0,8078 & 0,8988 & 1,7498 \\
\hline $2^{\circ}$ grau & $\mathrm{Y}=-412,535+1,559 \cdot \mathrm{X}+1,791 \cdot 10^{-4} \cdot \mathrm{X}^{2}$ & 0,8274 & 0,9845 & 1,9205 \\
\hline $3^{\circ}$ grau & $\mathrm{Y}=2.399,30-0,58 \cdot \mathrm{X}+5,24 \cdot 10^{-4} \cdot \mathrm{X}^{2}-1,66.10^{-8} \cdot \mathrm{X}^{3}$ & 0,8307 & 0,9837 & 1,9419 \\
\hline
\end{tabular}

$1:$ coeficiente de determinação.

$2:$ coeficiente de correlação ajustado.

3 : coeficiente da estatística de Durbin-Watson para auto-correlação de resíduos, cujo limite inferior é de 1,65 e superior de 1,69 , acima do qual confirma-se a hipótese.

$\mathrm{Y}=$ custo acumulado de reparos e manutenções, em dólares.

$\mathrm{X}=$ horas totais acumuladas de operação.

A função exponencial não se ajusta adequadamente aos dados, pois apresenta coeficientes de determinação de 0,6864 e correlação de 0,8285. A estatística de Durbin-Watson, para auto-correlação de resíduos, apresenta um valor de 0,3252 demonstrando que a hipótese não se confirma.

A função logarítmica também não se ajusta satisfatóriamente aos dados observados, apresentando coeficientes de determinação de 0,5587 e correlação de 0,7474 . O teste de Durbin-Watson apenas confirma a inadequação, apresentando o valor de 0,7476 . 


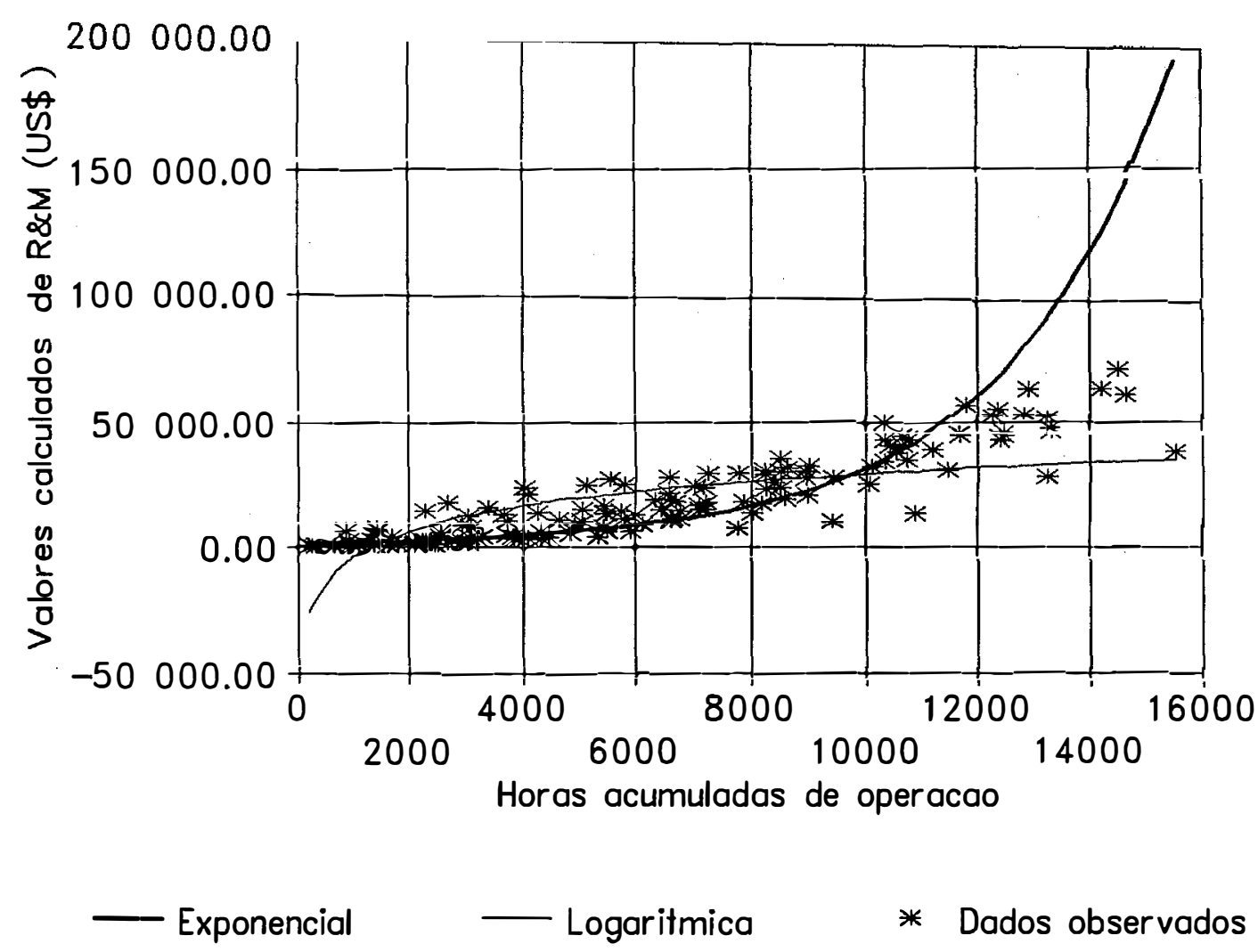

Fig. 05: forma das funções exponencial e logarítmica e seu ajuste relativo aos dados observados.

A função linear também não se ajusta adequadamente aos dados, embora apresentando coeficientes satisfatórios, de determinação de 0,8025 e também de correlação de 0,8958 , o teste de Durbin-Watson é inconcluso, com valor de 1,6649. Além disso a função não se aplica ao intervalo de zero à 1.587 horas acumuladas de operação, pois apresentaria valores negativos de custo de reparos e manutenções.

A função potência mostrou-se adequada ao modelo, apresentando coeficiente de determinação de 0,8078 e de correlação de 0,8988 , e o teste de Durbin-Watson apresentou um valor de 1,7498, mostrando que ocorre auto-correlação dos resíduos. 


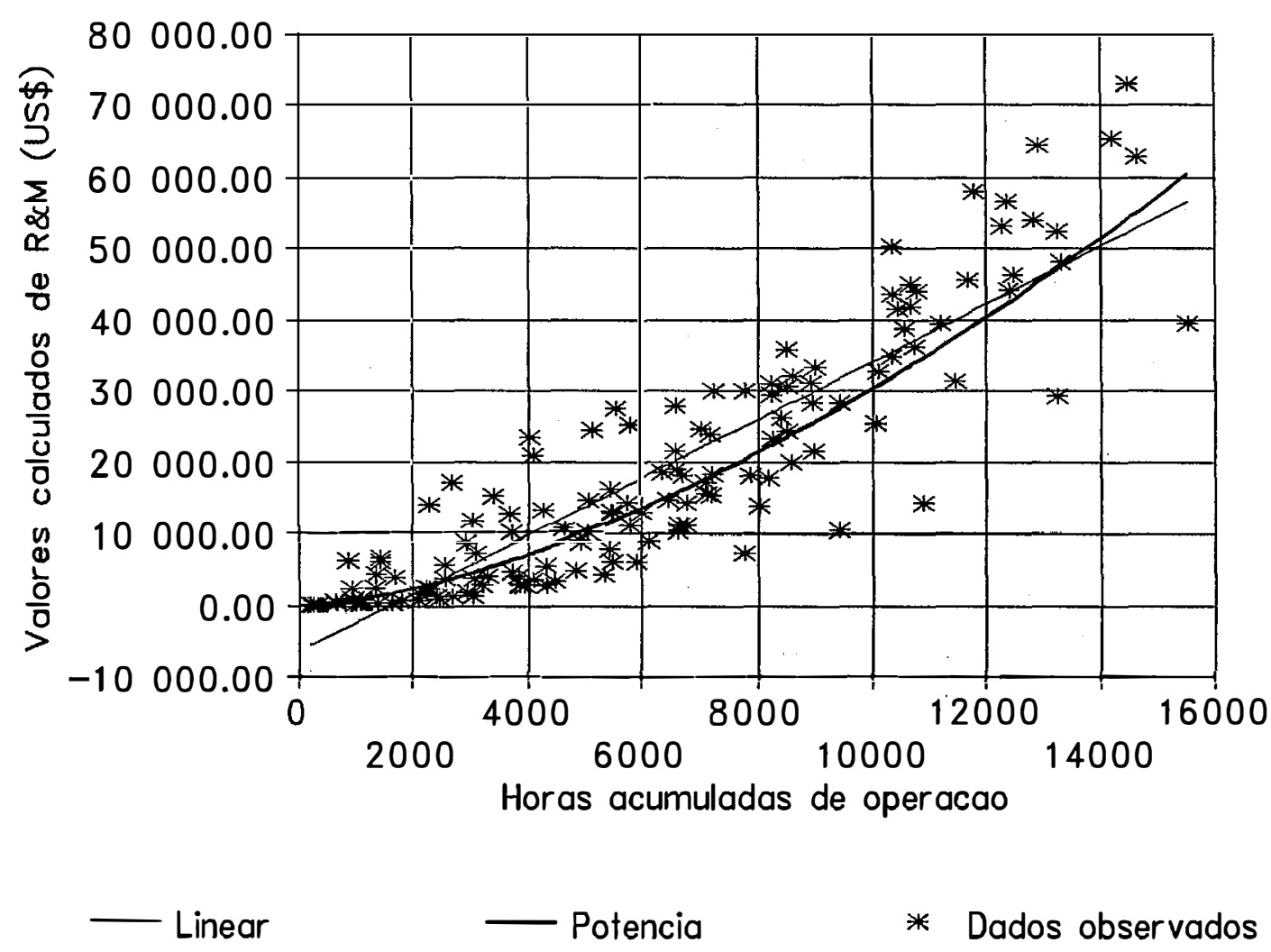

Fig. 06: funções linear e potência e seu ajuste aos dados observados.

A função polinomial de $2^{\circ}$ grau, embora apresentando coeficientes de determinação de 0,8274 , correlação de 0,9845 e valor do teste de Durbin-Watson de 1,9205, não é totalmente satisfatória por não se ajustar ao intervalo de zero à 258 horas acumuladas de operação.

A função polinomial de $3^{\circ}$ grau, com coeficientes de determinação de 0,8307, correlação de 0,9837 e Durbin-Watson de 1,9419, ajustou-se aos dados observados, sendo a restrição ao seu emprego o fato de não explicar adequadamente todos os intervalos possíveis de custos de reparos e manutenções, pois um trator novo já apresentaria, com zero horas de operação, um custo acumulado de reparos e manutenções de US\$2,399.30. 


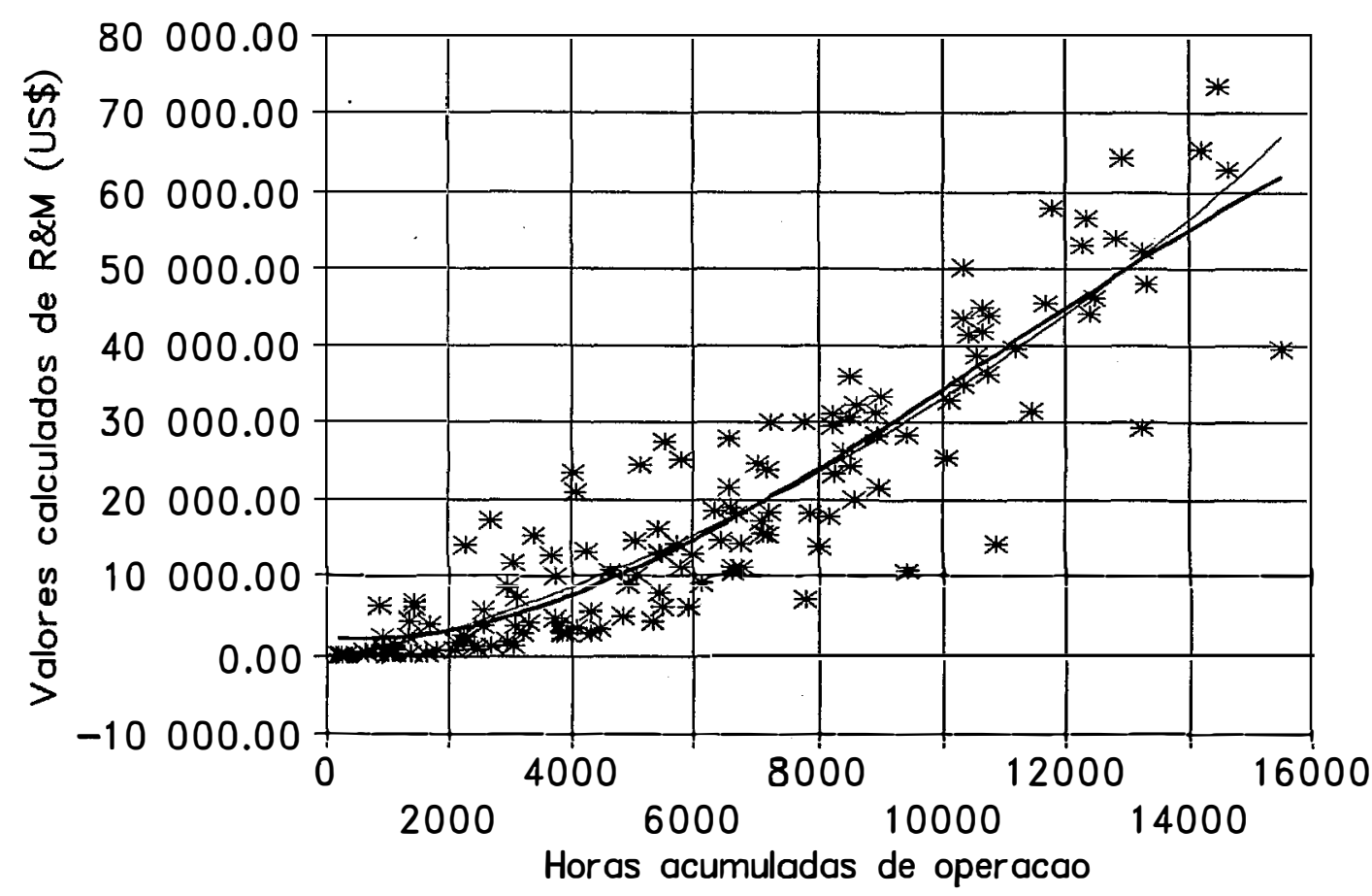

- Polinom grau 2 Polinom grau 3 * Dados observados

Fig. 07: ajuste das equações polinomiais de $2^{\circ}$ e $3^{\circ}$ graus aos dados observados.

Sendo a função potência a única que não apresentou restrições quanto ao intervalo de utilização, procedeu-se ao ajuste dessa função através do módulo NLIN, regressões não-lineares, do programa S.A.S. para certificação do modelo adotado ( apêndice 3 ).

Foi determinada uma nova equação para o modelo da função potência, com uma constante $\mathrm{C}$ para melhorar a acurácia, tal equação apresentou um coeficiente de determinação de 0,9222 e coeficiente de correlação de 0,9842, com a seguinte apresentação: 


$$
Y=0,027 . X^{1,523}+1,037, \text { sendo: }
$$

$\mathrm{Y}=$ custo acumulado de reparos e manutenções, em dólares até $\mathrm{X}$ horas. $\mathrm{X}=$ horas totais acumuladas de operação.

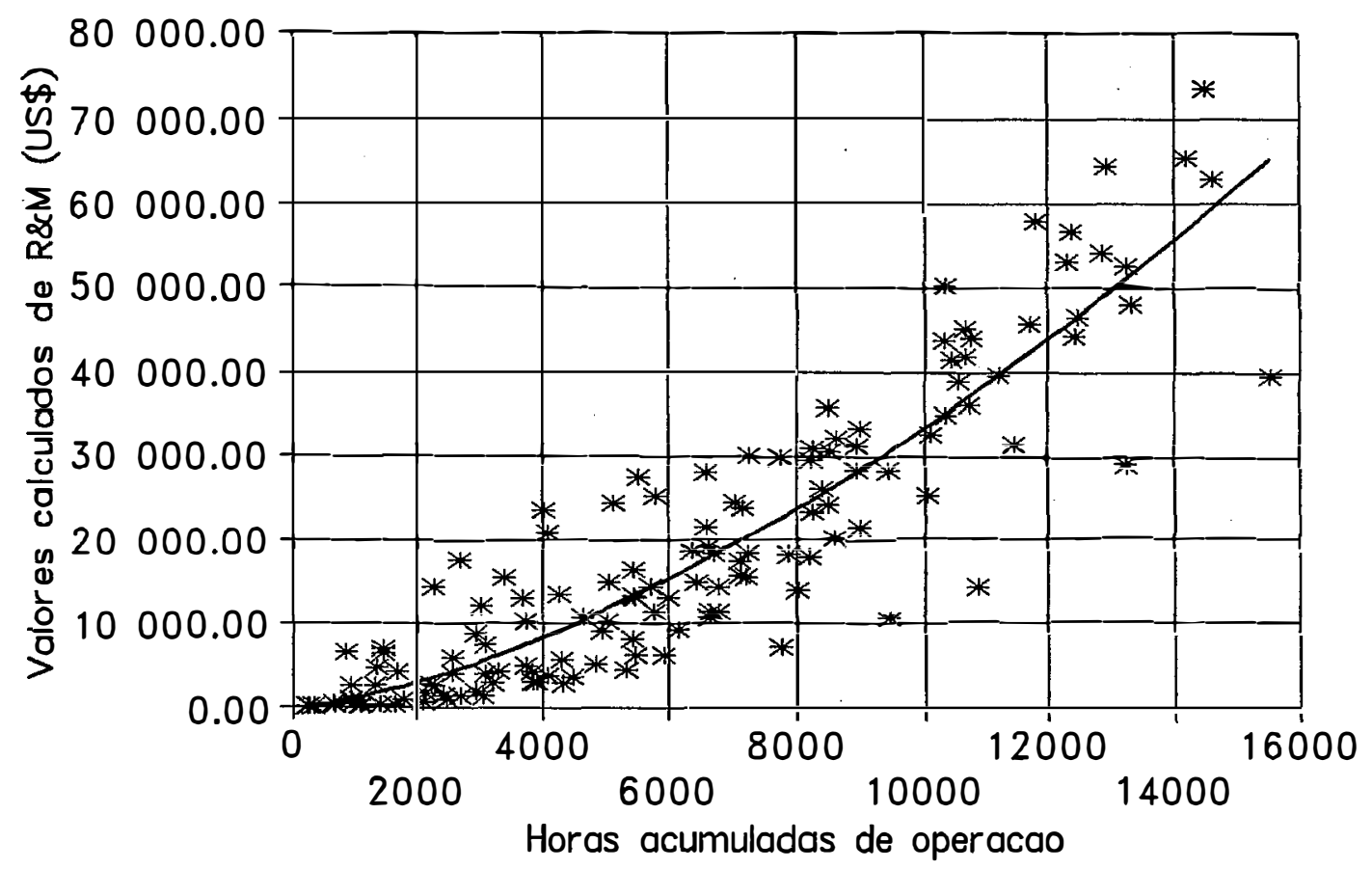

- Regr NLIN (SAS) * Dados observados

Fig. 08: função escolhida, para explicar os custos acumulados de reparos e manutenções em função de horas acumuladas de operação. 
Portanto a equação obtida para servir de modelo à estimativa dos custos acumulados de reparos e manutenções para tratores com tração dianteira auxiliar, potencia no volante compreendida na faixa entre 86,00 à $106,60 \mathrm{kw}$, empregados em atividades agrícolas nas empresas agro-industriais do setor sucro-alcooleiro, válida para o intervalo de 227 à 15.535 horas acumuladas de operação, assume a seguinte apresentação:

$$
\text { TAR }=0,027 . \text { TAUh }^{1,523}+1,037 \text {. sendo }
$$

TAR = custo acumulado de reparos e manutenções, em dólares (US\$).

TAUh $=$ horas totais acumuladas de operação até o ponto onde se deseja determinar o valor de TAR.

Para manter o valor de TAR atualizado é recomendável que se aplique um fator de correção ao mesmo, multiplicando-o pelo coeficiente abaixo, considerando como base o mes de abril de 1995,e considerando-se a evolução da taxa de cambio.

$$
\mathbf{F A}=(\mathbf{1}+\mathbf{g})^{\mathbf{n}}, \text { sendo: }
$$

FA = fator de atualização monetária.

$\mathrm{g}=$ taxa de inflação no período considerado.

$\mathrm{n}=$ número de períodos considerados, normalmente meses ou anos.

Sendo a constante $C=1,037$ pouco representativa, na ordem de grandeza dos valores estimados, em situações práticas a mesma pode ser descartada. 


\subsection{Determinação do custo total para um trator}

Com o intuito de exemplificar a composição do custo total de um trator utilizando-se a equação determinada neste estudo (31), segundo a metodologia de cálculo descrita em 3.4., adotou-se como similar novo equivalente aos amostrados o modelo VALMET $1280 \times 4$, com custo de aquisição de US\$ 57,222.22 (R\$ 51.500,00) em abril de 1995. A vida útil foi considerada como de 12.000 horas, com utilização durante 1.500 horas anuais. A depreciação foi calculada pelo método da Soma dos Dígitos dos Anos, pois pesquisas de mercado para tratores usados nem sempre estão disponíveis, e adotou-se um valor de revenda de $30 \%$ do custo de aquisição. Considerou-se uma taxa de $8 \%$ ao ano para a remuneração do capital, e para o avaliar o custo da mão-de-obra de operação adotou-se a média observada neste estudo, de US\$ 8.59/hora, incluídos os encargos sociais e provisões diversas, conforme facultado na legislação trabalhista. .

Cálculo do custo anual de reparos e manutenções, com a utilização da equação (31), estabelecida em função do custo acumulado:

$$
\begin{aligned}
& \mathrm{TAR}_{1}=0,027 .(1500)^{1,532}+1,037=\mathrm{US} \$ 1,856.92 \\
& \mathrm{TAR}_{2}=0,027 .(3000)^{1,523}+1,037=5,334.62-1,856.92=\text { US\$ 3,477.70 } \\
& \mathrm{TAR}_{3}=0,027 .(4500)^{1,523}+1,037=9,891 \cdot 27-5,334.62=\text { US\$ 4,556.65 } \\
& \text { TAR }_{4}=0,027 .(6000)^{1,523}+1,037=15,329.13-9,891.27=\text { US\$ 5,437.86 } \\
& \mathrm{TAR}_{5}=0,027 \cdot(7500)^{1,523}+1,037=21,532 \cdot 92-15,329 \cdot 13=\mathrm{US} \$ 6,203 \cdot 79 \\
& \mathrm{TAR}_{6}=0,027 .(9000)^{1,523}+1,037=28,424.38-21,532.92=\mathrm{US} \$ 6,891.46 \\
& \mathrm{TAR}_{7}=0,027 .(10500)^{1,523}+1,037=35,945.75-28,424.38=\text { US } \$ 7,521.37 \\
& \mathrm{TAR}_{8}=0,027 .(12000)^{1,523}+1,037=44,052 \cdot 14-35,945.75=\mathrm{US} \$ 8,106.39
\end{aligned}
$$


Foi calculado o fluxo de caixa projetado para este exemplo, que reflete o investimento inicial na aquisição do trator e as despesas previstas durante sua permanência na empresa e seu valor de revenda, para determinar o comportamento dos componentes do custo total no decorrer da vida útil do trator.

Tabela 08: fluxo de caixa.

\begin{tabular}{|l|l|r|r|r|r|r|r|r|}
\hline & \multicolumn{1}{|l|}{ DEPR $^{1}$} & JUROS $^{2}$ & ALOJ $^{3}$ & SEG $^{4}$ & SAL $^{5}$ & L/G $^{6}$ & R\&M $^{7}$ & COMB $^{8}$ \\
\hline ANO 1 & $8,901.23$ & $3,204.44$ & 429.17 & 429.17 & $12,885.00$ & 167.88 & $1,856.92$ & $8,563.07$ \\
\hline ANO 2 & $7,788.58$ & $2,492.35$ & 429.17 & 429.17 & $12,885.00$ & 167.88 & $3,477.70$ & $8,563.07$ \\
\hline ANO 3 & $6,675.92$ & $1,869.26$ & 429.17 & 429.17 & $12,885.00$ & 167.88 & $4,556.65$ & $8,563.07$ \\
\hline ANO 4 & $5,563.27$ & $1,335.19$ & 429.17 & 429.17 & $12,885.00$ & 167.88 & $5,437.86$ & $8,563.07$ \\
\hline ANO 5 & $4,450.62$ & 890.12 & 429.17 & 429.17 & $12,885.00$ & 167.88 & $6,203.79$ & $8,563.07$ \\
\hline ANO 6 & $3,337.96$ & 534.07 & 429.17 & 429.17 & $12,885.00$ & 167.88 & $6,891.46$ & $8,563.07$ \\
\hline ANO 7 & $2,225.31$ & 267.04 & 429.17 & 429.17 & $12,885.00$ & 167.88 & $7,521.37$ & $8,563.07$ \\
\hline ANO 8 & $1,112.65$ & 89.01 & 429.17 & 429.17 & $12,885.00$ & 167.88 & $8,106.39$ & $8,563.07$ \\
\hline TOTAL & $40,055.54$ & $10,681.48$ & $3,433.33$ & $3,433.33$ & $103,080.00$ & $1,343.04$ & $44,052.14$ & $68,504.55$ \\
\hline
\end{tabular}

1: depreciação calculada pela soma dos dígitos dos anos.

2: juros de $8 \%$ a.a., calculados por CRF.

3: alojamento, considerado $0,75 \%$ a.a. sobre ILP.

4: seguro, $0,75 \%$ a.a. sobre IIP.

5: salánio, média histórica na empresa, de US\$ 8.59/hora, inclusive encargos.

6: lubrificantes e graxas, segundo ASAE D497, pot no vol $=89,7 \mathrm{kw}$, US $\$ 1.50 /$ para cada um dos ítens.

7: reparos e manutenções calculados pela equação (31).

8: consumo de Diesel segundo ASAE EP496, 17,97 1hora, US\$ 0.3176/1. 
De acordo com o fluxo de caixa proposto para o exemplo, ao final de sua vida útil na empresa ( considerada de 12.000 horas ), o trator apresentaria a composição mostrada na fig. 09, para a participação relativa (em porcentagem) dos diversos ítens considerados como componentes do custo total, custos fixos somados aos operacionais.

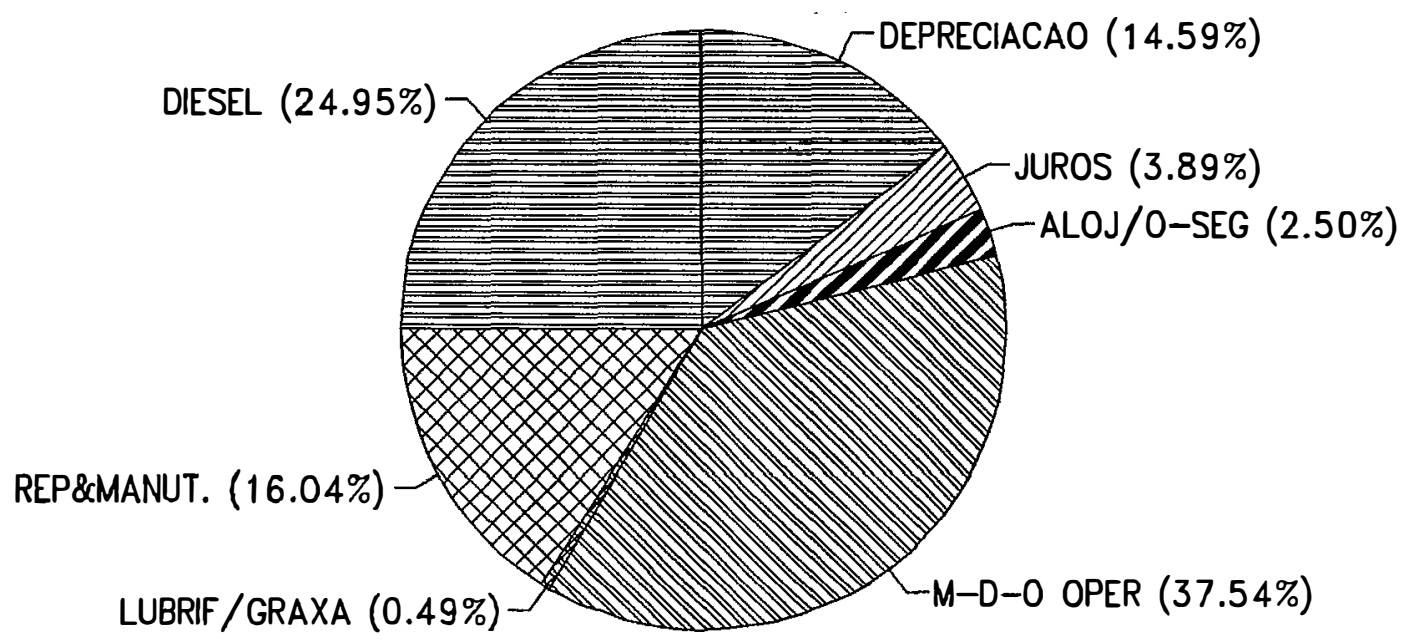

Fig. 09: participação percentual dos ítens componentes do custo total, conforme a simulação de fluxo de caixa proposta. 


\section{DISCUSSÃO}

\subsection{Comparação entre equações de estimativa de custo acumulado de} reparos e manutenções

Para efeito de comparação quanto ao comportamento dos custos de reparos e manutenções (R\&M), entre os valores estimados pela equação desenvolvida neste estudo, com os resultados previstos pelas equações citadas na literatura, adotou-se o trator padrão comentado em 4.3., portanto o custo de aquisição (ILP) será de US\$ 57,222.22 para as simulações efetuadas.

O trabalho pioneiro de LARSEN \& BOWERS (1965), foi efetuado com uma amostra heterogênea de tratores em uma ampla região geográfica, os estados do meio-oeste norte-americano, com tecnologia de mais de trinta anos atrás, o mesmo ocorrendo com BOWERS \& HUNT (1970) nos estados de Indiana e Illinóis no ano de 1966. Portanto, embora os dados revelem a mesma tendência em comparação com este estudo, os trabalhos citados fazem uma previsão de dispêndios significativamente mais elevada, devendo ser considerada a distancia tecnológica entre os universos amostrados.

Com base neste estudo, eq. (31), um trator após 10.000 horas de operação, Fig. (10), acumularia um custo de US\$33,371.62 com reparos e manutenções, segundo LARSEN \& BOWERS (1965) o custo seria de US $\$ 51,296.21$, eq. (2), uma diferença de $53,71 \%$ a mais na estimativa de reparos e manutenções. Para BOWERS \& HUNT (1970) o custo seria de 
US\$100,335.65, eq. (4), uma estimativa de $200,66 \%$ a mais com reparos e manutenções.

Parte da diferença pode ser atribuída a distância tecnológica entre as amostras, no entanto os trabalhos citados possuiam grande heterogeneidade com relação à marca dos tratores, potencia, idade, forma de utilização e política de manutenção. Tais fatores, de ocorrência aleatória quando se trabalha com amostras em grandes áreas, praticamente não ocorreram com a amostra objeto deste trabalho, por ter sido feita em uma empresa com atividades específicas e frota praticamente homogênea.

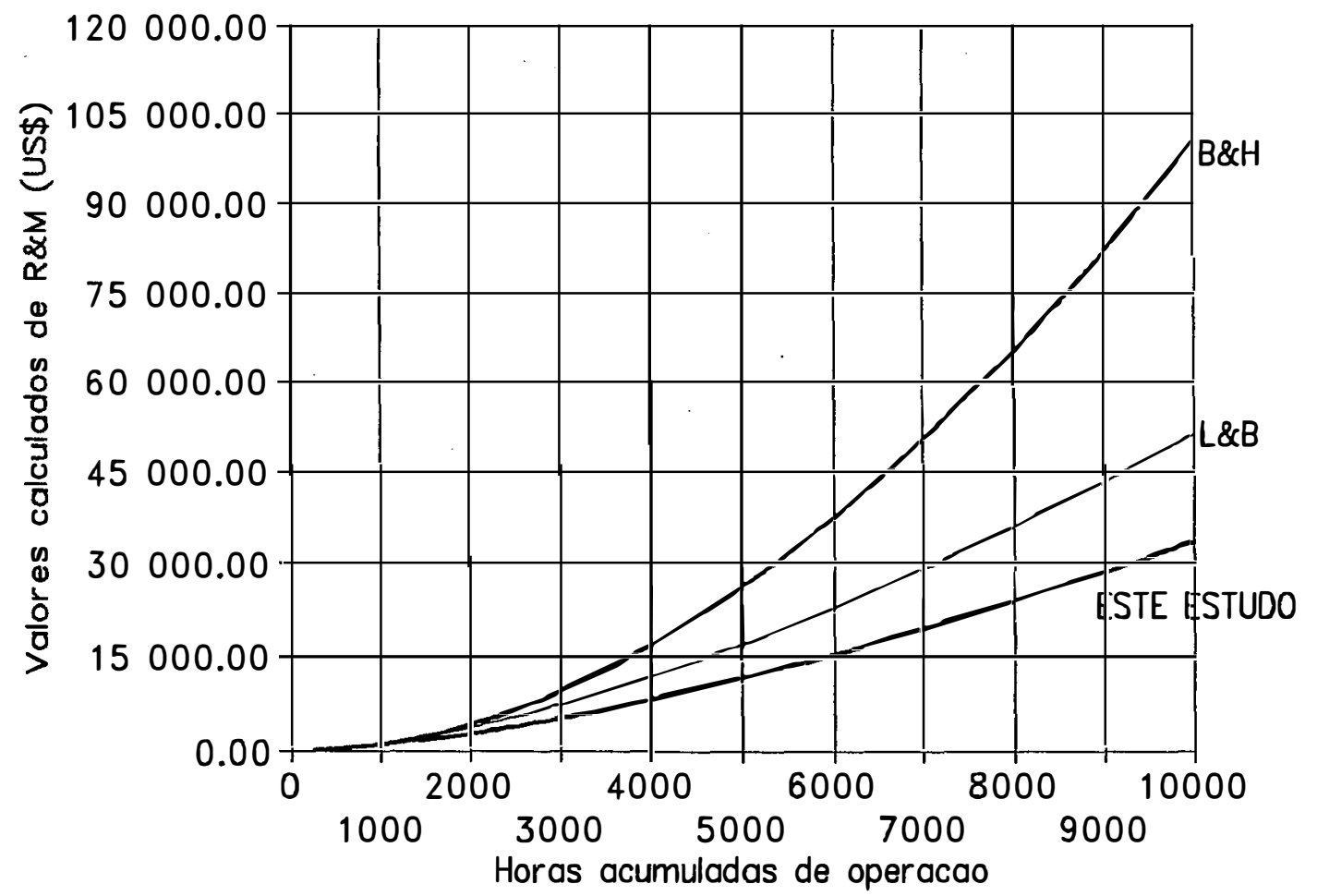

Fig. 10: equações de estimativa de custos acumulados de reparos e manutenções por Larsen \& Bowers (1965), Bowers \& Hunt (1970) e o presente estudo (1995). 
Pela comparação entre os resultados determinados neste estudo eq. (31), com o estudo de FAIRBANKS et alii (1971), que foi efetuado com base em 114 fazendas do estado de Kansas e uma população de 46 tratores, pela equação dos autores, eq. (6), após 10.000 horas de operação o custo seria de US $\$ 16,737,58$, uma participação de apenas $50,15 \%$ do que seria estimado com o emprego da equação determinada neste estudo.

$\mathrm{Na}$ comparação deste estudo com o trabalho desenvolvido por HUNT (1974), que realizou uma amostra de oito anos em fazendas de milho no estado de Illinóis entre 1958 e 1974, cujo custo foi estimado pela eq. (8), o valor seria de US\$74,138.87, nesta comparação a estimativa apresentou uma variação de $122,16 \%$ a mais que a deste estudo, dadas as condições diversas de operação e a distancia no tempo, 21 anos, entre este os estudos.

A mesma questão da distancia no tempo ocorre quando se compara este estudo com o trabalho de FARROW et alii (1980), realizado junto a dez empresas agrícolas do estado de Washington, com uma área agricultável de 35.000 acres, com informações de custos referentes ao período entre 1967 à 1978, os dados apresentaram coeficiente de correlação de 0,73, segundo a equação por eles determinada, eq. (10), o custo seria de US\$ 49,095.23, valor esse 47,12\% superior ao do presente estudo, eq. (31), para 10.000 horas acumuladas de operação. Uma variação de $47,12 \%$ nas estimativas pode ser considerada mínima, pois trata-se de um custo de ocorrencia aleatória e incidência extremamente variável, sendo que a tendência do comportamento dos dados de custo apresenta-se semelhante, como pode ser verificado na figura seguinte, fig. 11 . 


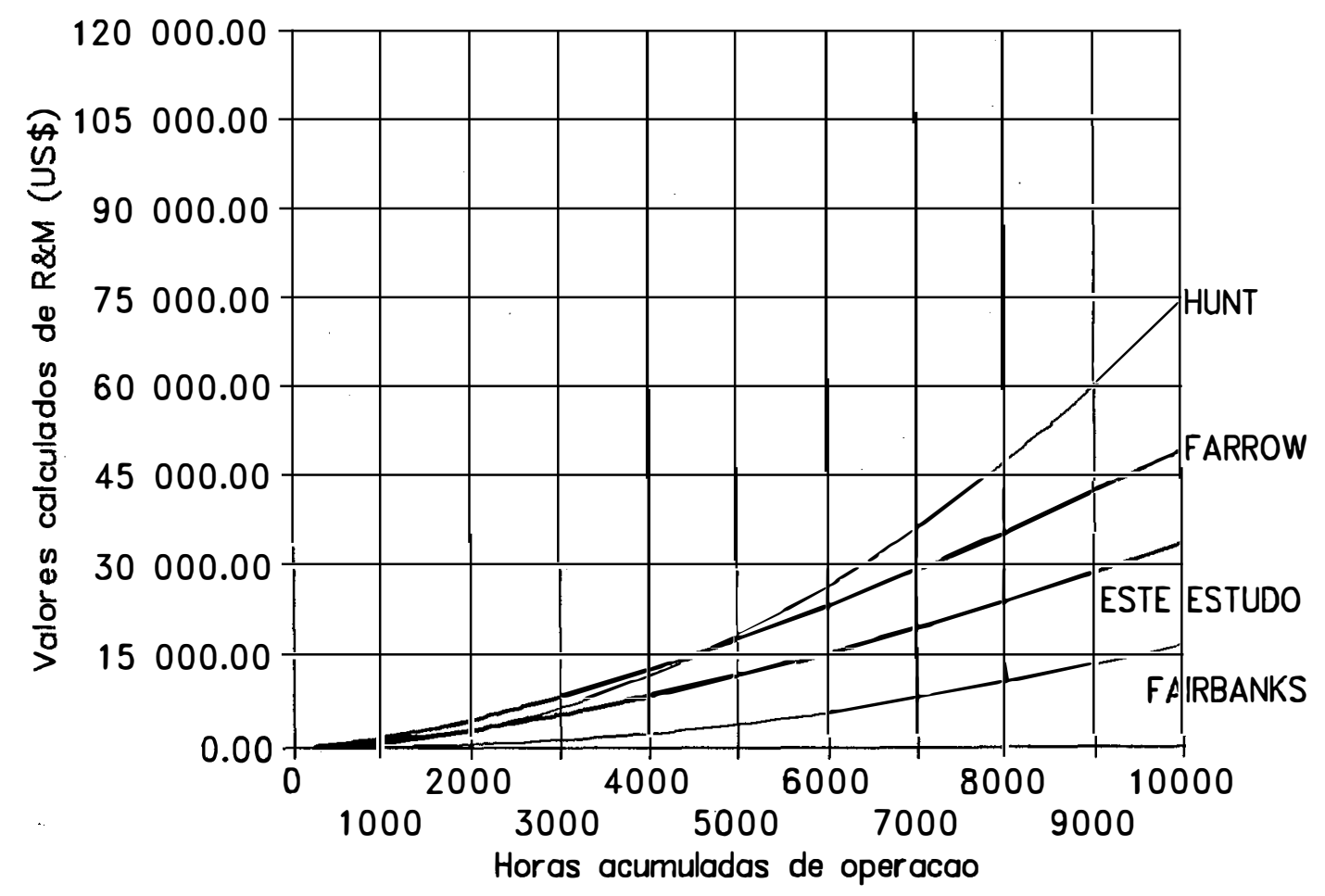

Fig. 11: comparação das equações de Hunt (1974), Farrow et alii (1980), Fairbanks et alii (1971) e este estudo (1995).

Um estudo mais recente foi realizado por MORRIS (1988), trabalhando com uma amostra de 50 tratores de uma empresa de Norfolk (UK), cuja potencia no volante variava entre 40 à $58 \mathrm{kw}$, com os registros do período de 1972 a 1983, com coeficiente de correlação de 0,61, pela estimativa do estudo, eq. (16), com coeficiente de determinação de 0,16 , o custo seria de US\$ $46,325.92$, uma variação $38,82 \%$ superior ao estimado pelo presente trabalho, eq. (31), embora mantendo a mesma tendência no comportamento da estimativa de custo, fig. 12. 
Quando se compara este estudo com amostragens de grande abrangência geográfica, como o estudo de ROTZ (1985), que utilizou os dados de custos de reparos e manutenções dos trinta anos anteriores, levantados através de questionários enviados aos proprietários agrícolas pelo serviço de extensão rural dos estados norte-americanos do meio-oeste, nota-se a mesma tendência, porém com valores estimados significativamente mais elevados. Utilizando-se a equação proposta pelo estudo citado, eq. (14), a estimativa seria de um custo de US\$ 57,222.22, fig. 12, após 10.000 horas de operação, ou $100,00 \%$ do valor de aquisição do trator considerado como padrão para este estudo, $71,47 \%$ superior ao estimado ao estimado pela eq. (31) deste estudo.

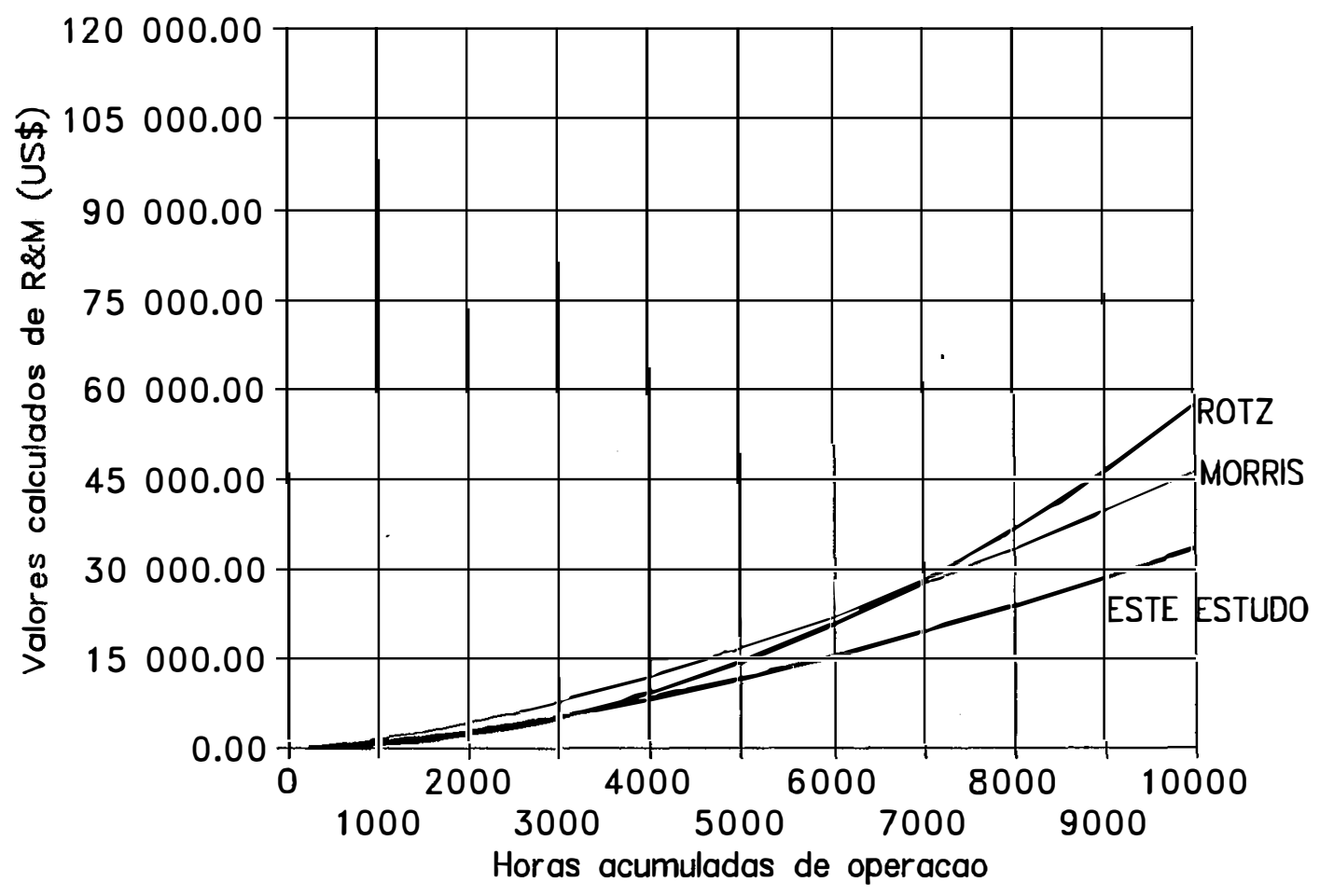

Fig. 12: comparação do resultado pelas equações de Rotz (1985), Morris (1988) e este estudo (1995). 
O mesmo comportamento para os dados de uma equação para estimativa de custo de reparos e manutenções pode ser observado no estudo realizado por WARD et alii (1985), fig. (13), que trabalharam com 21 tratores de tração 4x4, utilizados em atividades florestais, principalmente reboque de toras e limpeza de sub-bosques, na República da Irlanda, no período compreendido entre 1972 e 1981, em tais circunstâncias, totalmente diversas das observadas no presente estudo, o custo acumulado, eq. (12), seria de US $\$ 104,897.60$ para 10.000 horas de operação, um valor $214,33 \%$ acima do estimado por este estudo, eq. (31).

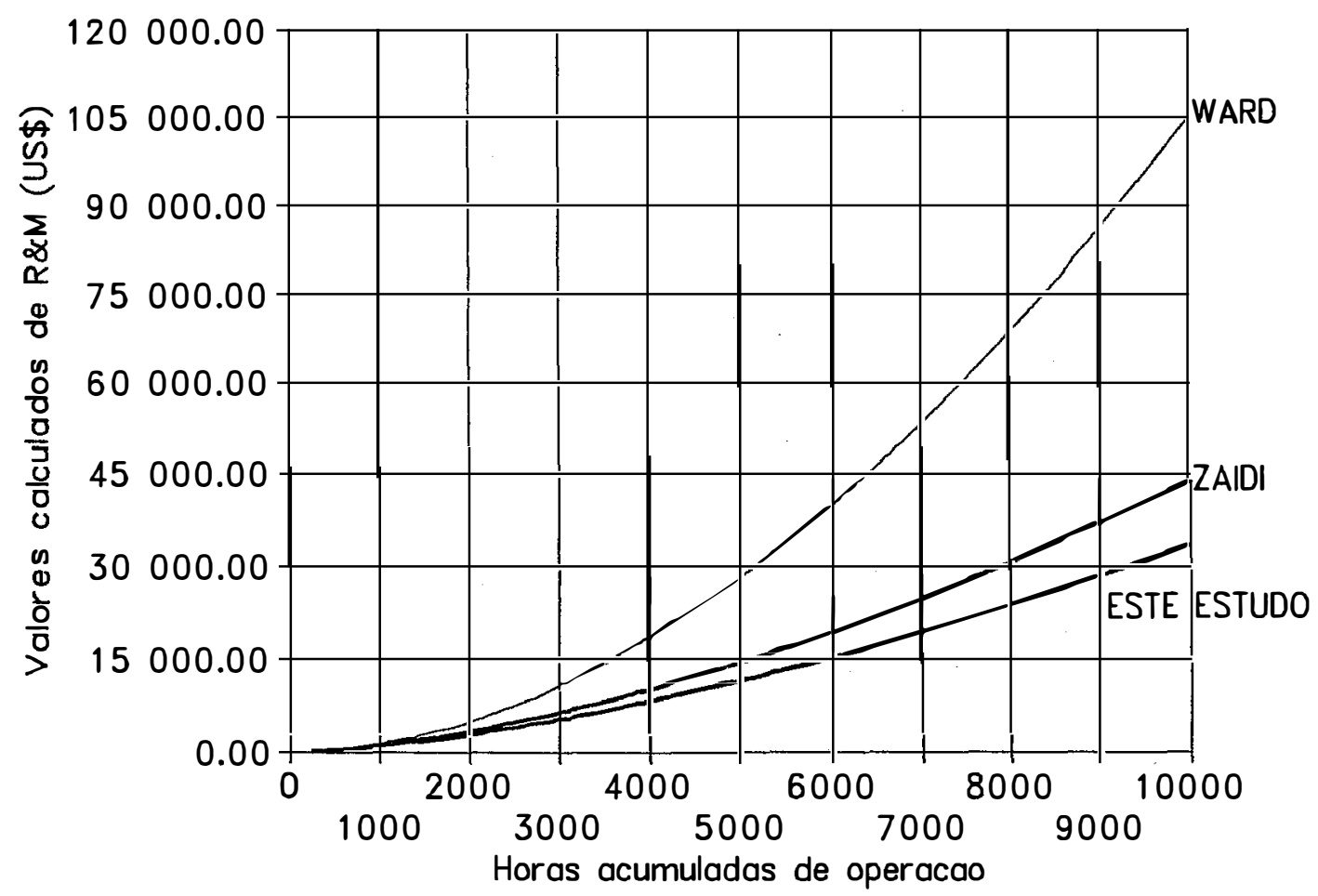

Fig. 13: comparação entre as equações de Ward et alii (1985), Zaidi et alii (1992) e o presente estudo (1995). 
O estudo que mais aproximou-se do presente trabalho em termos de valor estimado foi realizado por ZAIDI et alii (1992), fig. (13), que trabalhando com populações de tratores no Paquistão determinaram uma equação, eq. (18), segundo a qual o custo seria de US\$ 43,745.59 após 10.000 horas de operação, uma estimativa 31,09\% superior ao deste estudo.

Na tabela seguinte são apresentados os resultados comparativos entre as diversas equações desenvolvidas para estimativa do custo acumulado de reparos e manutenções. Foi adotado o ponto arbitrário de 10.000 horas totais acumuladas de operação para as equações (Hrs.Tot. Op.), visto que os diversos autores discordam com relação à vida útil total entre 10.000 horas e 12.000 horas , sempre considerando como exemplo o trator citado em 4.3., o modelo VALMET 1280x4. Os dados comparativos são apresentados em custo total acumulado de reparos e manutenções, em dólares (Custo Ac.) e em porcentagem do custo de aquisição do trator novo (Custo \%ILP), tendo como referencia o valor de aquisição de US\$ 57,222.22 para o modelo novo, vigente em abril de 1995.

Tabela 09: comparação entre as diversas equações de reparos e manutenções.

\begin{tabular}{|c|c|c|c|c|c|c|c|c|c|c|}
\hline AUTOR & L\&B (1) & $\mathrm{B} \& \mathrm{H} \quad$ (2) & FAIRB (3) & HUNT (4) & FARR (5) & WARD (6) & ROTZ (7) & MORR (8) & ZAIDI (9) & 1995 (10) \\
\hline Util . média & $600 \mathrm{~h} /$ ano & 493 h/ano & $741 \mathrm{~h} / \mathrm{ano}$ & $424 \mathrm{~h} /$ ano & $673 \mathrm{~h} / \mathrm{ano}$ & 590 h/ano & $1.000 \mathrm{~h} / \mathrm{ano}$ & 814 h/ano & & $1.505 \mathrm{~h} /$ ano \\
\hline Hrs Tot Op & $10.000 \mathrm{~h}$ & $10.000 \mathrm{~h}$ & $10.000 \mathrm{~h}$ & $10.000 \mathrm{~h}$ & $10.000 \mathrm{~h}$ & $10.000 \mathrm{~h}$ & $10.000 \mathrm{~h}$ & $10.000 \mathrm{~h}$ & $10.000 \mathrm{~h}$ & $10.000 \mathrm{~h}$ \\
\hline Custo Ac. & $51,296.21$ & $100,335.65$ & $16,737.58$ & $74,138.87$ & $49,095.23$ & $104,897.60$ & $57,222.22$ & $46,325.92$ & $43,745.59$ & $33,371.62$ \\
\hline Custo \%ILP & $89,64 \%$ & $175,34 \%$ & $29,25 \%$ & $129,56 \%$ & $85,80 \%$ & $183,32 \%$ & $100,00 \%$ & $80,96 \%$ & $76,45 \%$ & $58,32 \%$ \\
\hline
\end{tabular}

1: LARSEN \& BOWERS (1965).2: BOWERS \& HUNT (1970).3: FAIRBANKS et alii (1971).4: HUNT (1974).

5: FARROW et alii(1980).6: WARD et alii (1985).7: ROTZ (1985).8: MORRIS (1988).9: ZAIDI et alii (1992).

10: este estudo (1995). 


\subsection{Comparação entre estimativas de participação percentual de custos} de reparos e manutenções

Diversos autores, mesmo não desenvolvendo equações para estimativas de custos acumulados de reparos e manutenções, realizaram levantamentos à respeito e os apresentaram como porcentagem anual do custo inicial de aquisição do trator, ou apresentaram os custos em porcentagem do custo total.

Para efeito de comparação entre os diversos autores adotou-se as mesmas considerações do ítem 4.2., para custos de reparos e manutenções. Como porcentagem do custo total a Fig. 11 apresenta os valores calculados para este estudo, $16,04 \%$ do custo total ao final da vida útil. Desdobrando a composição do custo de reparos e manutenções em seus diversos ítens componentes, Fig. 03, temos: 3,80\% para pneumáticos, 18,03\% para reformas de entre-safra, $19,7 \%$ para mão-de-obra da oficina própria, $17,0 \%$ para despesas com serviços de terceiros e $41,32 \%$ para despesas com utilização de peças estocadas no almoxarifado da empresa.

Com base nas informações obtidas, de forma genérica, poderia ser considerado um índice de $9,62 \%$ do custo inicial de aquisiçào como dispêndio anual com reparos e manutenções, valor substancialmente superior aos 2,00\% do trabalho de DAVIDSON (1948), ou mesmo dos 3,50\% segundo BARGER et alii (1966) e dos 5,00\% de JONES (1963)..

Para este estudo a participação dos custos de reparos e manutenções ao final da vida útil, em porcentagem do custo total seria de $16,04 \%$. Porcentagem praticamente idêntica à recomendada por RICHEY et alii (1961), de 16,57\% do custo total. No entanto, outros autores relataram índices significativamente inferiores para a participação das despesas de reparos 
e manutenções no custo total ao final da vida útil, tais como FAIRBANKS et alii (1971) que relataram 8,04\% ou mesmo HUNT (1973) com 8,07\%, MAYFIELD et alii (1981) com 10,50\%, BUKHARI (1982) com 10,35\% e NORONHA et alii (1991) que consideraram esses custos como 9,74\% do total.

Para a participação desses custos como porcentagem do custo de aquisição do trator novo este estudo, de acordo com o ítem 4.2., considerou a porcentagem de $76,98 \%$, abaixo dos $120 \%$ recomendados por LARSEN \& BOWERS (1965) ou dos 100,00\% citados por ASAE (1989).

Segundo a simulação deste estudo 0 dispêndio com pneumáticos correspondeu à $3,80 \%$ do total com reparos e manutenções, participação menor que os $8,44 \%$ relatados por HUNT \& FUJII (1976) e dos 28,00\% de MORRIS (1988). Para mão-de-obra da oficina própria temos $19,70 \%$, e peças substituídas à $41,32 \%$, valores respectivamente inferiores aos $26,0 \%$ e $69,80 \%$ relatados por HUNT \& FUJII (1976).

Tabela 10: índices recomendados para dispêndio com reparos e manutenções (R\&M).

\begin{tabular}{|c|c|c|c|}
\hline AUTOR & INDICE/ANO $^{1}$ & INDICE/AC. ${ }^{2}$ & CUSTO TOT. $^{3}$ \\
\hline DAVIDSON (1948) & 2,00 & 16,00 & \\
\hline RICHEY et alii (1961) & $=$ & $=$ & 16,57 \\
\hline BARGER et alii (1963) & 3,50 & & 6,50 \\
\hline JONES (1963) & 5,00 & & 9,03 \\
\hline LARSEN\&BOWERS(1965) & 12,00 & 120,00 & - \\
\hline FAIRBANKS et alii (1971) & & - & 8,04 \\
\hline HUNT (1973) & - & $=$ & 8,07 \\
\hline MAYFIELD et alii (1981) & & $=$ & 10,50 \\
\hline BUKHARI (1982) & $=$ & 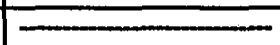 & 10,35 \\
\hline ASAE (1989) & 10,00 & 100,00 & 19,86 \\
\hline NORONHA et alii (1991) & 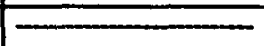 & ב- & 9,74 \\
\hline ESTE ESTUDO (1995) & 9,62 & 76,98 & 16,04 \\
\hline
\end{tabular}




\section{CONCLUSŌES}

Com base nas informações levantadas por este estudo podemos enumerar as seguintes conclusões:

- verificou-se, na prática, que a utilização dos tratores ultrapassa em muito a faixa de utilização considerada como vida econômica, entre 10.000 à 12.000 horas de operação recomendada pela literatura, atingindo 15.000 horas ou mais de uso acumulado.

- a vida média dos tratores amostrados situou-se em 11.154 horas acumuladas de operação.

- o comportamento médio dos custos acumulados de reparos e manutenções apresentaram-se proporcionais ao uso acumulado, medidos em horas ou anos.

- os custos de reparos e manutenções corresponderam, durante o período amostrado, a uma parcela significativa dos custos totais, embora não sendo o maior montante. Sua importância decorre do fato de não ser um custo meramente contábil, como frequentemente ocorre com as parcelas de depreciação e juros, e sim um desembolso efetivo, muitas vezes causando transtornos ao fluxo de caixa da empresa. 
- para uma população com pequenas variações de marca/modelo amostrado, forma de utilização e sistemática de manutenção, como o que ocorreu neste estudo, observou-se grande variabilidade nos custos de reparos e manutenções, denotando sua forma de ocorrência aleatória.

- para uma amostra suficientemente homogênea de tratores foi possível determinar uma equação satisfatória para estimativa do comportamento dos custos de reparos e manutenções, em relação ao uso acumulado, em horas.

- as diferentes fórmulas para estimativa de custos, comentadas na literatura, apresentaram resultados que revelaram a mesma tendência que este estudo, porém com ordem de grandeza diferenciada, em decorrência das condições locais das populações amostradas.

- levantamentos específicos para as diversas condições regionais do Brasil são inexistentes, tais levantamentos permitiriam estimativas mais precisas para as inúmeras marcas/modelos de tratores nas diversas condições de operação que ocorrem no país. 


\section{LITERATURA CITADA}

American Society of Agricultural Engineers. D230.4, Agricultural

Machinery Management Data. ASAE STANDARDS 1989.

St Joseph, Michigan, 1989, pg. 91-97.

- S495, Uniform

Terminology for Agricultural Machinery Management.

ASAE STANDARDS 1992. St Joseph, Michigan, 1992, pg. 285-286.

EP496, Agricultural

Machinery Management. ASAE STANDARDS 1992.

St. Joseph, Michigan, 1992, pg. 287-292.

. D497, Agricultural

Machinery Management Data. ASAE STANDARDS 1992. St.

Joseph, Michigan, 1992, pg. 293-299. 
BANCHI, Angelo Domingos. Planejamento da Utilização de uma Frota de Máquinas Agrícolas em Exploração Policultural, Determinando a Solução de Mínimo Custo com o Auxílio de Programação Linear. Campinas, S.P., 1989, 214 pg., Dissertação de Mestrado, FEAGRI-UNICAMP.

BARGER, E. L., LIJJEDAHL, J. B., CARLETON, W. M., McKIBBEN, E.G.. Tratores e seus Motores. Ed. Edgard Blucher Ltda, Convênio MEC-USAID, 1966, 397pg.

BOWERS, W., HUNT, D.R.. Application of Mathematical Formulas to Repair Cost Data. Transactions of The ASAE, St. Joseph, Michigan, 13 (6): pg. 806-809, nov-dec 1970.

BUKHARI, S.B.. Evaluation of Farmer's Competence to Maintain Farm Tractors. Agricultural Mechanization in Asia, Africa and Latin America. Japan, 13 (1): pg. 45-47, 1982.

DAVIDSON, J.B.. Agricultural Machinery. John Wiley \& Sons Inc., New York, $7^{\text {a }}$ Ed., 1948, 396 pg. 
FAIRBANKS, G.E., LARSON, G.H., CHUNG, D.S.. Cost of Using Farm Machinery. Transactions of The ASAE, St. Joseph, Michigan, 14 (1): pg. 98-101, jan-feb 1971.

FARROW, S., SHEPHERD, J.F., WAELTI, H.. A Regional Test of Machinery Repair Cost Equations. Paper-ASAE no 80-1017, American Society of Agricultural Engineers, St. Joseph, Michigan, june 1980, 20 pg..

HUNT, DONNELL R.. Farm Power and Machinery Management. $6^{\mathrm{a}}$ Ed. Iowa State University Press, Ames, Iowa, 1973, 324 pg..

HUNT, D.R.. Eight Years of Fann Machinery Cost Monitoring. Paper-ASAE no 74-1544, American Society of Agricultural Engineers, St. Joseph, Michigan, dec. 1974, 30 pg..

HUNT, D.R., FUJI, K.. Repair and Maintenance Costs by Machinery Categories. Paper-ASAE ํํ 76 - 1507, American Society of Agricultural Engineers, St. Joseph, Michigan, 1976, 27 pg.. 
JONES, F.R.. Farm Gás Engines and Tractors. Mc Graw-Hill Book Inc., New York, $4^{\mathrm{a}}$ Ed., 1963, 518 pg..

LARSEN, W.E., BOWERS, W.. Engineering Analysis of Machinery Costs. Paper-ASAE ño $65-162$, American Society of Agricultural Engineers, St. Joseph, Michigan, june 1965, 11 pg..

MAYFIELD, W., HINES, G. S., ROBERTS, L.. A New Method for Estimating Farm Machinery Costs. Transactions of The ASAE, St. Joseph, Michigan, 24 (6): 1446-1448, nov-dec 1981.

MIRANI, A.N., BUKHARI, S., ZAFARULLAH, M., BALOCH, J.. Unit Cost of Operations of Farm Tractors. Agricultutral Mechanization in Asia, Africa and Latin America. Japan, 20 (3): pg 44-46, 1989.

MOLINA. JR, W.F.. Depreciação do Trator Agrícola no Brasil: valor corrente de mercado. Separata do XXIII Congresso Brasileiro de Engenharia Agrícola, SBEA, Campinas (SP), julho de 1994. 
MORRIS, J.. Estimation of Tractor Repair and Maintenance Costs. Journal of Agricultural Engineering Research. The British Society for Research in Agricultural Engineering, 41 (3): pg. 191-200, nov. 1988.

NOJMOTO, TOSHIO. Obstáculos à Mecanização da Agricultura Brasileira. São Paulo (SP), 1987, 345 pg.. Tese de Doutorado, FEA-USP.

NORONHA, J. F. . Projetos Agropecuários: Administração Financeira, Orçamentação e Avaliação Econômica. FEALQ - USP, 1981, 274 pg.

NORONHA, J.F., MIALHE, L.G., DUARTE, L.P.. Custos dos Sistemas Tratorizados na Agricultura Brasileira. Apostila, 32 pg., Dpto de Economia e Sociologia Rural, ESALQUSP, Piracicaba (SP), 1991.

RICHEY, C.B., JACOBSON, P., HALL, C.W.. Agricultural Engineers Handbook. Mc Graw-Hill Book Co., New York, $4^{\mathrm{a}}$ Ed., 1963, 518 pg.. 
ROTZ, C. A.. A Standard Model for Repair Costs of Agricultural Machinery. Paper-ASAE no 85-1527, American Society of Agricultural Engineers, St. Joseph, Michigan, dec. 1985, $13 \mathrm{pg}$.

WARD, S.M., McNUTLY, P.B., CUNNEY, M.B.. Repair Costs of 2 and 4 WD tractors. Transactions of The ASAE, St. Joseph, Michigan, 28 (4): pg. 1074-1076, jul-aug 1985.

ZAIDI, M.A., SABIR, M.S., ZAFAR, A.W.. A Mathematical Model for Repair and Maintenance Cost of Agricultural Machinery. Agricultural Mechanization in Asia, Africa and Latin America. Japan, 23 (3): pg. 70-72, 1992. 


\section{APÊNDICES}


Apêndice 01: tabelas com os dados amostrados, totalizados anualmente para os tratores pesquisados, entre janeiro de 1987 e dezembro de 1994, em US\$ comercial de venda.

Os tratores cujos números vão de 701 à 707 referem-se à modelos VALMET 118x4, de 708 à 713 e 717 à 719 modelos VALMET 128x4 e 714,715 e 716 VALMET $148 \times 4$

Os diversos ítens componentes do custo operacional foram abreviados como segue, sempre correspondendo ao total anual;

- HRS TRAB: horas de operação do trator no ano correspondente.

- SAL OPER: total de salários pagos aos operadores, tratoristas.

- ENCARGOS: total de despesas da empresa com os encargos sociais dos operadores, tal valor compreende inclusive os diversos provisionamentos facultados pela legislação, não refletindo o real desembolso em dinheiro.

- DIESEL: despesas de combustível, óleo Diesel.

- LUBRIF: lubrificantes diversos, incluindo óleo de cárter, transmissão e hidráulico.

- GRAXAS: despesas com graxas, aplicadas sómente ao trator e não aos implementos utilizados.

- PNEUS: despesas com reparos e substituições de pnemáticos, incluindo mãode-obra de borracharia.

- PEÇAS: consumo de peças solicitadas ao almoxarifado da empresa, computadas pelo preço médio mensal de compra. 
- TERCEIROS: correspondem às despesas externas com recuperação de componentes executados por oficinas especializadas, tais como retíficas de motores e bombas injetoras, diferenciais, bombas hidráulicas, etc.

- M-D-O OFIC: custo da mão-de-obra da oficina da empresa, diretamente aplicada ao trator.

- REFORMA: despesas de reformas de entre-safra, para recuperação do trator à sua plena eficiência operacional. Incluem todas as despesas de peças, terceiros, pneus e mão-de-obra de oficina aplicados específicamente na atividade de reforma do trator.

- LUBRIF/GRX: total gasto com lubrificantes e graxas e sua participação no custo operacional total (em decimais).

- M-D-O OPER: salários e encargos e sua participação no total (em decimais).

- MANUT: despesas com reparos e manutenções compostas pelos gastos com pneus, peças, terceiros, m-d-o ofic. e reforma, e sua participação no total do custo operacional (em decimais).

-DIESEL: total gasto com combustível e sua participação no total operacional (em decimais).

- TOTAL: soma do total das despesas operacionais, ou seja, lubrificantes e graxas, mão-de-obra de operação, reparos e manutenções e Diesel. 


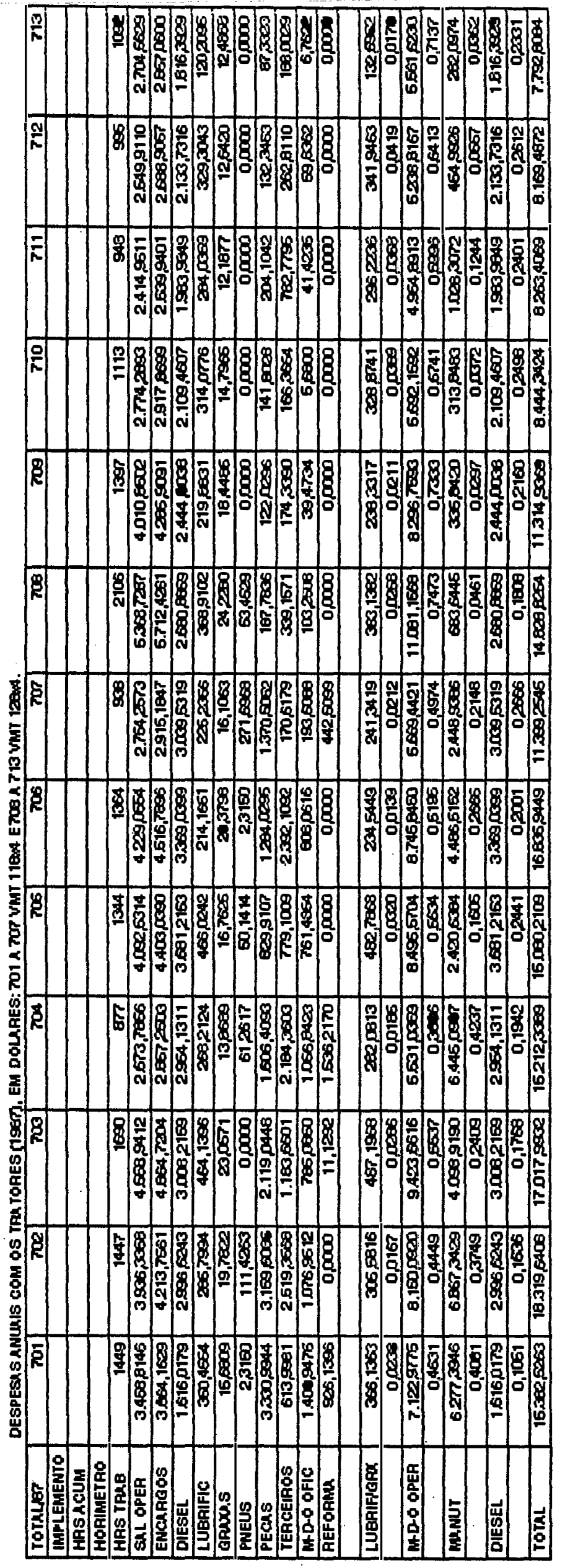




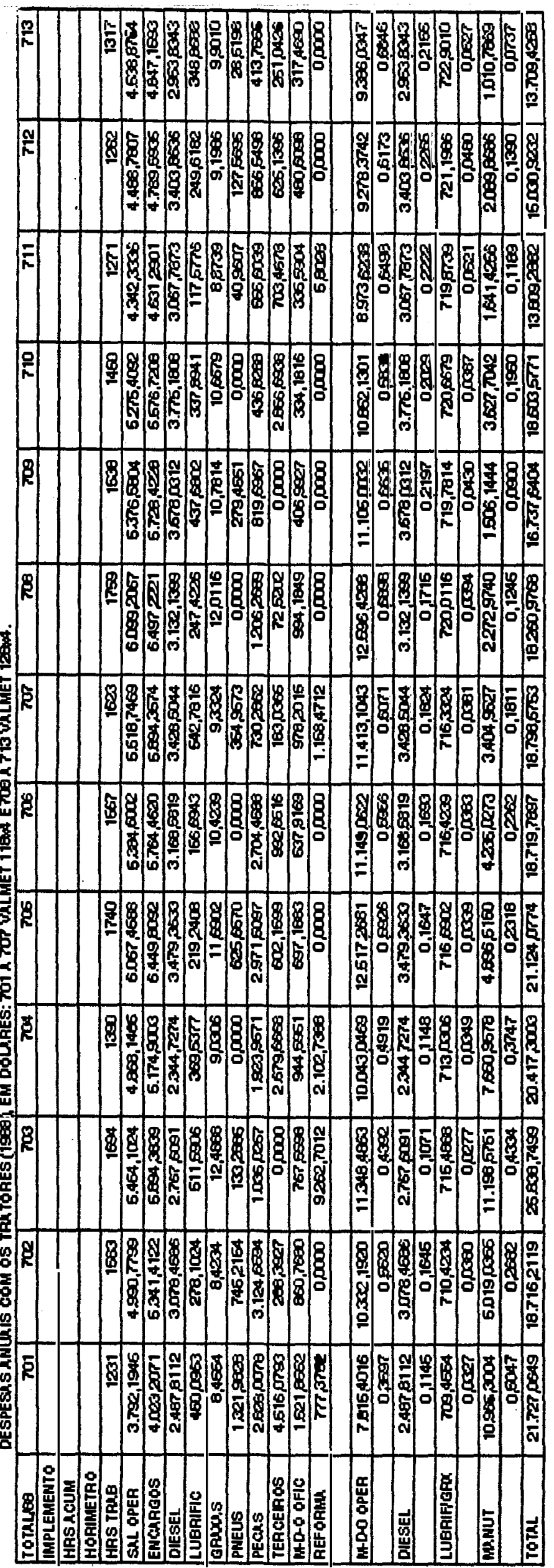




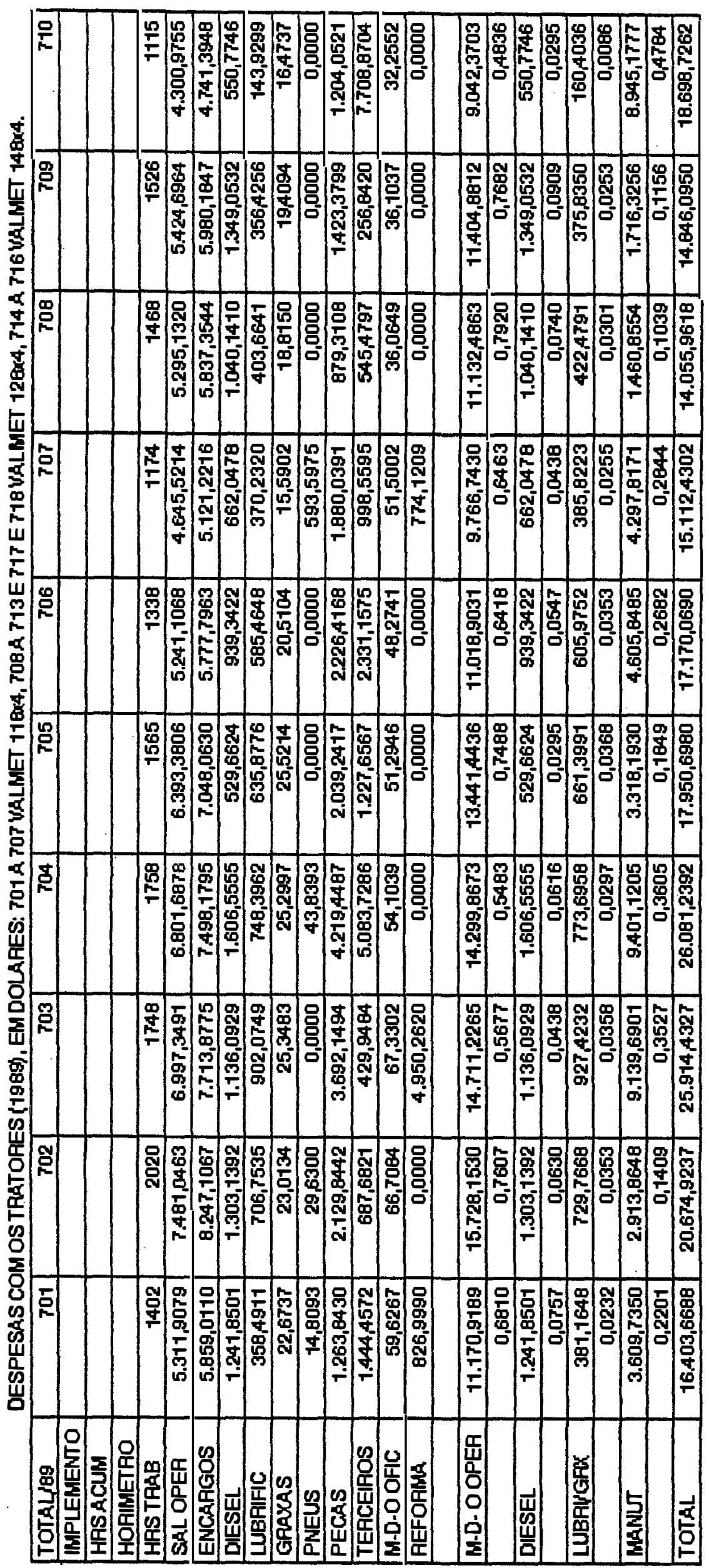




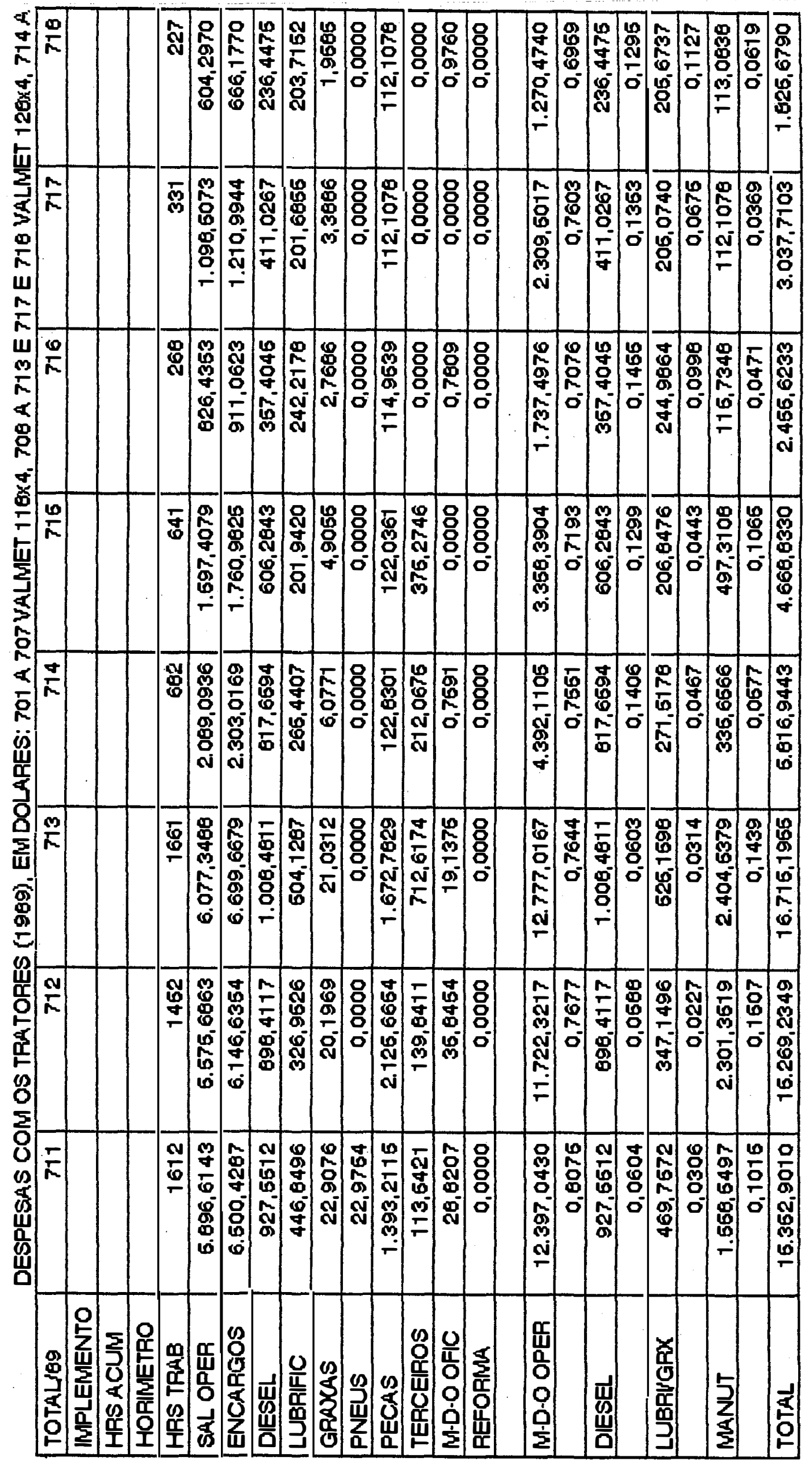




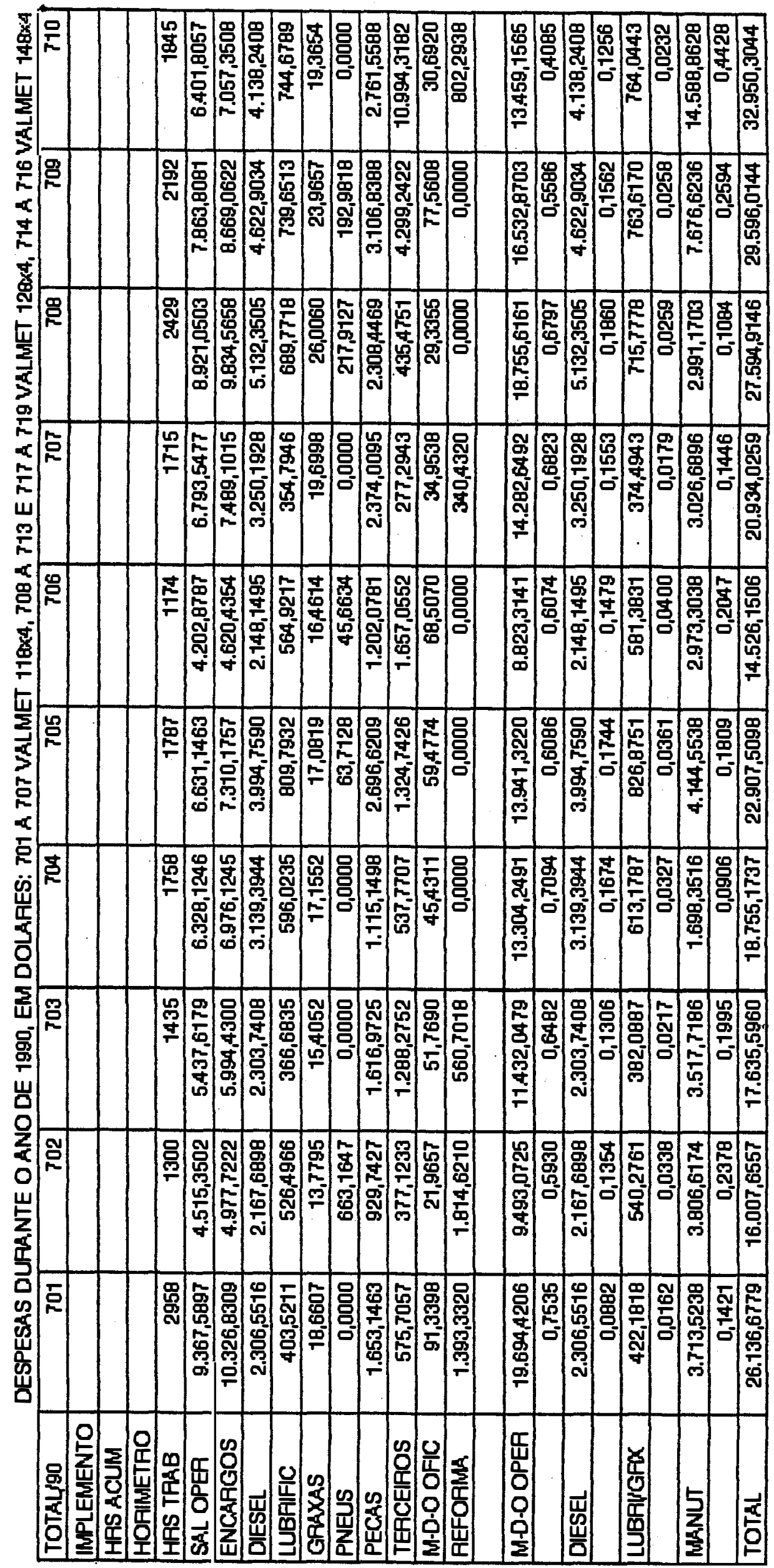




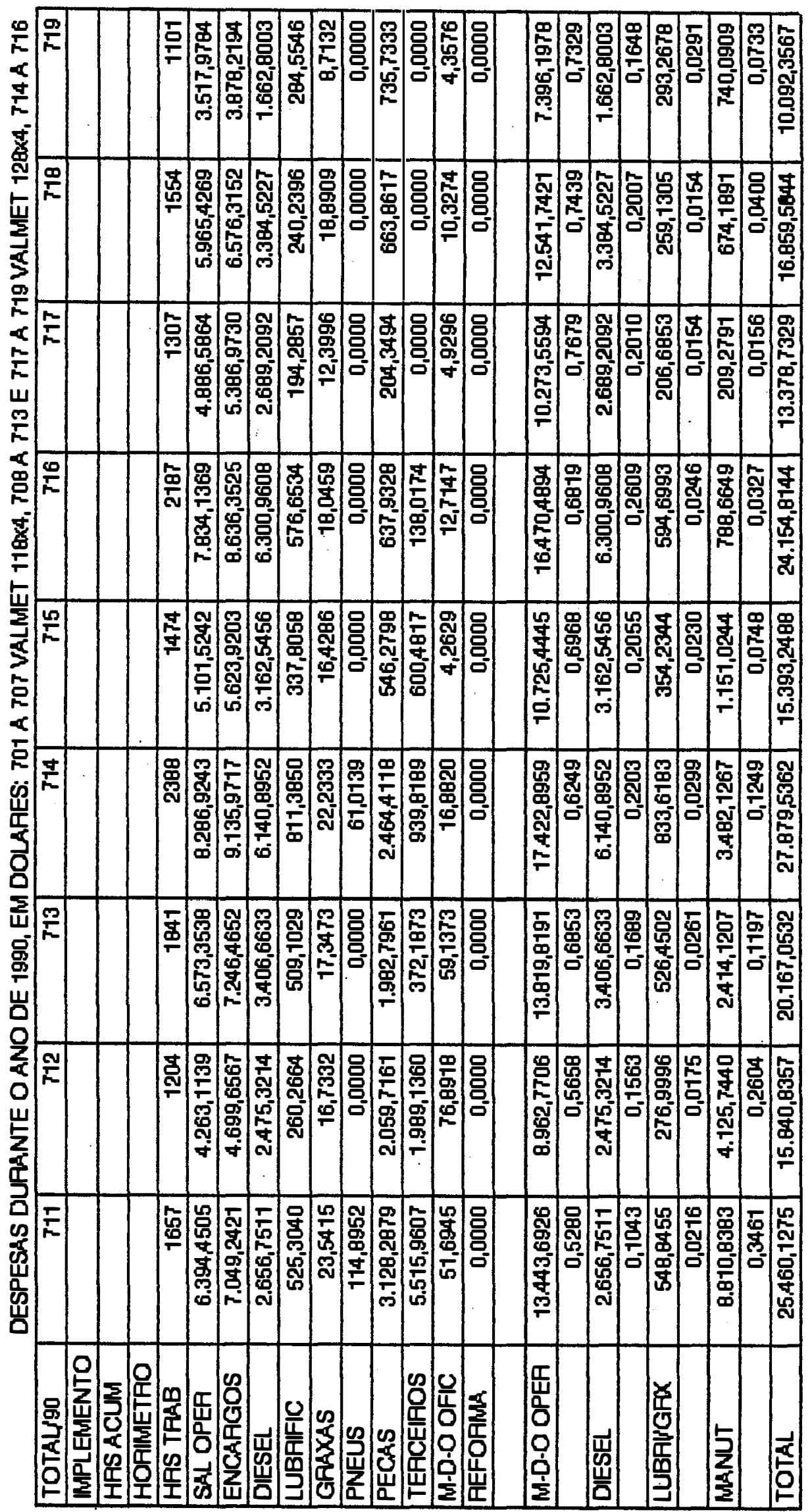




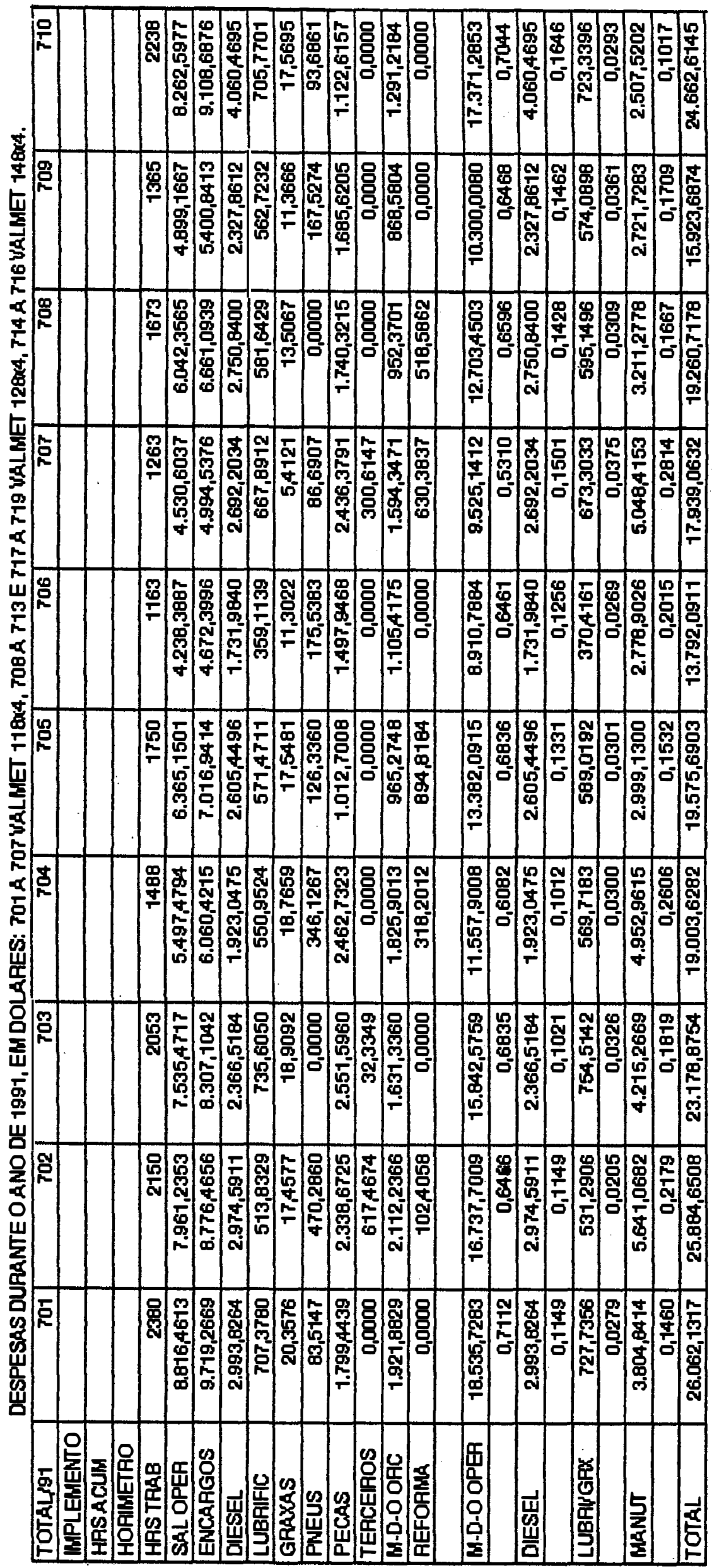




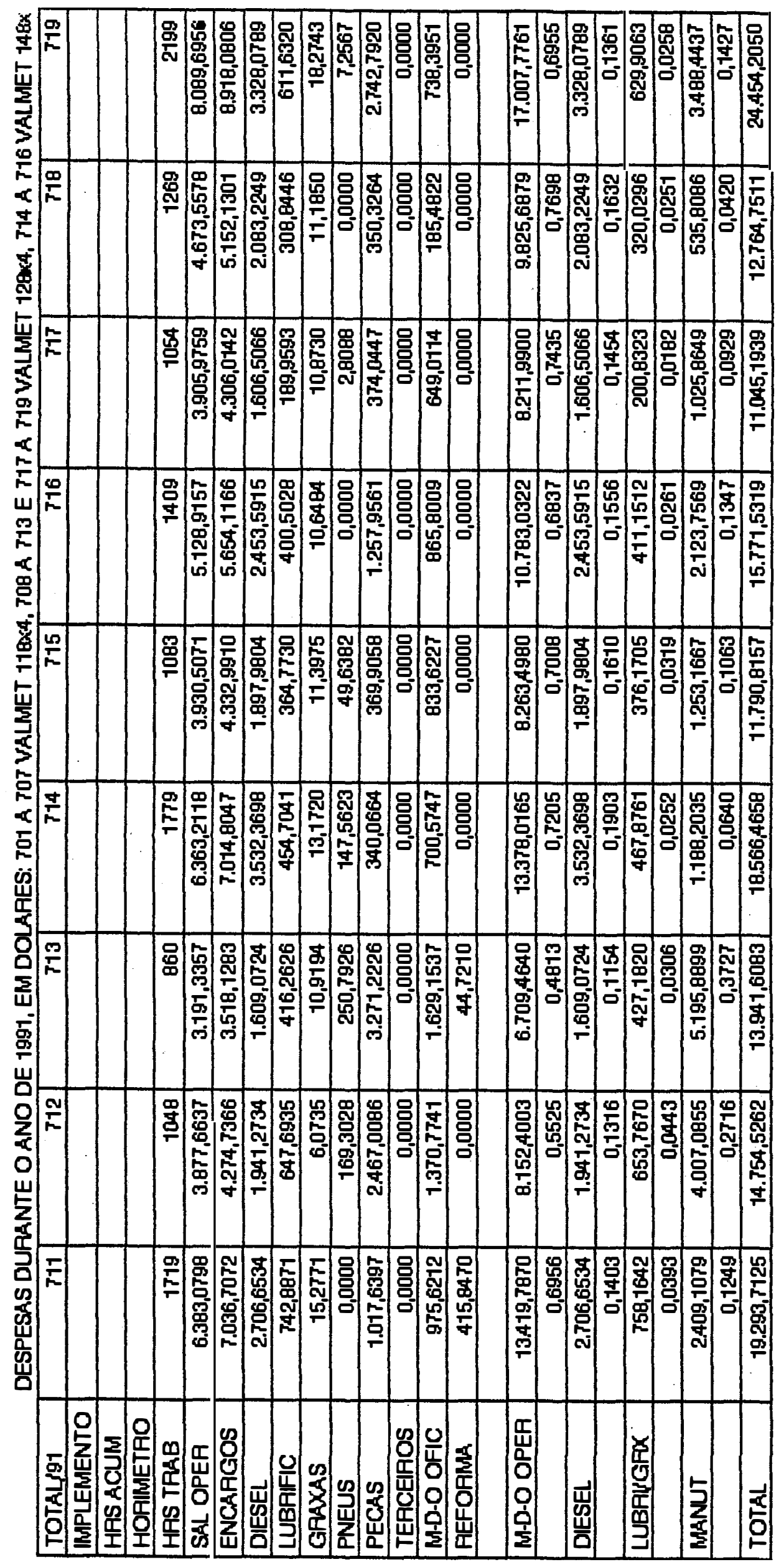




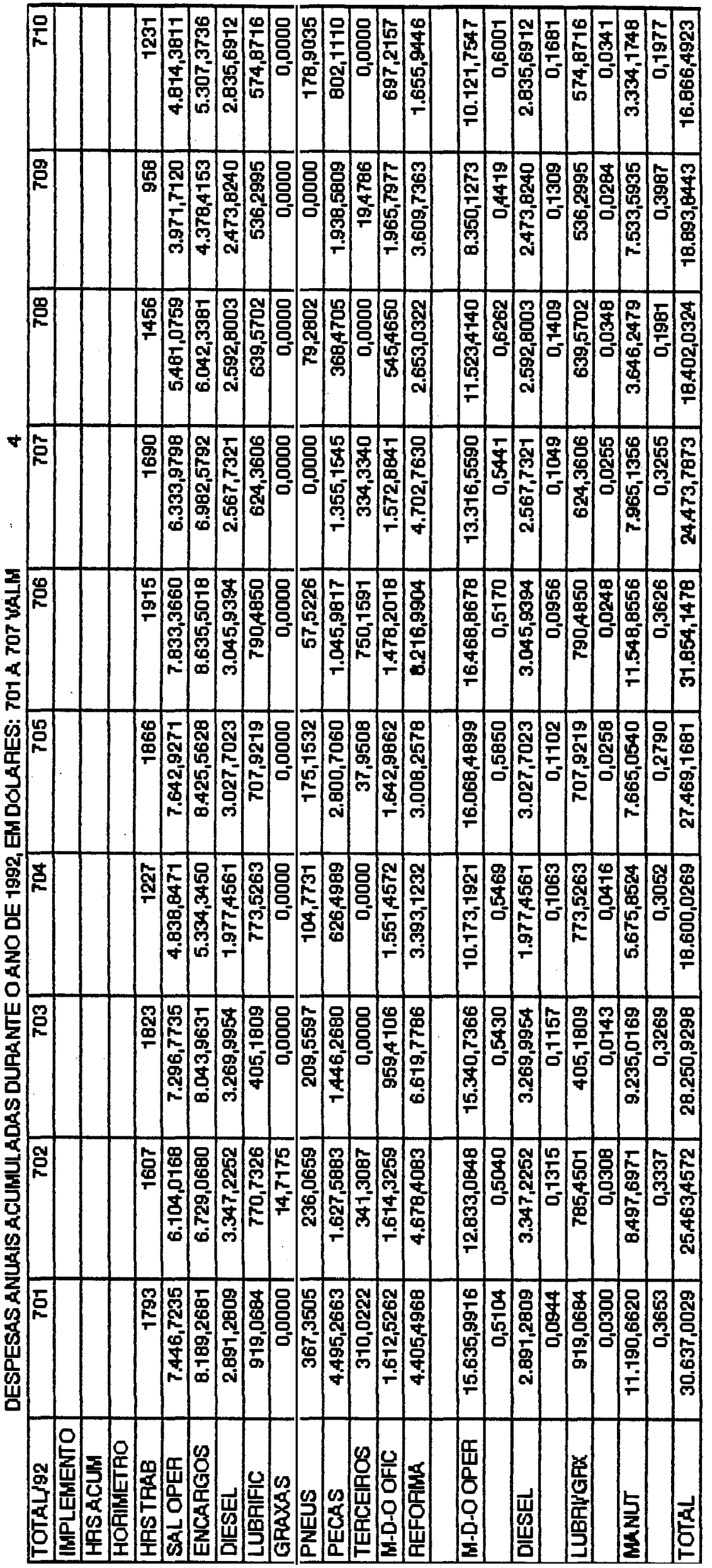




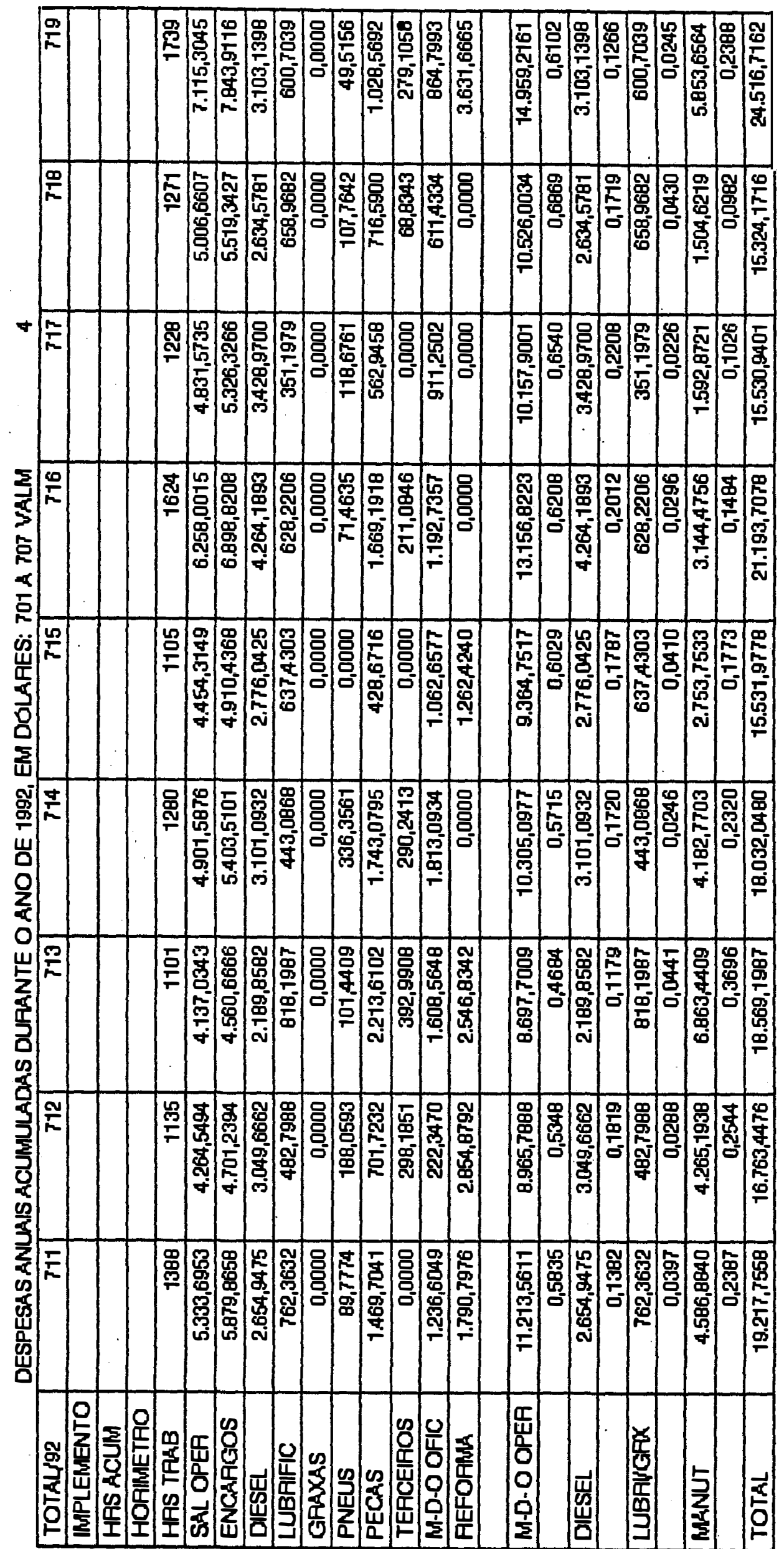




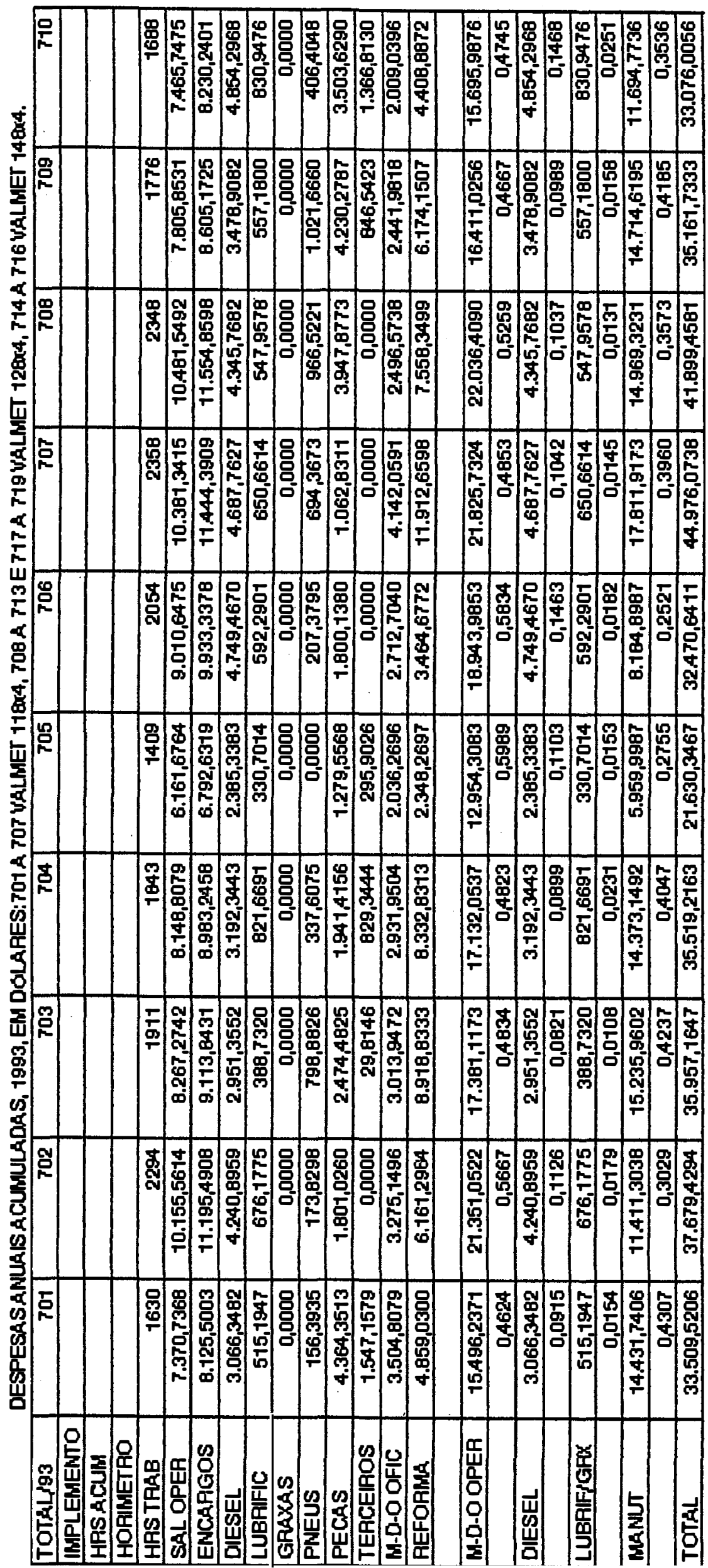




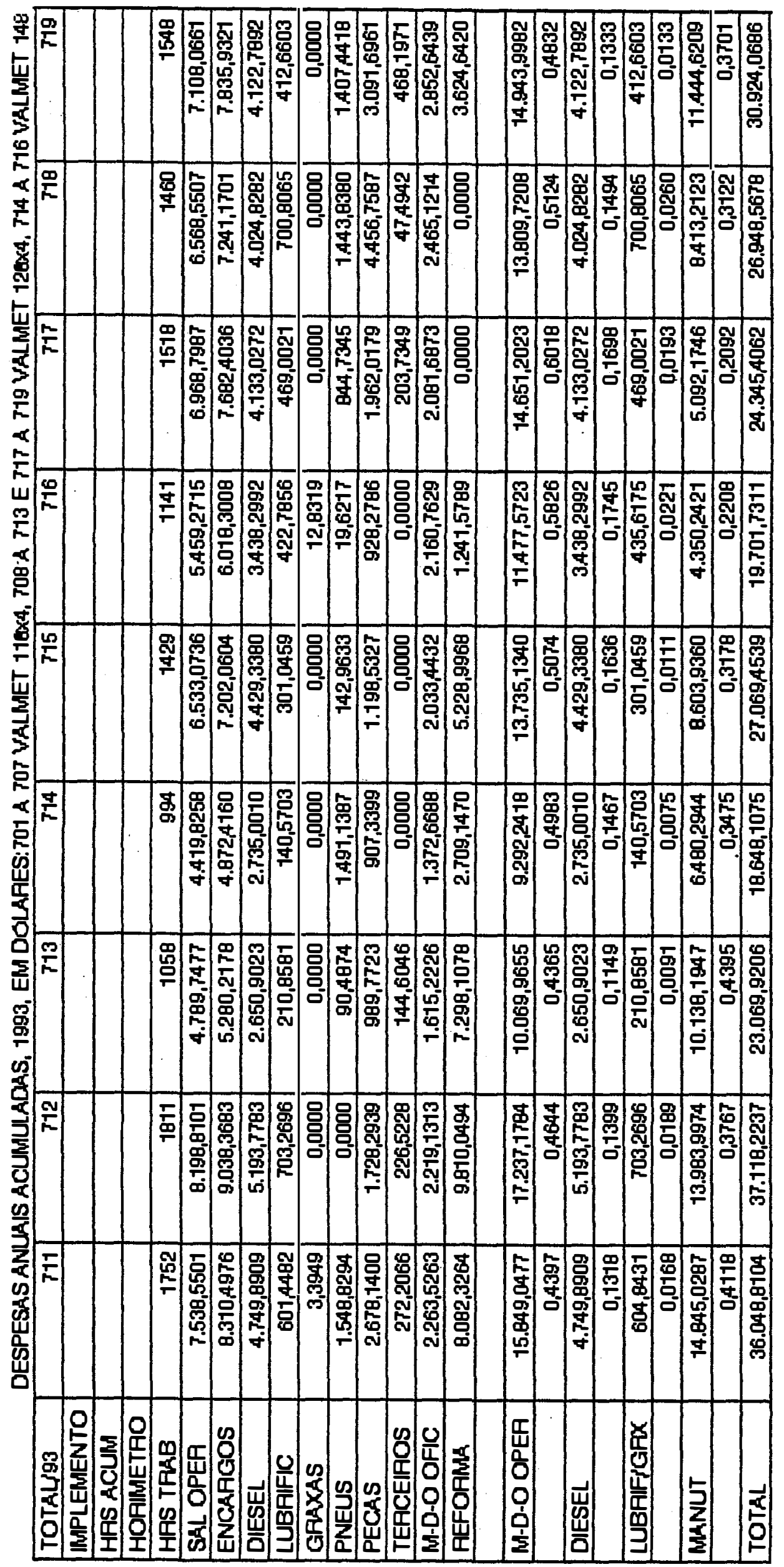




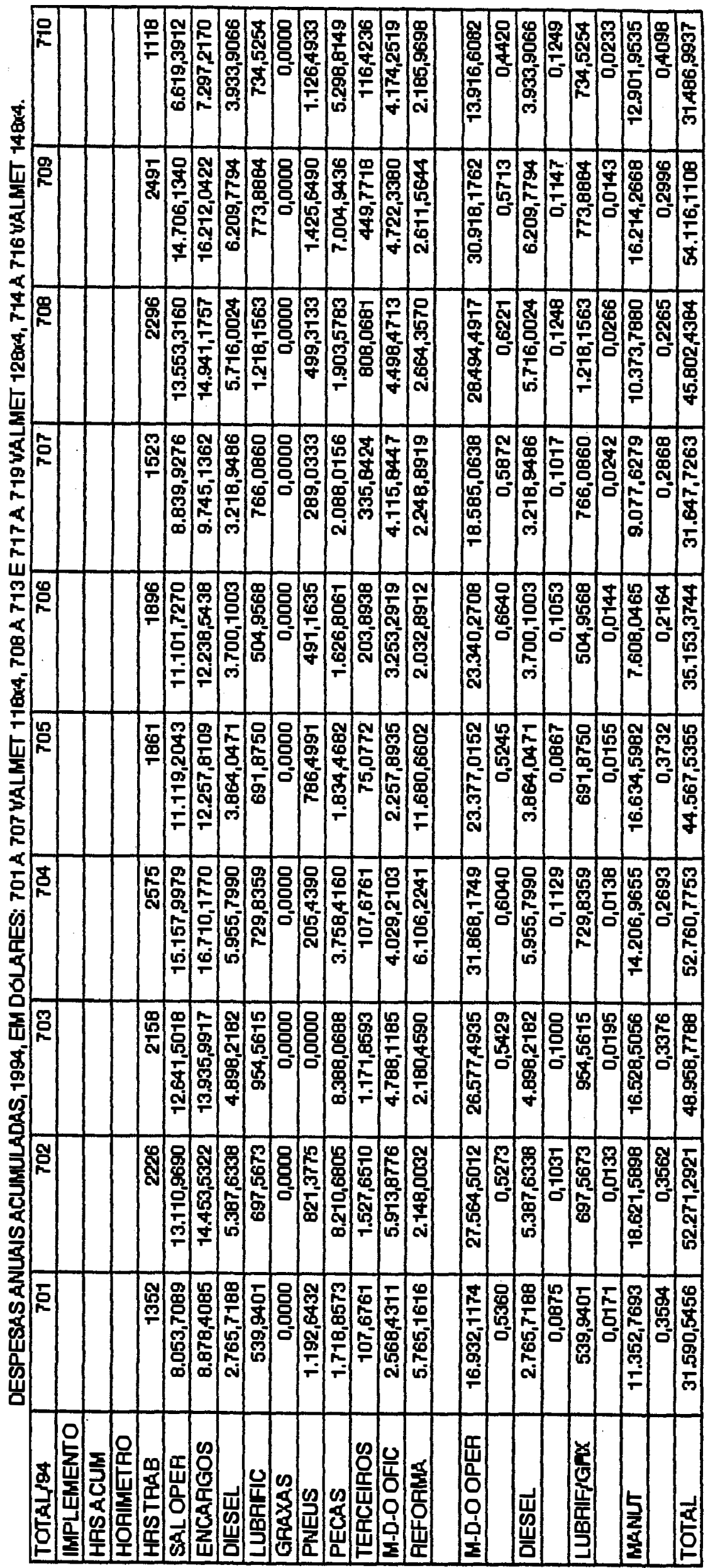




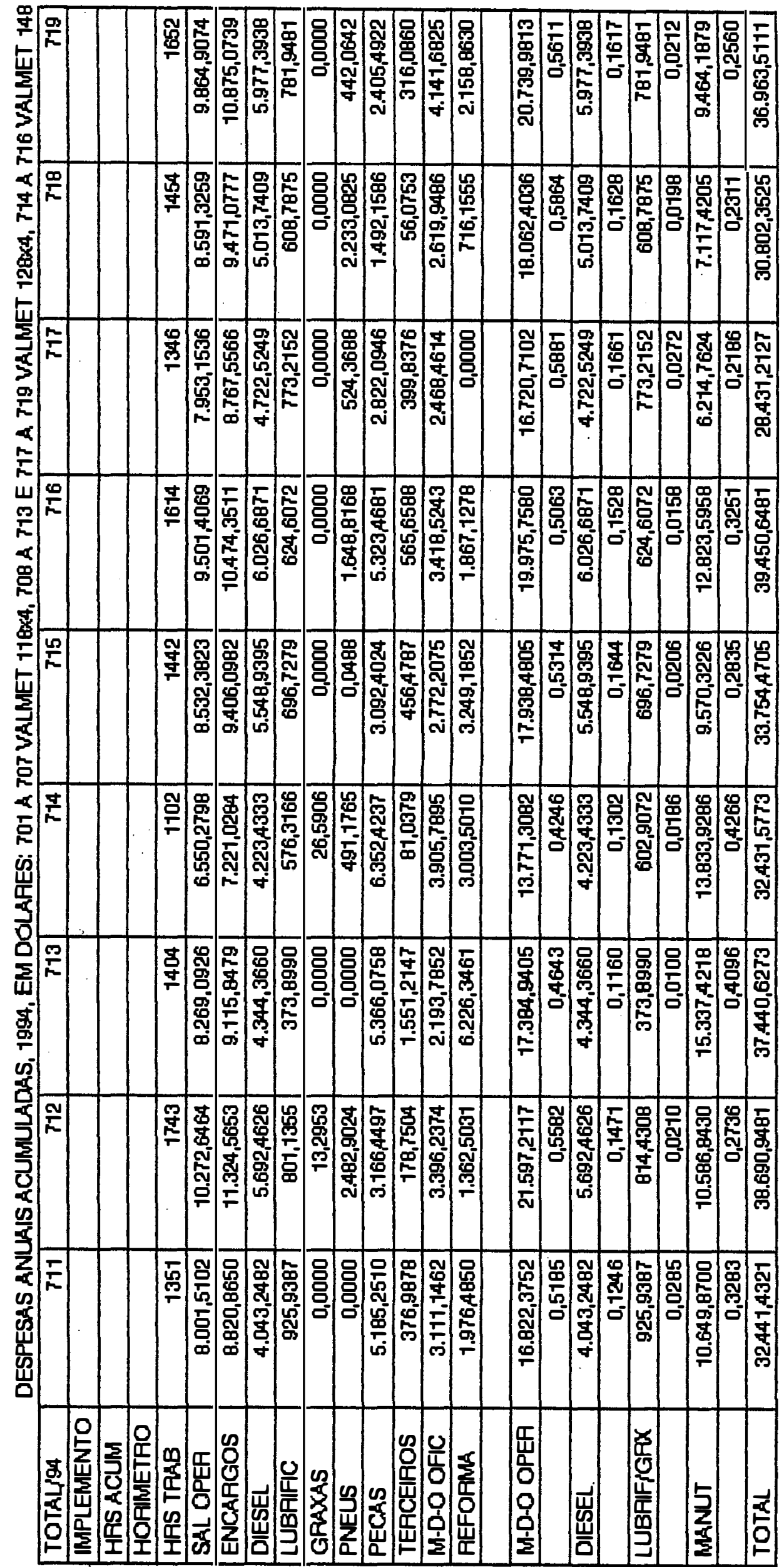


Apêndice 2: resultados das regressões de segundo e terceiros graus e lineares para os dados anuais acumulados observados, processadas pelo programa STATPACK.

Correlação linear dos dados anuais acumulados, sendo a coluna 1 horas de operação e 2 dispendio com R\&M.

$\longrightarrow$ CORREL (R\&M-ACUM. TXT):

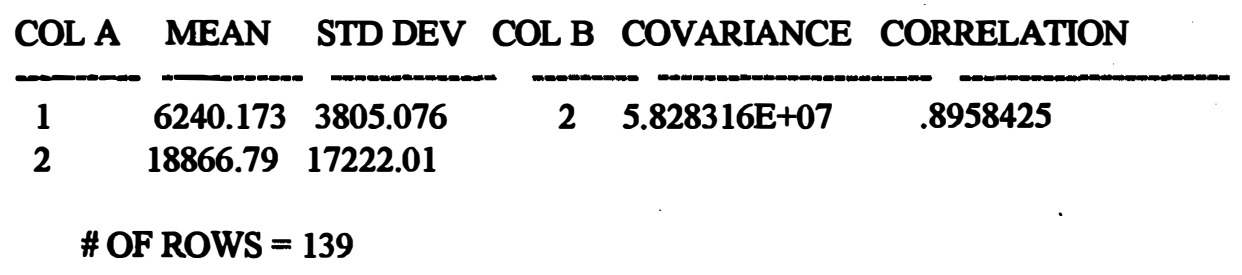

Regressåo polinomial de segundo grau.

$\longrightarrow$ POLYREG (R\&M-ACUM. TXT):

B $0 \quad-412.5352$

B $1 \quad 1.559067$

B 2 1.791357E-04

\begin{tabular}{lcccc} 
& SUM SQ & DEG FR & \multicolumn{1}{c}{ MEAN SQ } \\
\cline { 2 - 3 } & & & \\
DUE TO REGRESSION & $3.386448 \mathrm{E}+10$ & 2 & $1.693224 \mathrm{E}+10$ \\
ABOUT REGRESSION & $7.066014 \mathrm{E}+09$ & 136 & $5.195599 \mathrm{E}+07$ \\
TOTAL & $4.093049 \mathrm{E}+10$ & 138 & $2.965977 \mathrm{E}+08$ \\
R-SQUARED & $\mathbf{8 2 7 3 6 5 5}$ & & \\
F-TEST & 325.8958 & & \\
DURBIN-WATSON & 1.920515 & &
\end{tabular}

Regressão polinomial de terceiro grau.

$\longrightarrow$ POLYREG (R\&M-ACUM.TXT):
B $0 \quad 2399.301$
B $1 \quad-.5806972$
B $2 \quad 5.426491 E-04$
В $3-1.65867 \mathrm{E}-08$

\begin{tabular}{lcccc} 
& SUM SQ & DEG FR & \multicolumn{1}{c}{ MEAN SQ } \\
\cline { 2 - 3 } DUE TO REGRESSION & $3.399928 E+10$ & 3 & $1.13331 \mathrm{E}+10$ \\
ABOUT REGRESSION & $6.931206 \mathrm{E}+09$ & 135 & $5.134227 \mathrm{E}+07$ \\
TOTAL & $4.093049 \mathrm{E}+10$ & 138 & $2.965977 \mathrm{E}+08$ \\
R-SQUARED & .8306591 & & \\
F-TEST & 220.7362 & & \\
DURBIN-WATSON & 1.941876 & &
\end{tabular}


Resultado das regressões lineares:

Linear Exponencial Logaritmica Potencia

$\begin{array}{lcccc}\text { A coef reg } & -6434.858 & 1250.928 & -108242 & 1.665063 \mathrm{E}-02 \\ \text { B coef reg } & 4.054639 & 3.25218 \mathrm{E}-04 & 15009.05 & 1.565315 \\ \text { A std erro } & 1254.665 & .1371374 & 9701.189 & .5552501 \\ \text { B std erro } & .1718329 & 1.878168 \mathrm{E}-05 & 1139.732 & 6.523282 \mathrm{E}-02 \\ \text { std err est } & \mathbf{7 6 8 0 . 8 5 3} & .8395322 & 11482.81 & .6572215 \\ \text { Coef Det } & .8025339 & .6863796 & .5586633 & .8078 \\ \text { Covariance } & 5.870555 \mathrm{E}+07 & 4708.707 & 11039.9 & 1.151367 \\ \text { Corr Coef } & .8958426 & .8284803 & .7474379 & .8987769 \\ \text { Durbn-Watsn } & 1.664933 & .3253004 & .7475998 & 1.74981\end{array}$

Listagens dos pontos calculados para as regressões, sendo a coluna $\mathrm{X}$ os valores totais acumulados de horas anuais de operação e $\mathrm{Y}$ os valores acumulados correspondentes de despesas com reparos e manutenções em US\$ norte-americanos:

$\begin{array}{cccccc}\text { X } & \text { LIN } & \text { EXP } & \text { LOG } & \text { POT } & \text { Y } \\ 227 & -5514.455 & 1346.771 & -26818.71 & 81.16221 & 113.0838 \\ 268 & -5348.215 & 1364.849 & -24326.67 & 105.2511 & 115.7348 \\ 331 & -5092.772 & 1393.102 & -21157.78 & 146.4723 & 112.1078 \\ 641 & -3835.834 & 1540.875 & -11238.13 & 412.1433 & 497.3108 \\ 6882 & -3669.594 & 1561.559 & -10307.58 & 454.1468 & 335.6566 \\ 877 & -2878.939 & 1663.796 & -6533.133 & 673.2131 & 6445.091 \\ 938 & -2631.606 & 1697.133 & -5523.891 & 747.9365 & 2448.939 \\ 948 & -2591.06 & 1702.661 & -5364.711 & 760.4565 & 1028.307 \\ 995 & -2400.492 & 1728.887 & 4638.461 & 820.292 & 454.9926 \\ 1092 & -2007.192 & 1784.296 & -3242.266 & 948.8703 & 282.0974 \\ 1101 & -1970.7 & 1789.526 & -3119.063 & 961.1399 & 740.0909 \\ 1113 & -1922.044 & 1796.523 & -2956.375 & 977.5879 & 313.8483 \\ 1344 & -985.4229 & 1936.687 & -125.8047 & 1313.291 & 2420.639 \\ 1364 & -904.3301 & 1949.325 & 95.90625 & 1344.012 & 4486.515 \\ 1397 & -770.5269 & 1970.358 & 454.711 & 1395.259 & 335.842 \\ 1447 & -567.795 & 2002.66 & 982.5 & 1474.212 & 6867.343 \\ 1449 & -559.6856 & 2003.963 & 1003.227 & 1477.402 & 6277.395 \\ 1638 & 206.6411 & 2131.003 & 2843.375 & 1789.967 & 321.3869 \\ 1690 & 417.4824 & 2167.348 & 3312.445 & 1879.708 & 4098.919 \\ 1781 & 786.4541 & 2232.449 & 4099.617 & 2040.535 & 787.2729 \\ 2106 & 2104.212 & 2481.331 & 6615.36 & 2652.713 & 683.6445 \\ 2115 & 2140.704 & 2488.604 & 6679.375 & 2670.483 & 1648.335 \\ 2219 & 2562.386 & 2574.215 & 7399.836 & 2878.871 & 2669.733 \\ 2267 & 2757.009 & 2614.714 & 7721.039 & 2976.939 & 14096.05 \\ 2277 & 2797.555 & 2623.232 & 7787.094 & 2997.519 & 2544.861 \\ 2409 & 3332.768 & 2738.296 & 8632.906 & 3273.947 & 1292.884 \\ 2455 & 3519.281 & 2779.569 & 8916.805 & 3372.326 & 904.3998 \\ 2561 & 3949.072 & 2877.06 & 9551.25 & 3603.016 & 5853.891 \\ 2563 & 3957.182 & 2878.932 & 9562.969 & 3607.42 & 3941.553 \\ 2680 & 4431.574 & 2990.588 & 10232.95 & 3868.5 & 17242.7 \\ 2692 & 4480.231 & 3002.282 & 10300 & 3895.646 & 1347.252\end{array}$




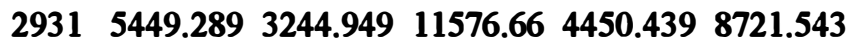
$\begin{array}{lllllll}2935 & 5465.508 & 3249.173 & 11597.13 & 4459.957 & 1841.987\end{array}$ $\begin{array}{llllllll}3030 & 5850.698 & 3351.126 & 12075.24 & 4687.971 & 11886.38\end{array}$ $\begin{array}{llllllll}3050 & 5931.791 & 3372.994 & 12173.99 & 4736.508 & 1323.082\end{array}$ $\begin{array}{lllllll}3070 & 6012.884 & 3395.005 & 12272.08 & 4785.212 & 3817.783\end{array}$ $\begin{array}{lllllll}3084 & 6069.649 & 3410.497 & 12340.37 & 4819.414 & 7317.154\end{array}$ $\begin{array}{lllllll}3198 & 6531.878 & 3539.314 & 12885.18 & 5101.176 & 2901.502\end{array}$ $\begin{array}{lllllll}3300 & 6945.451 & 3658.69 & 13356.41 & 5358.138 & 4228.535\end{array}$ $\begin{array}{lllllll}3384 & 7286.04 & 3760.017 & 13733.68 & 5573.163 & 15297.49\end{array}$

$\begin{array}{lllllll}3678 & 8478.104 & 4137.276 & 14984.09 & 6349.458 & 12886.73\end{array}$ $\begin{array}{lllllll}3729 & 8684.891 & 4206.469 & 15190.78 & 6487.815 & 4846.213\end{array}$ $\begin{array}{lllllll}3735 & 8709.219 & 4214.685 & 15214.91 & 6504.167 & 10151.71\end{array}$ $\begin{array}{llllllll}3831 & 9098.464 & 4348.348 & 15595.81 & 6767.741 & 4228.283\end{array}$ $\begin{array}{lllllll}3864 & 9232.268 & 4395.267 & 15724.56 & 6859.224 & 3028.157\end{array}$ $\begin{array}{lllllll}3865 & 9236.322 & 4396.697 & 15728.41 & 6861.982 & 2956.619\end{array}$ $\begin{array}{lllllll}3920 & 9459.327 & 4476.048 & 15940.5 & 7015.458 & 2940.124\end{array}$ $\begin{array}{lllllll}4025 & 9885.064 & 4631.535 & 16337.25 & 7311.825 & 23497.17\end{array}$ $\begin{array}{lllllll}4070 & 10067.52 & 4699.815 & 16504.13 & 7440.182 & 3697.422\end{array}$ $\begin{array}{lllllll}4082 & 10116.18 & 4718.192 & 16548.3 & 7474.541 & 20852.43\end{array}$ $\begin{array}{lllllll}4269 & 10874.4 & 5014.037 & 17220.59 & 8017.427 & 13327.39\end{array}$ $\begin{array}{lllllll}4303 & 11012.25 & 5069.787 & 17339.66 & 8117.61 & 5655.256\end{array}$ $\begin{array}{lllllll}4321 & 11085.24 & 5099.553 & 17402.32 & 8170.833 & 2827.703\end{array}$ $\begin{array}{lllllll}4461 & 11652.89 & 5337.105 & 17880.89 & 8588.982 & 3558.312\end{array}$ $\begin{array}{llllll}4649 & 12415.16 & 5673.603 & 18500.46 & 9162.295 & 10635.35\end{array}$ $\begin{array}{lllllll}4849 & 13226.09 & 6054.901 & 19132.64 & 9786.741 & 5005.987\end{array}$ $\begin{array}{lllllll}4933 & 13566.68 & 6222.591 & 19390.41 & 10053.41 & 8971.957\end{array}$ $\begin{array}{lllllll}5039 & 13996.47 & 6440.843 & 19709.52 & 10393.61 & 10082.19\end{array}$ $\begin{array}{lllllll}5050 & 14041.07 & 6463.927 & 19742.25 & 10429.16 & 14800.24\end{array}$ $\begin{array}{lllllll}5132 & 14373.55 & 6638.623 & 19983.99 & 10695.43 & 24437.18\end{array}$ $\begin{array}{lllllll}5333 & 15188.53 & 7087.081 & 20560.63 & 11358.35 & 4417.474\end{array}$ $\begin{array}{lllllll}5438 & 15614.27 & 7333.269 & 20853.27 & 11710.37 & 8032.299\end{array}$ $\begin{array}{lllllll}5443 & 15634.54 & 7345.203 & 20867.05 & 11727.23 & 16300.69\end{array}$ $\begin{array}{lllllll}5450 & 15662.92 & 7361.944 & 20886.34 & 11750.85 & 13178.4\end{array}$ $\begin{array}{llllllll}5488 & 15817 & 7453.489 & 20990.63 & 11879.34 & 6172.633\end{array}$ $\begin{array}{lllllll}5488 & 15817 & 7453.489 & 20990.63 & 11879.34 & 13039.12\end{array}$ $\begin{array}{lllllll}5523 & 15958.91 & 7538.814 & 21086.05 & 11998.15 & 27475.6\end{array}$ $\begin{array}{lllllll}5732 & 16806.33 & 8069.048 & 21643.54 & 12716.42 & 14259.19\end{array}$ $\begin{array}{llllllll}5781 & 17005.01 & 8198.663 & 21771.29 & 12886.97 & 11240.92\end{array}$ $\begin{array}{llllll}5783 & 17013.12 & 8203.998 & 21776.49 & 12893.96 & 25195.52\end{array}$ $\begin{array}{lllllll}5911 & 17532.11 & 8552.721 & 22105.08 & 13343.49 & 6111.543\end{array}$ $\begin{array}{lllllll}5981 & 17815.94 & 8749.66 & 22281.78 & 13591.66 & 12979.04\end{array}$ $\begin{array}{llllll}6129 & 18416.02 & 9181.101 & 22648.66 & 14121.77 & 9188.757\end{array}$ $\begin{array}{llllll}6350 & 19312.1 & 9865.266 & 23180.33 & 14926.92 & 18606.86\end{array}$ $\begin{array}{lllllll}6436 & 19660.8 & 10145.08 & 23382.24 & 15244.59 & 14779.9\end{array}$ $\begin{array}{lllllll}6567 & 20191.96 & 10586.64 & 23684.66 & 15733.06 & 27954.9\end{array}$ $\begin{array}{lllllll}6587 & 20273.05 & 10655.72 & 23730.3 & 15808.14 & 21526.81\end{array}$ $\begin{array}{llllll}6606 & 20350.09 & 10721.77 & 23773.53 & 15879.56 & 19079.6\end{array}$ $\begin{array}{lllllll}6629 & 20443.34 & 10802.27 & 23825.69 & 15966.19 & 10522.87\end{array}$ $\begin{array}{llllllll}6653 & 20540.65 & 10886.91 & 23879.94 & 16056.77 & 11234.94\end{array}$ $\begin{array}{llllllll}6713 & 20783.93 & 11101.43 & 24014.69 & 16284.02 & 18226.81\end{array}$ $\begin{array}{lllllll}6771 & 21019.1 & 11312.82 & 24143.81 & 16504.79 & 11307.43\end{array}$ $\begin{array}{lllllll}6784 & 21071.81 & 11360.76 & 24172.6 & 16554.4 & 14246.76\end{array}$ $\begin{array}{lllllll}7040 & 22109.8 & 12347.09 & 24728.55 & 17542.63 & 24565.95\end{array}$ $\begin{array}{lllllll}71 & 22417.95 & 12656.08 & 24889.72 & 17839.97 & 17244.24\end{array}$ 
$\begin{array}{lllllll}7123 & 22446.34 & 12684.92 & 24904.47 & 17867.45 & 15669.05\end{array}$

$\begin{array}{llllllll}7174 & 22653.12 & 12897.07 & 25011.53 & 18068.07 & 23829.51\end{array}$

$\begin{array}{lllllll}7207 & 22786.93 & 13036.22 & 25080.42 & 18198.35 & 15448.23\end{array}$

$\begin{array}{lllllll}7235 & 22900.46 & 13155.48 & 25138.63 & 18309.16 & 18358.34\end{array}$

$\begin{array}{lllllll}7271 & 23046.42 & 13310.41 & 25213.13 & 18451.98 & 30148.48\end{array}$

$\begin{array}{lllllll}7761 & 25033.2 & 15609.86 & 26191.97 & 20435.16 & 29983.11\end{array}$

$\begin{array}{llllllll}7762 & 25037.25 & 15614.94 & 26193.91 & 20439.29 & 7408.644\end{array}$

$\begin{array}{lllllll}7872 & 25483.26 & 16183.66 & 26405.13 & 20894.48 & 18170.87\end{array}$

$\begin{array}{lllllll}8018 & 26075.24 & 16970.63 & 26680.94 & 21504.25 & 13956.66\end{array}$

$\begin{array}{lllllll}8186 & 26756.42 & 17923.64 & 26992.17 & 22213.72 & 17779.03\end{array}$

$\begin{array}{llllll}8225 & 26914.55 & 18152.42 & 27063.52 & 22379.62 & 29502.98\end{array}$

$\begin{array}{llllll}8239 & 26971.31 & 18235.26 & 27089.03 & 22439.26 & 30991\end{array}$

$\begin{array}{llllll}8243 & 26987.53 & 18259 & 27096.31 & 22456.32 & 23346.47\end{array}$

$\begin{array}{lllllll}8403 & 27636.27 & 19234.26 & 27384.88 & 23142.37 & 26191.95\end{array}$

$\begin{array}{llllll}8498 & 28021.46 & 19837.78 & 27553.6 & 23553.21 & 35824.33\end{array}$

$\begin{array}{lllllll}8500 & 28029.57 & 19850.69 & 27557.14 & 23561.9 & 24247.93\end{array}$

$\begin{array}{lllllll}8521 & 28114.72 & 19986.73 & 27594.16 & 23653.06 & 30628.45\end{array}$

$\begin{array}{lllllll}8595 & 28414.76 & 20473.57 & 27723.94 & 23975.36 & 20035.11\end{array}$

$\begin{array}{llllllll}8620 & 28516.13 & 20640.71 & 27767.53 & 24084.62 & 32170.17\end{array}$

$\begin{array}{lllllll}8927 & 29760.91 & 22807.91 & 28292.78 & 25440.75 & 31228.23\end{array}$

$\begin{array}{llllllll}8930 & 29773.07 & 22830.17 & 28297.83 & 25454.14 & 28309.07\end{array}$

$\begin{array}{lllllll}8976 & 29959.58 & 23174.27 & 28374.94 & 25659.67 & 21490.26\end{array}$

$\begin{array}{lllllll}8992 & 30024.46 & 23295.18 & 28401.67 & 25731.31 & 33317.29\end{array}$

$\begin{array}{lllllll}9420 & 31759.84 & 26774.22 & 29099.58 & 27674.06 & 28370.8\end{array}$

$\begin{array}{llllll}9435 & 31820.66 & 26905.16 & 29123.47 & 27743.11 & 10619.92\end{array}$

$\begin{array}{llllll}10052 & 34322.38 & 32883.71 & 30074.22 & 30634.96 & 25444.08\end{array}$

$\begin{array}{lllllll}10107 & 34545.38 & 33477.19 & 30156.13 & 30897.76 & 32745.63\end{array}$

$1033435465.7836042 .1430489 .4931990 .86 \quad 43646.49$

$\begin{array}{lllllll}10341 & 35494.17 & 36124.28 & 30499.66 & 32024.8 & 50197.48\end{array}$

$\begin{array}{lllllll}10347 & 35518.49 & 36194.85 & 30508.36 & 32053.9 & 34880.14\end{array}$

$\begin{array}{llllll}10443 & 35907.74 & 37342.71 & 30646.97 & 32520.62 & 41405.18\end{array}$

$\begin{array}{llllll}10575 & 36442.95 & 38980.69 & 30835.5 & 33166.36 & 38813.35\end{array}$

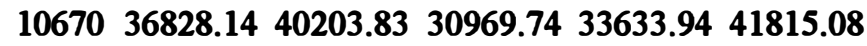

$\begin{array}{llllll}10680 & 36868.69 & 40334.8 & 30983.78 & 33683.29 & 45012.07\end{array}$

$\begin{array}{llllll}10752 & 37160.62 & 41290.41 & 31084.63 & 34039.36 & 36204.88\end{array}$

$\begin{array}{llllll}10761 & 37197.11 & 41411.44 & 31097.19 & 34084.03 & 44003.87\end{array}$

$\begin{array}{llllll}10891 & 37724.21 & 43199.78 & 31277.42 & 34730.74 & 14266.17\end{array}$

$\begin{array}{llllll}11213 & 39029.81 & 47969.03 & 31714.75 & 36351.49 & 39561.46\end{array}$

$\begin{array}{llllll}11461 & 40035.36 & 51998.23 & 32043.1 & 37617.83 & 31404.08\end{array}$

$\begin{array}{llllll}11698 & 40996.31 & 56164.58 & 32350.3 & 38842.54 & 45530.01\end{array}$

$\begin{array}{lllll}11798 & 41401.7758021 .17 & 32478.05 & 39363.54 & 57914.02\end{array}$

$\begin{array}{llllll}12284 & 43372.33 & 67956.25 & 33083.92 & 41931.13 & 53081.49\end{array}$

$\begin{array}{lllllll}12354 & 43656.15 & 69521.02 & 33169.2 & 42305.71 & 56641.15\end{array}$

$\begin{array}{llllll}12401 & 43846.72 & 70591.85 & 33226.2 & 42557.92 & 44156.93\end{array}$

$\begin{array}{lllllll}12471 & 44130.55 & 72217.31 & 33310.69 & 42934.58 & 46421.4\end{array}$

$\begin{array}{llllll}12843 & 45638.87 & 81504.73 & 33751.85 & 44956.13 & 53993.2\end{array}$

$\begin{array}{llllll}12916 & 45934.86 & 83462.87 & 33836.92 & 45356.71 & 64404.45\end{array}$

$\begin{array}{lllllll}13239 & 47244.51 & 92707.3 & 34207.66 & 47144.8 & 29235.49\end{array}$

$\begin{array}{llllll}13243 & 47260.73 & 92828 & 34212.19 & 47167.05 & 52419.15\end{array}$

$\begin{array}{lllllll}13322 & 47581.04 & 95243.83 & 34301.44 & 47608.17 & 48038.68\end{array}$

$1419551120.74 \quad 126514.4 \quad 35254.1152581 .2465345 .97$

$\begin{array}{lllllll}14512 & 52406.07 & 140253.3 & 35585.61 & 54430.96 & 73169.65\end{array}$

$\begin{array}{lllllll}14627 & 52872.35 & 145598 & 35704.08 & 55107.61 & 62778.52\end{array}$

$\begin{array}{llllll}15535 & 56553.96 & 195614.9 & 36608.03 & 60555.61 & 39609.28\end{array}$ 
Apêndice 03: dados para o processamento no S.A.S. e o respectivo resultado final do processamento, tendo na coluna $\mathrm{X}$ os valores totais acumulados de horas anuais de operação e na coluna $\mathrm{Y}$ os valores acumulados com despesas anuais de reparos e manutenções em US\$ norte-americanos.

Utilizou-se o procedimento NLIN e como modelo matemático a equação $\mathbf{Y}=\mathbf{a} * \mathbf{X}^{\mathbf{b}}+\mathbf{C}$.

$\begin{array}{cc}\mathbf{X} & \mathbf{Y} \\ 227 & 113.0838 \\ 268 & 115.7348 \\ 331 & 112.1078 \\ 641 & 497.3108 \\ 682 & 335.6566 \\ 877 & 6445.0907 \\ 938 & 2448.9386 \\ 948 & 1028.3072 \\ 995 & 454.9926 \\ 1092 & 282.0974 \\ 1101 & 740.0909 \\ 1113 & 313.8483 \\ 1344 & 2420.6384 \\ 1364 & 4486.5152 \\ 1397 & 335.8420 \\ 1447 & 6867.3429 \\ 1449 & 6277.3946 \\ 1638 & 321.3869 \\ 1690 & 4098.9190 \\ 1781 & 787.2729 \\ 2106 & 683.6445 \\ 2115 & 1648.3352 \\ 2219 & 2669.7328 \\ 2267 & 14096.0490 \\ 2277 & 2544.8612 \\ 2409 & 1292.8843 \\ 2455 & 904.3997 \\ 2561 & 5853.8913 \\ 2563 & 3941.5525 \\ 2680 & 17242.6950 \\ 2692 & 1347.2518 \\ 2931 & 8721.5425 \\ 2935 & 1841.9864 \\ 3030 & 11886.3780 \\ 3050 & 1323.0815 \\ 3070 & 3817.7833 \\ 3084 & 7317.1534 \\ 3198 & 2901.5019\end{array}$




\begin{tabular}{|c|c|}
\hline 3300 & 4228.5346 \\
\hline 3384 & 15297.4940 \\
\hline 3678 & 12886.7300 \\
\hline 3729 & 4846.2131 \\
\hline 3735 & 10151.7080 \\
\hline 3831 & 4228.2825 \\
\hline 3864 & 3028.1566 \\
\hline 3865 & 2956.6185 \\
\hline 3920 & 2940.1239 \\
\hline 4025 & 23497.1690 \\
\hline 4070 & 3697.4222 \\
\hline 4082 & 20852.4300 \\
\hline 4269 & 13327.3910 \\
\hline 4303 & 5655.2552 \\
\hline 4321 & 2827.7034 \\
\hline 4461 & 3558.3120 \\
\hline 4649 & 10635.3460 \\
\hline 4849 & 5005.9868 \\
\hline 4933 & 8971.9571 \\
\hline 5039 & 10082.1910 \\
\hline 5050 & 14800.2430 \\
\hline 5132 & 24437.1840 \\
\hline 5333 & 4417.4739 \\
\hline 5438 & 8032.2985 \\
\hline 5443 & 16300.6940 \\
\hline 5450 & 13178.3970 \\
\hline 5488 & 6172.6322 \\
\hline 5488 & 13039.1200 \\
\hline 5523 & 27475.5930 \\
\hline 5732 & 14259.1910 \\
\hline 5781 & 11240.9160 \\
\hline 5783 & 25195.5200 \\
\hline 5911 & 6111.5429 \\
\hline 5981 & 12979.0420 \\
\hline 6129 & 9188.7571 \\
\hline 6350 & 18606.8600 \\
\hline 6436 & 14779.8990 \\
\hline 6567 & 27954.9020 \\
\hline 6587 & 21526.8120 \\
\hline 6606 & 19079.5960 \\
\hline 6629 & 10522.8740 \\
\hline 6653 & 11234.9350 \\
\hline 6713 & 18226.8120 \\
\hline 6771 & 11307.4320 \\
\hline 6784 & 14246.7582 \\
\hline 7040 & 24565.9530 \\
\hline 7116 & 17244.2360 \\
\hline 7123 & 15669.0520 \\
\hline 7174 & 23829.5136 \\
\hline 7207 & 15448.2270 \\
\hline 7235 & 18358.3365 \\
\hline 7271 & 30148.4810 \\
\hline 7761 & 29983.1130 \\
\hline 7762 & 7408.6442 \\
\hline
\end{tabular}




\begin{tabular}{|r|r|}
\hline 7872 & 18170.8730 \\
8018 & 13956.6630 \\
8186 & 17779.0290 \\
8225 & 29502.9806 \\
8239 & 30990.9999 \\
8243 & 23346.4698 \\
8403 & 26191.9480 \\
8498 & 35824.3330 \\
8500 & 24247.9280 \\
8521 & 30628.4520 \\
8595 & 20035.1110 \\
8620 & 32170.1680 \\
8927 & 31228.2330 \\
8930 & 28309.0680 \\
8976 & 21490.2570 \\
8992 & 33317.2880 \\
9420 & 28370.7940 \\
9435 & 10619.9220 \\
10052 & 25444.0830 \\
10107 & 32745.6250 \\
10334 & 43646.4898 \\
10341 & 50197.4820 \\
10347 & 34880.1400 \\
10443 & 41405.1850 \\
10575 & 38813.3510 \\
10670 & 41815.0760 \\
10680 & 45012.0620 \\
10752 & 36204.8760 \\
10761 & 44003.8650 \\
10891 & 14266.1700 \\
11213 & 39561.4560 \\
11461 & 31404.0820 \\
11698 & 45530.0100 \\
11798 & 57914.0155 \\
12284 & .53081 .4929 \\
12354 & 56641.1450 \\
12401 & 44156.9290 \\
12471 & 46421.3975 \\
12843 & 53993.1970 \\
12916 & 64404.4475 \\
13239 & 29235.4930 \\
13243 & 52419.1428 \\
13322 & 48038.6802 \\
14195 & 65345.9663 \\
14512 & 73169.6506 \\
14627 & 62778.5188 \\
15535 & 39609.2810 \\
\hline & \\
\hline
\end{tabular}


Resultado do processamento no módulo NLIN do S.A.S.

NOTE: Convergence criterion met.

$\begin{array}{lrrr}\text { Non-Linear Least Squares Summary Statistics } & \text { Dependent Variable Y } \\ \text { Source } & \text { DF } & \text { Sum of Squares } & \text { Mean Square } \\ \text { Regression } & 2 & 83371876459 & 41685938229 \\ \text { Residual } & 137 & 7036437756 & 51360860 \\ \text { Uncorrected Total } & 139 & 90408314214 & \\ \text { (Corrected Total) } & 138 & 40930486329 & \\ \text { NOTE: The Jacobian is singular. }\end{array}$

\begin{tabular}{rrrrr} 
Parameter Estimate & $\begin{array}{c}\text { Asymptotic } \\
\text { Std. Error }\end{array}$ & & \multicolumn{2}{c}{$\begin{array}{c}\text { Asymptotic 95 \% } \\
\text { Confidence Interval } \\
\text { Lower }\end{array}$} \\
& & & Upper
\end{tabular}

Asymptotic Correlation Matrix

\begin{tabular}{cccc} 
Corr & A & B & C \\
\hline A & $\cdot$ & $\dot{1}$ & 0.9994781792 \\
B & $\cdot$ & 0.9994781792 & 1
\end{tabular}


Apêndice 4: nas páginas seguintes são apresentados os catálogos promocionais dos tratores utilizados neste estudo, onde são apresentadas suas principais características técnicas.

- página 87, VALMET 118x4.

- página 88, VALMET 128x4.

- página 89, VALMET 148x4. 


\section{TRATOR VALMET 118-4}

\begin{tabular}{|c|c|}
\hline moton & . \\
\hline Motor. & MWM D2296TN \\
\hline Tpo & Dlesel injoça direta \\
\hline 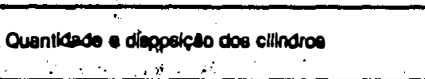 & $\begin{array}{l}6 \text { cillindros verilcals } \\
\text { em yinha, camlsas } \\
\text { omididers removinots. }\end{array}$ \\
\hline 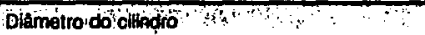 & $102 \mathrm{~mm}$ \\
\hline Curso dos Ambolices & $120 \mathrm{~mm}$ \\
\hline CAlindrada total & $5883 \mathrm{~cm}^{3}$ \\
\hline Relagalo do compressalo & 16,6:1 \\
\hline Poléncla bruta na molor a 2300 .rpm & $88 \mathrm{~kW}(118 \mathrm{cy})$ \\
\hline 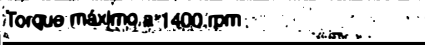 & $402 \mathrm{Nm}(41,0 \mathrm{mmin})$ \\
\hline A PNEUS DISPON & \\
\hline olmentros $\& \&$, & $149113-28,91 \cdots$ \\
\hline 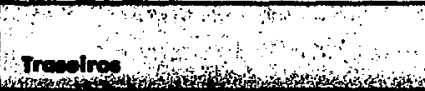 & $\begin{array}{l}10.4 / 1534 \mathrm{Ai} \\
23.1 / 1826 \mathrm{R2}\end{array}$ \\
\hline
\end{tabular}

\begin{tabular}{|c|c|}
\hline Comorimento $, \quad, \quad, \quad \cdots$ & $439 \mathrm{~cm}$ \\
\hline Alura no volante : " & $198 \mathrm{~cm}$ \\
\hline Largura total (oftola mingma) & $207 \mathrm{~cm}$ \\
\hline Distânclientre elxos: & $267 \mathrm{~cm}$ \\
\hline Altura thre do solo & $40 \mathrm{~cm}$ \\
\hline Biolas dilanteiras (ajustáveis) & $176-186-202-212 \mathrm{~cm}$. \\
\hline Bitolas fraselras (ajustáveis) com pneus 18.4/15-34 & $\begin{array}{l}160-170-180-190-200- \\
210 \mathrm{~cm}\end{array}$ \\
\hline Ralo de gloo (som fritoes) & $\therefore 650\left(690^{\circ}\right) \mathrm{cm}$ \\
\hline Ralo de glró (com frelos) & $565\left(500^{\circ}\right) \mathrm{cm}$ \\
\hline
\end{tabular}

$$
\text { PESOS }
$$

\begin{tabular}{|l|c|}
\hline $\begin{array}{l}\text { Peso em ordem de marcha } \\
\text { (8em lastro e sem acessbrios) }\end{array}$ & $4340 \mathrm{Kg}$ \\
\hline $\begin{array}{l}\text { Peso em ordem de marcha } \\
\text { (com lastro tolal e com acessorios) }\end{array}$ & \\
\hline $\begin{array}{l}\text { Peso de embarque } \\
\text { (sem lastro e sem acessórios) }\end{array}$ & $7250 \mathrm{Kg}$ \\
\hline
\end{tabular}

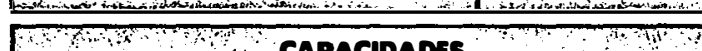

\begin{tabular}{|c|c|}
\hline Tarque de combústhel & 155 titios \\
\hline Caixa de Câmblo e diferencial : , & 48 litros \\
\hline Carter do motor of & $15 \operatorname{litpos}$ \\
\hline Gislema de áriefoclónento & 16 litros \\
\hline Tranemisséo final (cada lado) & 10 lltros \\
\hline Sistema hidráulico & 27 litros \\
\hline Reservatórlo do filtro do ar primário & 2 litros \\
\hline Reservatório do fluldo do frelo a embreagem & 0,5 Ittro $\because$ \\
\hline Diferenclal do eixo odlanteiro & \\
\hline $\begin{array}{l}\text { Reduçào planetárla do elxo dlanteiro: } \\
\text { (cadg logo) }\end{array}$ & 10 iltros \\
\hline
\end{tabular}
O fobricanto so reserva o dirolio de aliorar as espoctifkopares som aviso próblo

\section{SISTEMA DE INJECRO}

Fillragem de combuslivel, com um pré-lillıo sedimenlador e um filtro duplo de $1 / 2$ litro. Bornba Injetora BOSCH a pistảo corn regulador centrílugo RSV. Bicos injetores BOSCH.

\section{SISTEMA DE ARRSTCMMANTO} Relrigeraçâo a água, pressurizado, com radiador, bomba d’água, termostato e venlilado

\section{SISTEMA 19 ARICO}

12 Volts. negalivo à massa. Bateria de 12 Volts com capacidade de 135 Ali. Alternador regulador de voltagem eletrônico BOSCH. Molor de partida BOSCH $3 \mathrm{~kW}$

\section{STSMA DE FILTRACEM DE AR}

Fillro primário: fillro do ar em banho do bloo com pré-purilicador do ar lipo ciclone o decantador de poeira. Filtro secundário: a seco com elemento de papel e indicador de resirição.

\section{GMBPEACEM}

Simplea

Disco único, a seco, 330 mm de diâmetro, mola membrana.

\section{Independonto (opeional)}

Dois discos, a seco, $310 / 310 \mathrm{~mm}$ de diâmetro, mola membrana.

\section{Trenemesão}

Calxa do cimbio

De engrenamenlo conslante, com 12 velocidades à frente e 4 a ré. Sincronizada em cada grupo.

Diferencial

Pinhảo-coroa com reduçåo 8:41, 4 satéliles e 2 planelárias, com bloqueio mecânico acionado por pedal.

\section{REOUCHO FINAL}

De engrenagens pàralelas, nas extremidades do eixo Iraseiro, reduçăo 11:53.

\section{EIXO DLANIEIRO}

Direcional, com traçăo, pinhăocoroa com reduçăo 10:40, 4 satéliles e 2 planetárias, reduçåo final planelária 4,5:1.

\section{SISTSMA HIDRAULKCO}

Bomba de engrenagens aćionada diretamente pelo motor fornecendo até 36 Umin a 220 bar $\left(220 \mathrm{~kg} f / \mathrm{cm}^{2}\right)$. Conlrole de posição e Iração. Conlrole manual da velocidade de descida do implemento.

Opcionalmente pode ser equipado com cilindros exlernos de levantamento.

\section{LEVANTE HIDRAULICO DE 3 PONTOS}

Categoria II. Com estabilizadores telescópicos.

Capacidade de levantamento $25000 \mathrm{~N}$ (2500 kgl) conlorme norma ISO 730. $35000 \mathrm{~N}$ ( $3500 \mathrm{kgl}$ ) quando equipado com cilindros exlernos de levantamento.

\section{TOMADA DE POTENCIA}

Standard $35 \mathrm{~mm}$ (1 3/8") 6 estrias e $44 \mathrm{~mm}$ (1 3/4"). 6 estrias para trabalhos pesados. $540 \mathrm{rpm}$ a $1747 \mathrm{rpm}$ no motor. Tolalmenle independenle quando o trator é equipado com embreagem dupla. Opcional: segunda velocidade com 1000 rpm a 2270 rpm no motor.

\section{TRFIOS}

Tipo a disco seco. Acionamento hidráulico para o freio de serviço. Freio de estacionamento mecânico.

DIREç:日)

Direçônhldénulica hldroslática.

\section{INSTRUMENTOS}

Tralômelro de acionamentomecânico que inclui conta-giros e indicador de horas trabalhada Tralómelro de acionamentomecånico que inclui conta-giros e indicador de horas trabalhada pilotos indicativas para pressão do óleo do motor, carga da bateria, luz alta, freio de estacionamento travado e embreagem da tomada de potência acionada (trator com eslacionamento inava

\section{BAPRA DE TRAÇAO}

Barra de traçåo com regulagem lateral e longitudinai. Suporte para entate U.

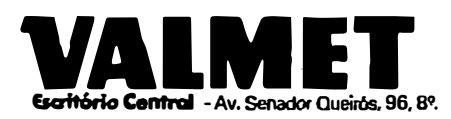

C.P. 1085, 01051 Såo Paulo, SP - Fone: 227-2522 (PABX) Telex 1121400 VMET End. Telegr. VALMETBRAS

Fabitico - Rua Cap. Francisco de Almelda, 695 - C.P. 328 08700 Mogi das Guzes, SP - Fone: 469-9933 (PABX) Telex 1133386 VMET BR Pepos * Acsirtência Tórico -Rua Valmet, 160 C.P. 328 -08700 Mogi das Cruzes, SP - Fone: 469-3014 (KS) 469-251 Telex 1133386 VMET BR 


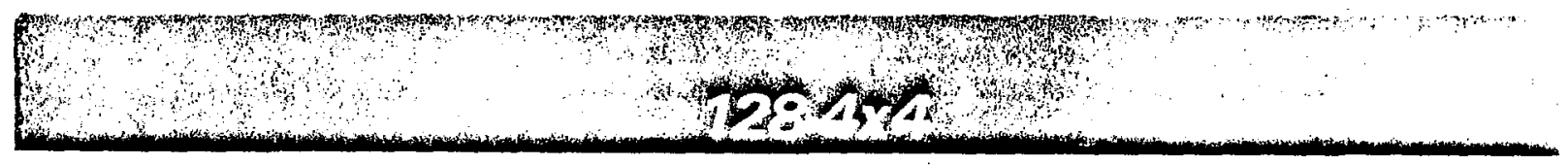

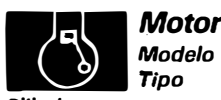

Modelo

Cilindros Tipo

Diâmetro dos cilindros

Diesel, injeção direta, 4 tempos.

Curso do pistāo

Cilindrada total

Relação de compressão

Potência bruta do motor a 2.300ripm

Torque máximo $(1.400 \mathrm{rpm})$

Sistema de injeção filtragem de combustivel com pré-filtro

sedimentador e um filtro duplo de 1/2 litro. Bomba injetora de pistões

Sistema de arrefecimento Pressurizado, com radiador, bomba d'água,

termostato e ventilador de 6 pás. Arrefecimento a água.

\section{Transmissão}

Caixa de càmbio De engrenamento constante sincronizada, com 12 velocidades à frente e 4 à ré. Diferencial Com bloqueio mecânico acionado por pedal.

Transmissão final De engrenagens paralelas, nas extremidades do eixo traseiro.

Embreagem Simples: monodisco, a seco, 330 $\mathrm{mm}$ de diämetro, mola-membrana. TDPindependente (opcional): dois discos, a seco, 310/310mm de diametro.

Barra de tração Oscilante, com engate " $U$ ". Regulagens laterais e longitudinais.

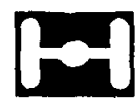

\section{Eixo dianteiro}

Direcional, com tração, diferencial central e reduçōes

\section{8}

Direção

Hidráulica-hidrostática.

\section{0}

\section{Sistema hidráulico}

Bomba de engrenagens acionada diretamente pelo motor. e velocidade dedescida.

Levante de três pontos Categoriall. Com estabilizadores reguláveis.

Capacidade delevantamento $34.330 \mathrm{~N}(3.500 \mathrm{~kg}$ ).

Tomada de potência Standard $35 \mathrm{~mm}\left(13 / 8^{\prime \prime}\right), 6$ estrias e $44 \mathrm{~mm}$ (1 3/4"), 6 estrias, para trabalhos pesados, 540 a 1.747 rpm no motor. Totalmente independente quando equipado com embreagem para TDP independente. Opcional: segunda velocidade com 1.000 a $2.270 \mathrm{rpm}$ no motor.

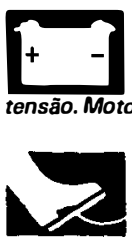

\section{Sistema elétrico}

12 Volts, negativo à massa. Bateria de 12 Volts com capacidade de $135 \mathrm{Ah}$. Alternador $\mathrm{e}$ regulador de de partida de $3 \mathrm{~kW}$.

\section{Freios}

Tipo disco seco. Acionamentohidráulico para o freio de serviço. Freio de estacionamento de acionamento mecánico.

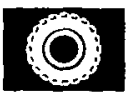

\section{Pneus disponiveis}

Dianteiros

Traseiros
14.9-26R1

18.4-34R1
$23.1-26 R 2$

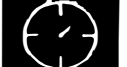

\section{Instrumentos}

Tratōmetro De acionamento mecânico. que incluicontagiros eindicadorde horas trabalhadas. Combustivel Indicador elétrico denivel.

Temperatura Termómetro elétrico para temperatura da água.

Luzes.piloto Indicativas de pressão do óleo do motor. carga dabateria

luz alta freio de estacionamento acionado e embreagem de TD

acionada (quandoequipado com embreagem independente).
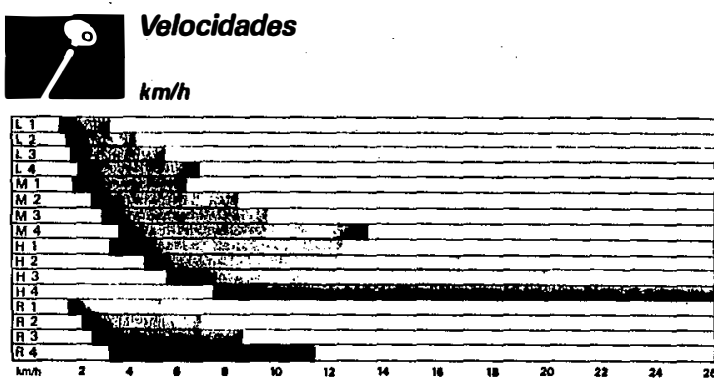

\section{$\longrightarrow$ Dimensōes Gerais (mm)}

Altura noescape

Dlstánclaentre eixos

2.560

Vaoliure

Bitolas dianteiras (ajustávels)

2.670

400

1.760

1.860

2.020

2.120

Bitolas traseiras (ajustávels)

1.600

1.700

1.800

1.900
2.000
2.100
$-34 R 1$

Compneus 18.4-34R1

Ralo de giro sem freios

6.900

Ralo de giro com freios

5.000

Posos (kg)

Peso em ordem de marcha (sem lastro e sem acessórios)

Poso emordem de marcha (comlastro total e com acessórios) $\quad 7.090$

$\begin{array}{ll}\text { Poso de embarque (sem lastro e sem acessórios) } & 4.327\end{array}$

Capacidades (litros)

Tanque de combustivel

$155(220 *)$

Caixa de cambio e diferencial

Cárter do motor

Sistema de arrefecimento

Transmissảo final (cada lado)

Sistemahldráulico

Diforencial do eixo dianteiro

Reduçáo planetária do eixo dianteiro (cada lado)

Reservatório de fluido de freio

- Opcional, com tanque de combustivel adicional.

Acessórios Pesos frontais, pesos traseiros, protetor frontal e teto.

O fabricante se reserva do direito de alterar as especificą̧eses sem aviso prévia.

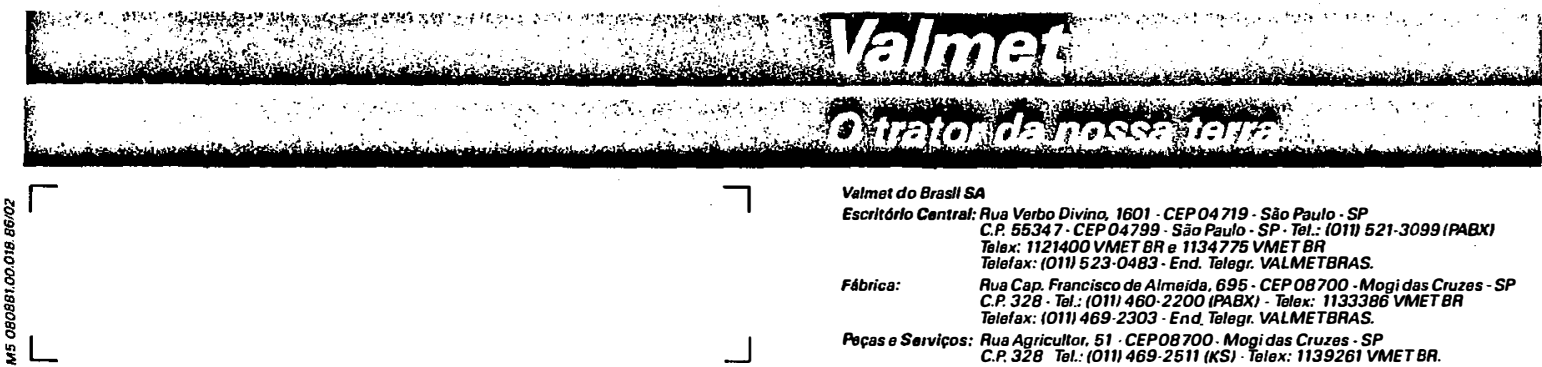




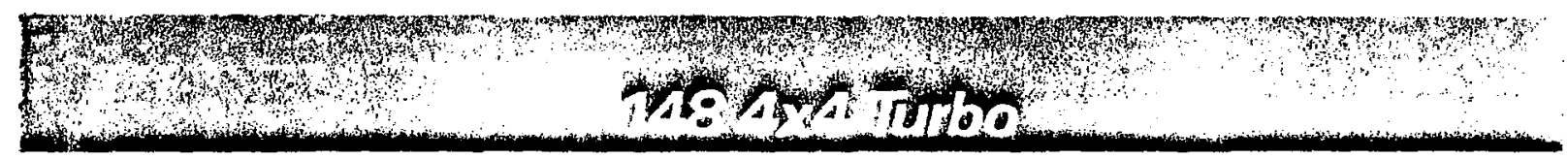

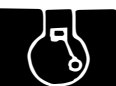

Motor

Modelo

Tipo

Cilindros

Diämetro dos cilindros

Diesel, injeção direta, 4 tempos, turboalimentado 6, verticais em linha, camisas úmidas removiveis.

Curso do pistão

Cilindrada total

Relação de compressão

Potência bruta do motor a $2.300 \mathrm{rpm}$

$120 \mathrm{~mm}$

$5.883 \mathrm{~cm}^{3}$

15,9:1

Sistema de injeção Filtragem de combustivel com pré-filtro

sedimentador e um filtro duplo de 1/2 litro. Bomba injetorade pistōes em linha, com regulador RSV. Bicos injetores de 4 furos.

Sistema de arrefecimento Pressurizado, com radiador, bomba d'água, termostato e ventilador de 6 pás. Arrefecimento a água.

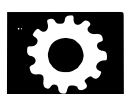

\section{Transmissão}

Caixa de câmbio De engrenariento constante sincronizada, com 12 velocidades d̀ frente $e$ à Diterencial Combloqueio mecánico acionado por pedal. Transmissão final De engrenagensparalelas, nas extremidades do eixo traseiro.

Embreagem Simples: monodisco, a seco, 350 mm de diâmetro. TDPindependente (opcionall: dois discos, a seco, 330/330mm de diámetro.

Barra de tração Oscilante, com engate " $U$ ". Regulagens laterais e longitudinais.

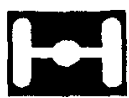

\section{Eixo dianteiro}

Direcional, com tração, diferencial central e reduçōes planetárias.

\section{8}

Direção

Hidráulica-hidrostática.

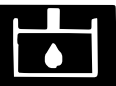

\section{Sistema hidráulico}

Bomba de engrenagens acionada diretamente pelo motor. Controle de posição, profundidade, tração, reação e velocidade de descida.

Levante de trôs pontos Categoria II. Com estabilizadores reguláveis. Capacidade de levantamento $34.330 \mathrm{~N}$ (3.500kgf).

Tomada de potência Standard $35 \mathrm{~mm}\left(13 / 8^{\prime \prime}\right), 6$ estrias e $44 \mathrm{~mm}$ (1 3/4"), 6 estrias para trabalhos pesados, 540 a 1.747 rpm no moto Totalmente independente quando equipado com embreagem para TDP independente. Opcional: segunda velocidade com 1.000 a $2.270 \mathrm{rpm}$ no motor.

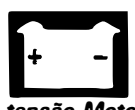

\section{Sistema elétrico}

12 Volts, negativo à massa. Bateria de 12 Volts com capacidade de 135 Ah. Alternador e regulador de tensão. Motor de partida de $3 \mathrm{~kW}$.

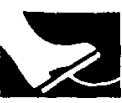

Freios

Tipo disco seco. Acionamento hidráulico para o freio de serviço. Freio de estacionamento de acionamento mecánico.

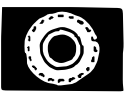

Pneus disponiveis

Dianteiros

$14.9-28 R 1$

Traseiros

$14.9 \cdot 26 R 1$

18.4 - $38 R 1$

$23.1-30 R 1$

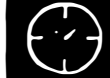

\section{Instrumentos}

Tratómetro De acionamento mecânico, que inclui contagirose indicador de horas trabalhadas.

Combustivel Indicador elétrico denivel.

Temperatura Termómetro elétrico para temperatura da água.

Lures piloto Indicativas de pressão do bleo do motor, carga da bateria,

luz alta freio de estacionamento acionado e embreagemda acionada (quando equipado com embreagem independente).
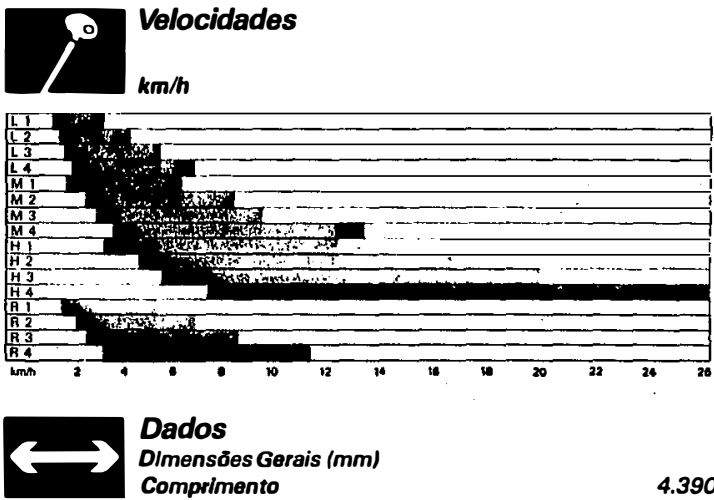

Dados

DImensōes Gerais (mm)

Comprimento

4.390

Altura no escape

Largura total (bitola minima sem contrapesos)

Distíncla entre eixos

Válivere

Bitolas dianteiras (ajustáveis)

2.670

1.760

2.020

Bitolas traseiras (ejustávels)

2.120

1.600

1.700

1.800

2.000

2.100

Ralo de giro sem freios

Com pneus $18.4-38 R$

Ralo de giro com freios

6.900

Posos (kg)

Peso em ordem de marcha (sem lastro e sem acessórlos)

Peso em ordem de marcha (com lastro total e com acessorios) $\quad 7.650$

Peso de embarque (sem lastro e sem acessórlos)

Capacidades (litros)

Tanque de combustivel

Caixa de cámblo e diferenclal

Cárter do motor

Sistema dearrefeclmento

Transmlssáo final (cada lado)

Sistema hidráulico

Diferenclal do eixo dianteiro

Reduçåo planetáría do elxo dianteiro (cada lado)

Reservatórlo de fluido de freio

Acessórios Pesos frontais, pesos traseiros, protetor frontal e teto.

O fabricante se reserva do direito de alterar as especificaçoes sem aviso prévio.

Escritorto Contral: Rua Verbo Divina, 1601 - CEP 04719 . São Paulo - SP C.P. 55347. CEP O4799. Säo Paulo - SP. Tel:. (O11) 521-3099 (PAQX) Telex: 1121400 VMETBR 11134775 VMETBR
Telefax: 10111523.0483 . End. Telegr. VALMETBRAS

Fabrica: Rua Cap. Francisco de Almeida, 695.CEP O87OO-Mogidas Cruzes.SP C.P. 328. Tel:; 1011) 460.2200(PAEX). Telax: 113338
Teletax: (011) 469-2303. End. Telegr. VALMETBRAS.

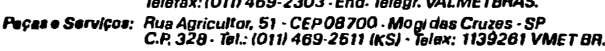

